\title{
EHDM: Um Método para o Projeto de Aplicações Hipermídia para Ensino
}

\author{
Luciano Tadeu Esteves Pansanato
}

Orientação: Prof ${ }^{a}$. Dr. ${ }^{a}$ Maria das Graças Volpe Nunes

Dissertação apresentada ao Instituto de Ciências Matemáticas e de Computação - USP, como parte dos requisitos para a obtenção do título de Mestre em Ciências - Área de Ciências de Computação e Matemática Computacional 
Dedico este trabalho à minha família. 
Ensinar é um exercício de imortalidade.

De alguma forma continuamos a viver naqueles cujos olhos aprenderam a ver o mundo pela magia da nossa palavra.

O professor, assim, não morre jamais...

(Rubem Alves) 


\section{Agradecimentos}

A Deus.

À minha família, principalmente meus pais, Hélio e Irene, minha irmã Maria Angélica, minha avó Nena, minhas "dindas" Victória e Regina, e meu primo Germano.

À minha orientadora Maria das Graças Volpe Nunes.

A todos os professores e funcionários do ICMC.

Aos meus amigos, em especial ao Ricardo, Renato, João, Alexandre, Gisele, Ana Elisa, Ildeberto, Mario, Luiz Carlos, Marcos e Wagner.

Aos meus amigos do CEFET-PR, em especial ao Gabriel, Vanderley e Adriane.

Ao CEFET-PR.

$\grave{A}$ CAPES. 


\section{Sumário}

Agradecimentos .........................................................................................................................iv

Lista de Figuras e Tabelas..............................................................................................viii

Resumo

Abstract .......................................................................................................................... xii

Introdução............................................................................................................................ 1

1.1 Consideraçōes Iniciais ................................................................................................................... 1

1.2 Motivação e Objetivos ............................................................................................................. 4

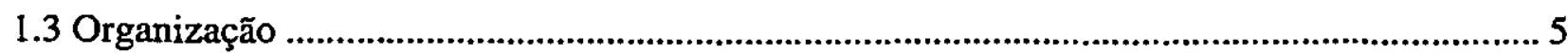

Desenvolvimento de Aplicações Hipermídia................................................................6

2.1 Considerações Iniciais ........................................................................................................ 6

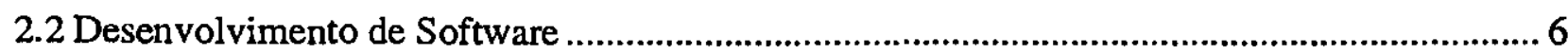

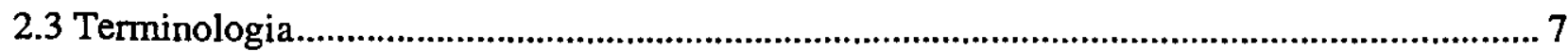

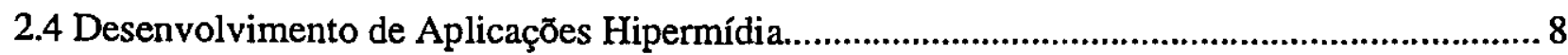

2.5 Aspectos Cognitivos de Aplicações Hipermídia....................................................................... 10

2.6 Considerações Finais ..................................................................................................... 12

Métodos para Projeto de Aplicações Hipermídia .................................................... 13

3.1 Consideraç๊es Iniciais ............................................................................................... 13

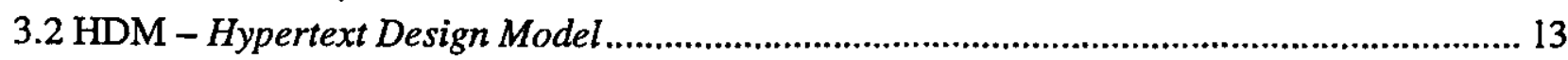

3.3 RMM - Relationship Management Methodology............................................................... 16

3.4 OOHDM - Object-Oriented Hypermedia Design Method ……………….............................. 19

3.5 EORM - Enhanced Object-Relationship Model ................................................................... 21

3.6 HMBS/M - Hypertext Model Based on Statecharts / Method .................................................. 24

3.7 Considerações Finais ......................................................................................................... 27

SASHE - Sistema de Autoria e Suporte Hipermídia para Ensino.................... 28

4.1 Considerações Iniciais ................................................................................................... 28

4.2 MCA - Modelo de Contextos Aninhados......................................................................... 28

4.2.1 Definiçø̃es do Modelo Básico ...........................................................................................2 29 
4.2.2 Modelo de Apresentaçãó

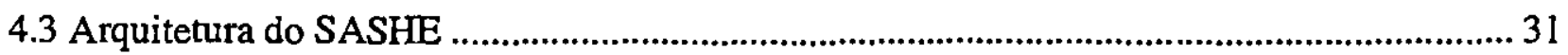

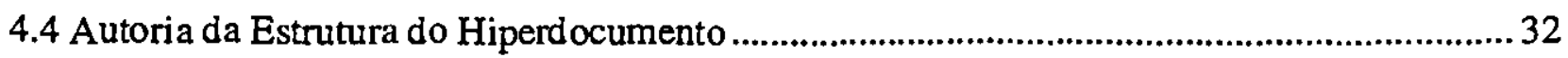

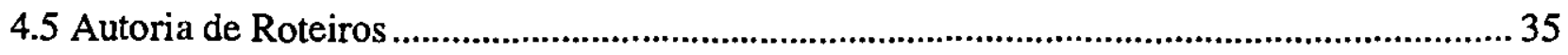

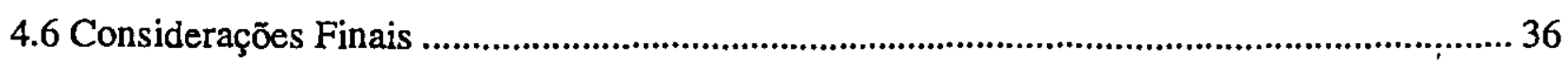

Base Teórica para Modelagem do Domínio de Conhecimento...........................37

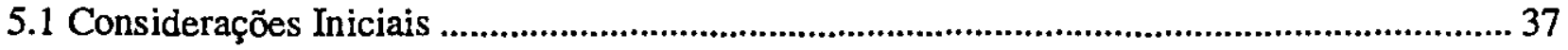

5.2 O Modelo de Michener ................................................................................................ 37

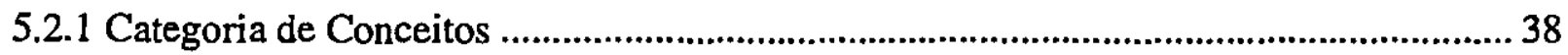

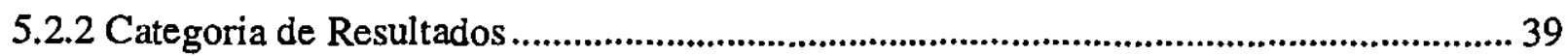

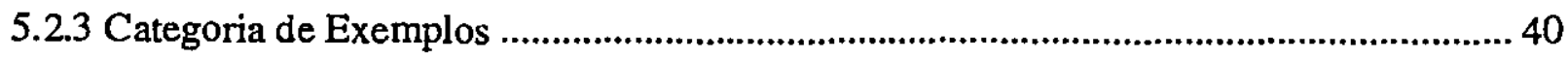

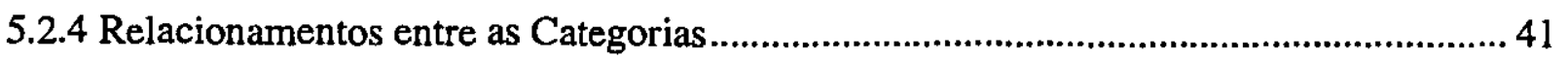

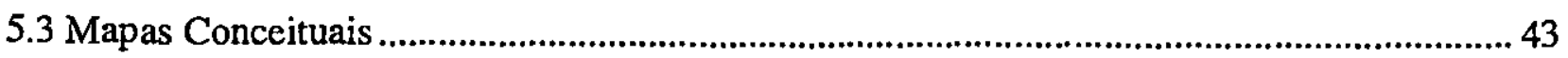

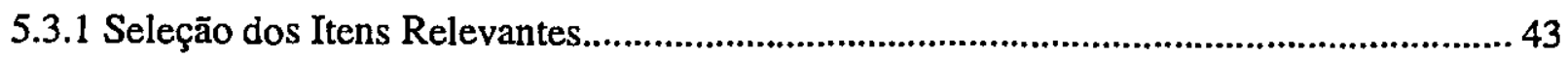

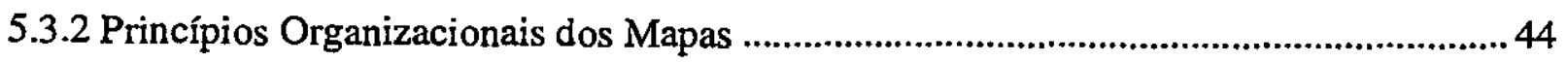

5.3.3 Mapas Conceituais como Instrumentos de Ensino........................................................ 45

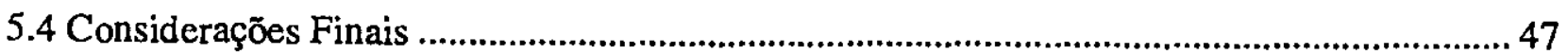

EHDM - Educational Hyperdocuments Design Method .........................................48

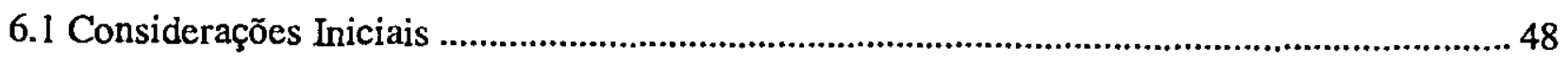

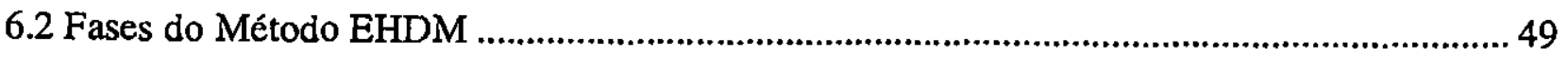

6.3 Modelagem Conceitual Hierárquica ................................................................................ 50

6.3.1 Categorias de Conhecimento e seus Relacionamentos de Ordem....................................51

6.3.2 Relacionamentos entre as Categorias de Conhecimento................................................5 54

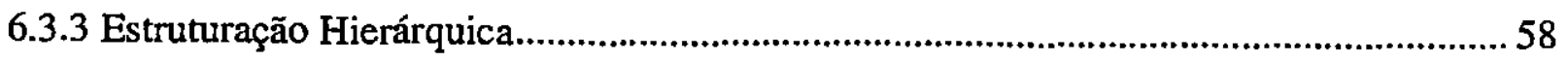

6.3.4 Considerações sobre o Modelo Conceitual Hierárquico ..................................................5 59

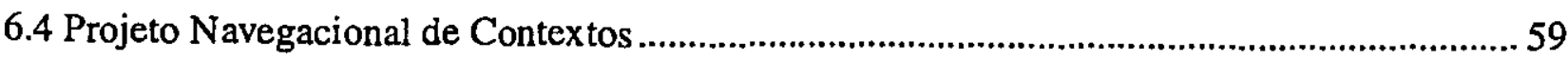

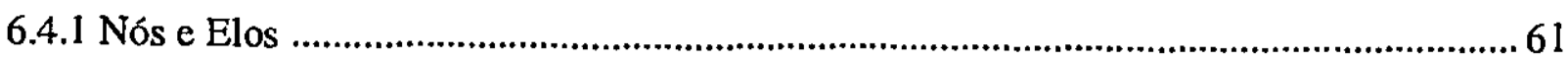

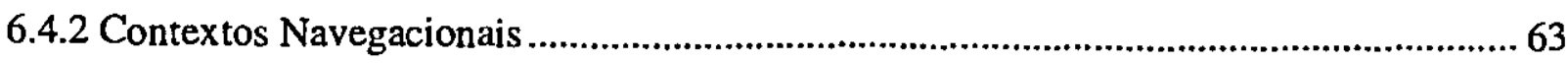

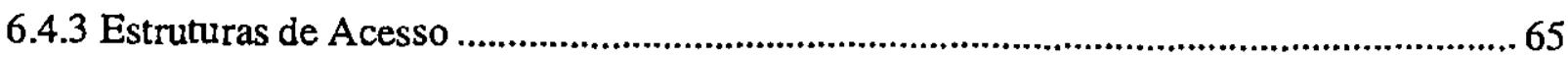

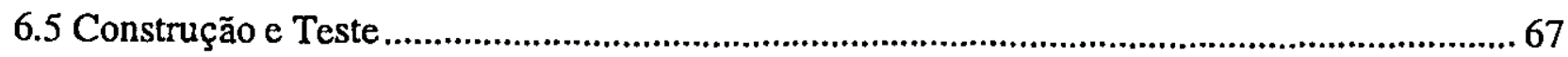

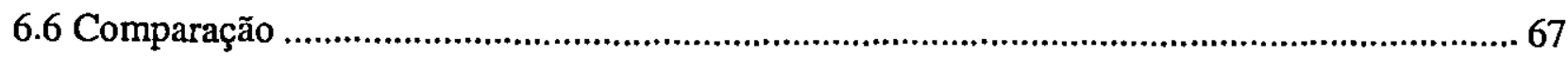

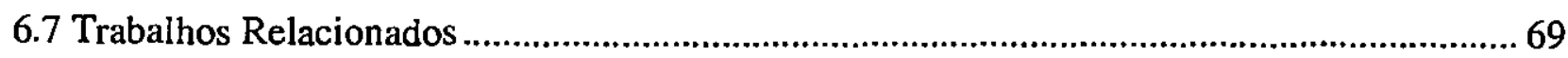

6.7.1 MAPHE - Metodologia de Apoio a Projetos de Hipertextos Educacionais .................... 69

6.7.2 Daphne - Definição de Aplicações Hipermídia na Educação............................................. 70 


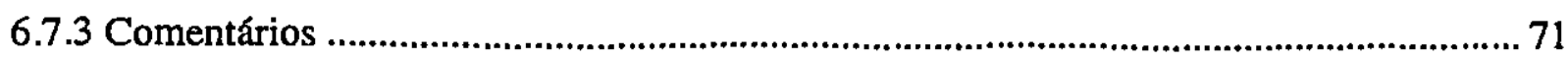

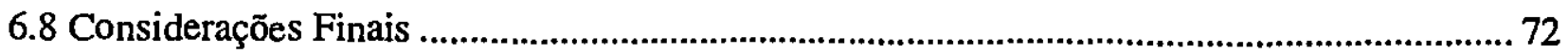

EHDT - Educational Hyperdocuments Development Tool .................................. 73

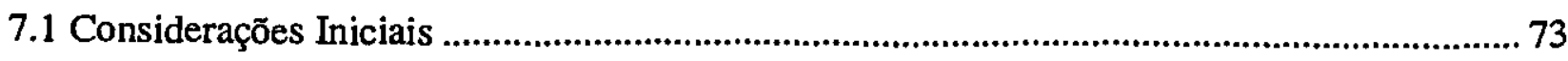

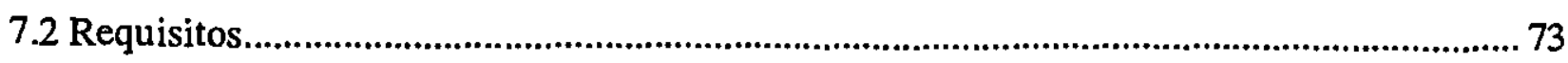

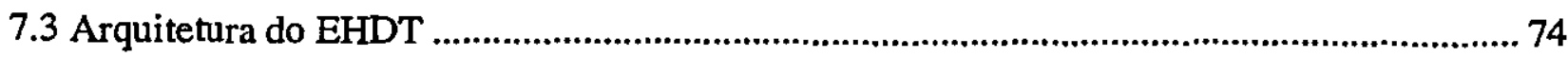

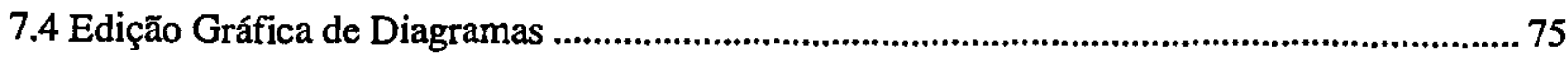

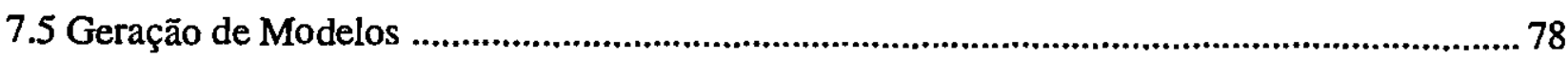

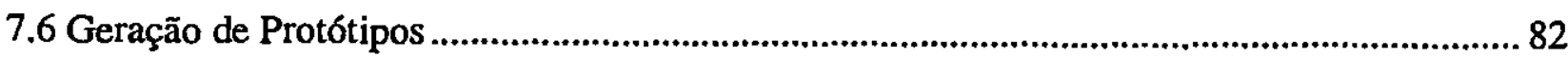

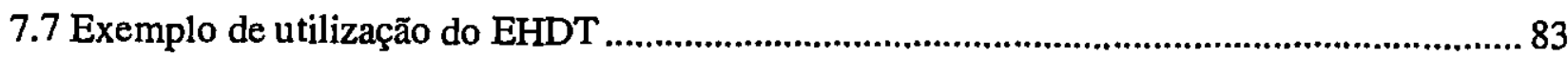

7.7.1 Definição do Escopo do Hiperdocumento ................................................................ 83

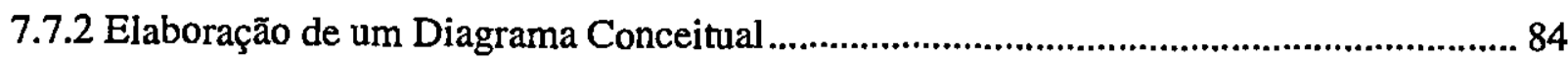

7.7.3 Elaboração de um Diagrama Navegacional .............................................................. 85

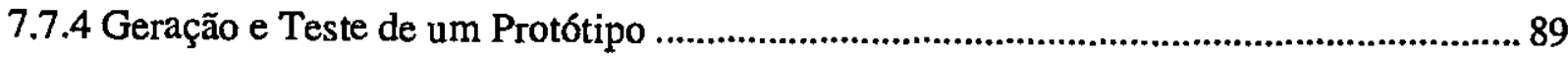

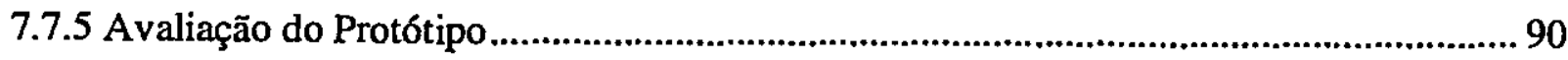

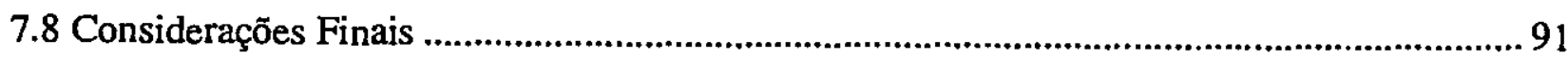

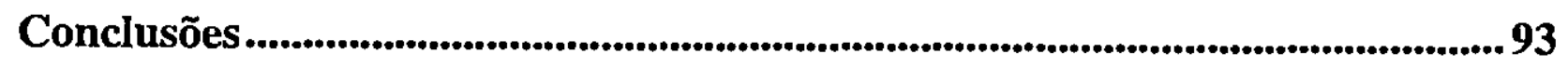

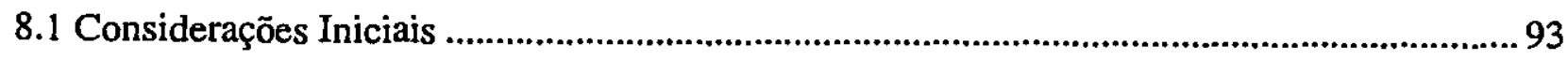

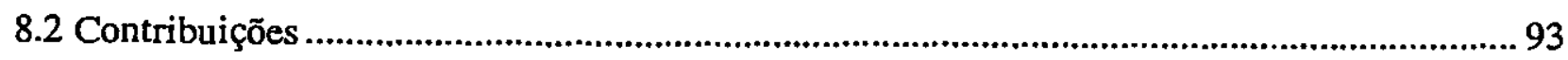

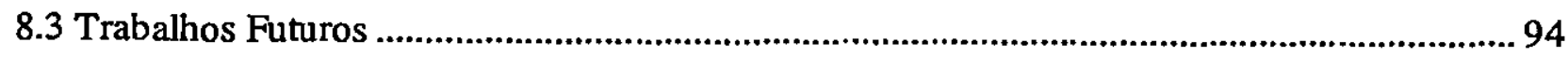

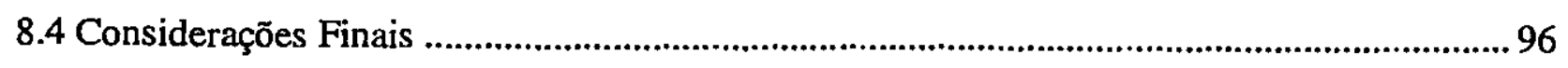

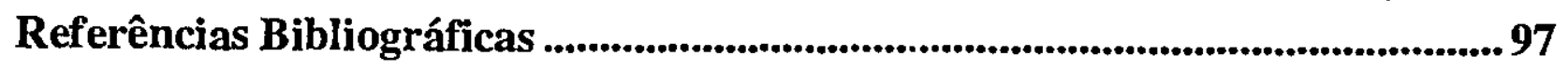

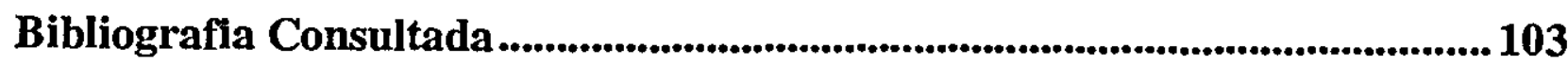




\section{Lista de Figuras e Tabelas}

Figura 2.1: Abordagens bottom-up e top-down (Nanard \& Nanard, 1995) ................................ 10

Figura 3.1: Exemplo de estruturas de informação e elos do HDM.............................................. 14

Figura 3.2: Exemplo de esquema HDM (Garzotto et al., 1993) .............................................. 15

Figura 3.3: A metodologia RMM (Isakowitz et al., 1995) ...................................................... 16

Figura 3.4: Exemplo de diagrama entidade-relacionamento (Isakowitz et al., 1995) ................. 17

Figura 3.5: Exemplo de diagrama RMDM (Isakowitz et al., 1995) .......................................... 18

Figura 3.6: Resumo da metodologia OOHDM (Schwabe \& Rossi, 1995) ................................ 19

Figura 3.7: Exemplo simplificado de esquema conceitual (Schwabe et al., 1996) ..................... 20

Figura 3.8: Visão geral do método de projeto EORM (Lange, 1994) ......................................... 22

Figura 3.9: Fases do método HMBS/M ................................................................................ 24

Figura 3.10: Exemplo simplificado de modelo de objetos (Turine, 1998) ................................ 25

Figura 3.11: Exemplo simplificado de modelo navegacional de tipos (Turine, 1998)................. 26

Figura 4.1 - Hierarquia de classes do MCA (Soares et al., 1994) ............................................... 29

Figura 4.2: Arquitetura do SASHE Versão 2.0.................................................................... 31

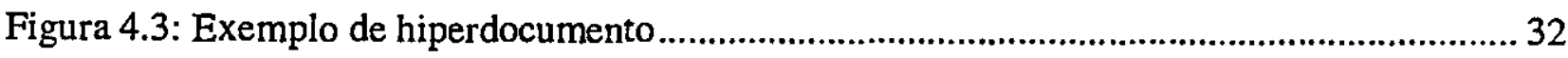

Figura 4.4: Interface para inserir uma informação................................................................ 33

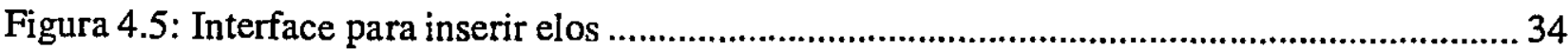

Figura 4.6: Interface para a definição de roteiros .................................................................... 35

Figura 5.1: As três categorias do Modelo de Michener (Takehara, 1994) .................................. 38

Figura 5.2: A categoria de conceitos (Takehara, 1994) ......................................................... 39

Figura 5.3: A categorị de resultados (Takehara, 1994) ........................................................ 40

Figura 5.4: A categoria de exemplos (Takehara, 1994) ........................................................... 40

Figura 5.5: Modelos para exemplificar inclusão de conjuntos e triângulo retângulo................... 41

Figura 5.6: Itens duais da categoria exemplo (Takehara, 1994) .............................................. 42

Figura 5.7: Itens duais da categoria resultado (Takehara, 1994) .............................................4 42

Figura 5.8: Itens duais da categoria conceito (Takehara, 1994) .............................................. 42

Figura 5.9: Os relacionamentos entre as três categorias (Takehara, 1994) ................................ 42

Figura 5.10: Mapa de hierarquia conceitual de unidades com possíveis sequiências instrucionais

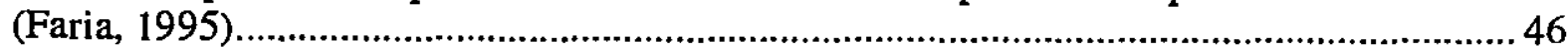

Figura 5.1 1: Exemplo de sequiência de ensino na disciplina Geografia Física - Climatologia

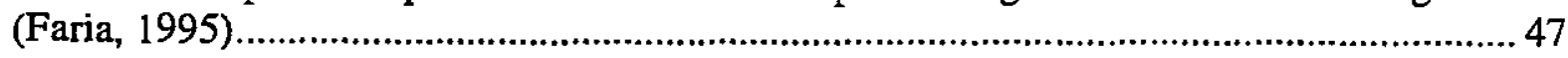

Figura 6.1: Ilustração do EHDM como o resultado do emprego de várias idéias ....................... 49 
Figura 6.2: Fases do método EHDM

Figura 6.3: Etapas do Ciclo de Vida por Prototipação Evolutiva (Fortes, 1996) ....................... 50

Figura 6.4: Primitivas para a categoria Conceito e seus relacionamentos de ordem................... 52

Figura 6.5: Exemplo de relação entre conceitos por "precedência necessária"............................ 52

Figura 6.6: Exemplo de relação entre conceitos por "precedência preferencial" ......................... 52

Figura 6.7: Primitivas para a categoria Resultado e seu relacionamento de ordem ..................... 53

Figura 6.8: Exemplo de relação entre resultados .................................................................... 53

Figura: 6.9: Primitivas para a categoria Exemplo e seu relacionamento de ordem..................... 54

Figura 6.10: Exemplo de relação entre exemplos ................................................................... 54

Figura 6.11: Primitivas para os relacionamentos entre as categorias de conhecimento ............... 54

Figura 6.12: Exemplo para o relacionamento de "motivação / ilustração" .................................. 55

Figura 6.13: Exemplo para o relacionamento de "necessidade".................................................. 55

Figura 6.14: Exemplo para o relacionamento de "utilização" .................................................... 55

Figura 6.15: Representação das categorias e relacionamentos segundo a UML ......................... 56

Figura 6.16: Exemplo de modelagem para a teoria "Movimentos Retilíneos" ........................... 57

Figura 6.17: Exemplo de modelagem para o conceito "Colonialismo no Brasil"........................ 57

Figura 6.18: Exemplo de expansão hierárquica......................................................................... 58

Figura 6.19: Classes epistemológicas para as categorias de conhecimento.................................. 59

Figura 6.20: Primitivas gráficas de modelagem navegacional .................................................... 60

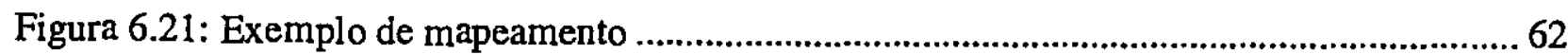

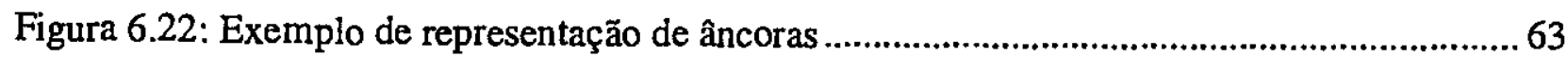

Figura 6.23: Exemplo de mapeamento com filtro de relacionamentos ...................................... 63

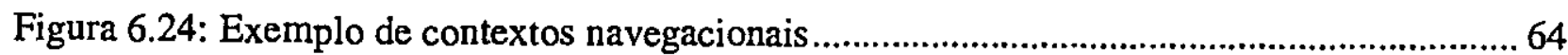

Figura 6.25: Exemplo de definição de índice e roteiro ............................................................6 65

Figura 6.26: Diferença entre índice e roteiro.......................................................................66

Tabela 6.1: Comparação do EHDM com os demais métodos ..................................................... 68

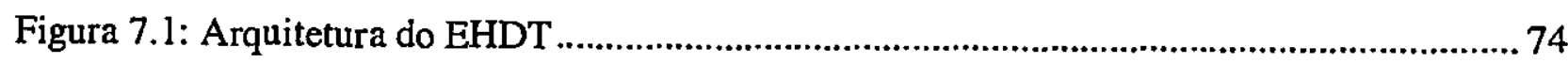

Figura 7.2: Exemplo de Diagrama Conceitual...................................................................... 76

Figura 7.3: Interface para inserir um elemento conceitual .................................................... 76

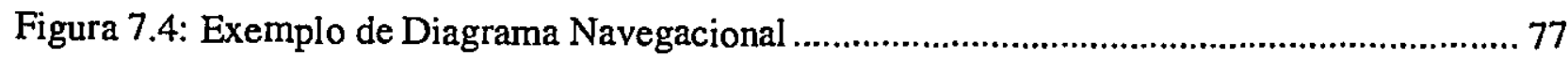

Figura 7.5: Interface para inserir um elemento navegacional ................................................. 77

Figura 7.6: Interface para especificar as informaçōes ............................................................. 78

Figura 7.7: Interface para gerar diagrama navegacional........................................................ 79

Figura 7.8: Interface para a seleção de opções de mapeamento ............................................... 79

Figura 7.9: Interface para gerar roteiro ........................................................................... 8 ! 


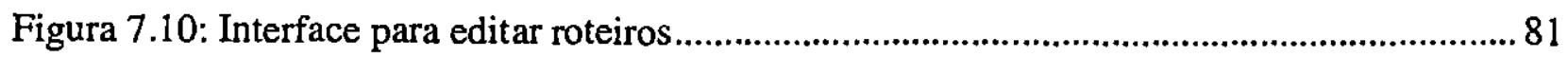

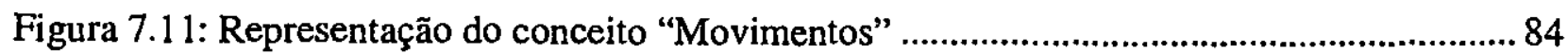

Figura 7.12: Diagrama conceitual para a expansão do conceito "Movimentos"............................ 84

Figura 7.13: Diagrama conceitual para a expansão do conceito "Conceitos básicos" .................. 85

Figura 7.14: Diagrama conceitual para a expansão do conceito "Movimentos Retilíneos"......... 85

Figura 7.15: Opções para gerar um diagrama navegacional para o hiperdocumento .................... 86

Figura 7.16: Opções selecionadas para gerar o diagrama navegacional ......................................... 86

Figura 7.17: Diagrama navegacional gerado a partir do diagrama conceitual da Figura 7.12 ..... 86

Figura 7.18: Diagrama navegacional gerado a partir do diagrama conceitual da Figura 7.13 ..... 87

Figura 7.19: Diagrama navegacional gerado a partir do diagrama conceitual da Figura 7.14 ..... 87

Figura 7.20: Opções para gerar um roteiro para o hiperdocumento ........................................... 87

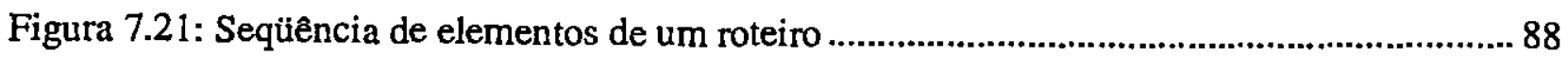

Figura 7.22: Exemplos de informações adicionadas a um nó.................................................... 89

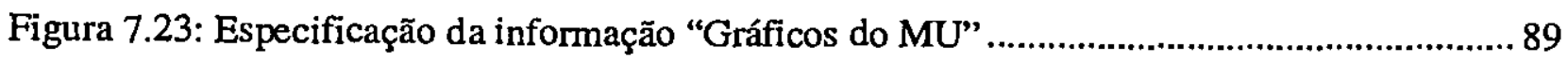

Figura 7.24: Exemplo de navegação pelos "esqueletos" do hiperdocumento protótipo.................90

Figura 7.25: Exemplo de navegação pelo hiperdocumento final................................................91 


\section{EHDM: Um Método para o Projeto de Aplicações Hipermídia para Ensino}

\section{Resumo}

Este trabalho apresenta o Método para Projeto de Hiperdocumentos para Ensino, ou EHDM (Educational Hyperdocuments Design Method), que proporciona uma abordagem sistemática para apoiar o projeto e desenvolvimento de aplicações hipermídia para ensino. O método utiliza o modelo proposto por Michener e a técnica de mapeamento conceitual para modelar o domínio de conhecimento do hiperdocumento. As três fases que compõem o método - modelagem conceitual hierárquica, projeto navegacional de contextos e construção e teste - são apresentadas. Uma ferramenta denominada Educational Hyperdocuments Development Tool (EHDT) foi desenvolvida para auxiliar o desenvolvimento de hiperdocumentos para ensino destinados ao sistema SASHE. Essa ferramenta utiliza o EHDM como base metodológica. $O$ EHDT fornece mecanismos para facilitar laços de realimentação rápidos entre as fases do método e para apoiar abordagens de projeto bottom-up e top-down. 


\section{EHDM: Um Método para o Projeto de Aplicações Hipermídia para Ensino}

\section{Abstract}

This works presents the Educational Hyperdocuments Design Method, or EHDM, which provides a systematic approach to support the design and development of educational hypermedia applications. It uses Michener's model and the technique of concept mapping for modeling the knowledge domain. The three phases that comprise the method - hierarchical conceptual modeling, contextual navigational design and construction and test - are presented. The Educational Hyperdocuments Development Tool (EHDT) was implemented to assist the development of educational hyperdocuments for the system SASHE. This tool uses the EHDM as methodological base. It also provides mechanisms that to facilitate fast feedback loops between the method phases and support bottom-up and top-down approaches. 


\section{Capítulo 1}

\section{Introdução}

\subsection{Considerações Iniciais}

Os computadores têm uma importância crescente na sociedade atual, e a sua utilização na educação pode proporcionar uma melhoria no processo educativo devido à possibilidade da aplicação de novas abordagens de ensino-aprendizagem.

A disseminação da Internet abriu nova perspectiva para a educação, principalmente devido ao seu potencial de comunicação e acesso à informação. O serviço World Wide Web (WWW), um dos que contribuíram para o sucesso atual da Internet, utiliza a tecnologia hipermídia, que permite a exploração livre (pelo usuário) de páginas com informações representadas por diversas mídias e estruturadas através de ligações. Essa característica das aplicações hipermídia ${ }^{1}$ cria um ambiente favorável à aquisição de conhecimento, incentivando a utilização desta tecnologia na educação.

A hipermídia não é o único recurso computacional utilizado na educação, pois existem vários tipos de instrução assistida por computador (CAI - Computer-Assisted Instruction): tutoriais, exercício e prática, jogos instrucionais e simulação ou modelagem (Hannafin \& Peck, 1988).

Os tutoriais geralmente possuem uma estrutura sequiencial rígida, com o programa apresentando informações sobre um assunto e, em seguida, fazendo uma série de perguntas a respeito. Conforme as respostas dadas às perguntas, o sistema prossegue ou desvia para rever o conteúdo ou proporcionar mais informação. Eles incorporam uma ou mais estratégias pedagógicas para efetuar um controle, pelo sistema, através da interação com o aprendiz (respostas a perguntas, por exemplo) (Hannafin \& Peck, 1988). Por causa da sua capacidade de transmitir informações de modo pedagogicamente organizado, os tutoriais são utilizados para instrução e treinamento. Entretanto, eles possuem diálogo limitado, pois estão presos à sua estrutura rígida de interação (Valente, 1993).

\footnotetext{
'O termo "aplicações hipermídia" será utilizado para referir as aplicaçōes tanto de hipertexto quanto de hipermídia.
} 
Os sistemas tutoriais inteligentes (ITS - Inteligent Tutorial System) incorporam técnicas de inteligência artificial para adaptar-se às diferentes características de cada aprendiz, ou seja, eles utilizam diferentes estratégias pedagógicas de acordo com as atitudes tomadas pelo aprendiz durante a interação com o sistema (Nwana, 1990).

Os programas de exercício e prática (drill and practice) são semelhantes aos tutoriais no que diz respeito à estrutura, mas com uma grande quantidade de exercícios, requerendo a resposta freqüente do aprendiz e fornecendo um feedback imediato, com a interação sob controle total do sistema (Hannafin \& Peck, 1988). Eles são limitados pedagogicamente porque sempre utilizam a estratégia estímulo-resposta. Por outro lado, podem ser eficazes para atingir o objetivo proposto: treinamento (Valente, 1993).

Nos jogos instrucionais, o desafio é utilizado como estratégia para atingir um objetivo educacional. Entretanto, a competição geralmente desvia a atenção do aprendiz do propósito real, que é a transmissão de alguma informação (Valente, 1993). Por outro lado, os jogos instrucionais podem ser utilizados para a criação de situaçōes que favorecern a aprendizagem.

$\mathrm{Na}$ simulação, o programa aceita entradas preenchidas pelo aprendiz e responde como se fosse o sistema sendo sirnulado, permitindo que o aprendiz experimente os resultados de decisões boas ou ruins sem consequiências perigosas ou de alto custo (Hannafin \& Peck, 1988). Essa característica da simulação indica urn controle da interação misto, pois o aprendiz pode dispor de vários níveis de atividade dependendo do domínio da simulação, mas sempre dentro das regras impostas pelo programa (Jong, 1991). A modelagem é similar à simulação, mas possui a característica adicional de permitir a interferência nas propriedades do modelo implementado no programa (Jong, 1991).

Nas aplicaçōes hipermídia, o aprendiz explora documentos organizados por páginas (ou nós) e estruturados através de ligaçōes (ou elos), com uma rica variedade de associaçōes entre as informaçōes. O sistema apenas fornece o material e proporciona uma forma de navegação através dele, com o controle da interação totalmente a cargo do aprendiz, permitindo que este tenha progresso de acordo com os seus interesses e objetivos. A característica pedagógica mais importante dessas aplicações é a flexibilidade de exploração pelo aprendiz do material fornecido (Whalley, 1993).

No entanto, as aplicações hipermídia possuem alguns problemas no contexto de ensino. A falta de coerência (Thüring et al., 1995) e a sobrecarga cognitiva (Conklin, 1987) podem influenciar a compreensão de um hiperdocumento ${ }^{2}$. Esses problemas não são exclusivos de

\footnotetext{
${ }^{2}$ Neste trabalho. inuitas vezes o terno "hiperdocumento" corresponde ao termo "aplicação hipernídia".
} 
ensino, mas ocorrem em hiperdocumentos de um modo geral e as recomendações para evitá-los constituem importantes diretrizes de projeto (Thüring et al., 1995).

Nesse contexto de ensino, o controle que o aprendiz é capaz de ter sobre o material didático em aplicaçōes hipermídia é uma questão importante por causa da responsabilidade que este passa a ter no processo de aprendizagem (Large, 1996). Ele deve decidir que caminhos seguir, quando voltar ou pular adiante, quando seguir um determinado caminho e quando evitar as distraçōes com possíveis caminhos irrelevantes. A demanda cognitiva sobre o aprendiz é maior porque ele deve tomar as decisões corretas para que o aprendizado ocorra de fato.

Um resultado mais efetivo pode ser obtido se for possível estabelecer um equilíbrio entre o controle do aprendiz e do sistema, de modo a oferecer um certo grau de orientação para que o aprendiz possa atingir seu objetivo sem perder a flexibilidade da leitura (Large, 1996; Nunes \& Fortes, 1997).

Obter esse resultado corresponde a introduzir estratégias pedagógicas nas aplicações hipermídia, mas essa tarefa é difícil porque os sistemas de autoria hipermídia tradicionais (HyperCard e ToolBook, por exemplo) possuem apenas recursos genéricos para auxiliar o autor no desenvolvimento de aplicações. Além disso, sem um sistema de autoria a aplicação deve ser construída de maneira "ad hoc" utilizando-se uma linguagem de programação ou de script, dificultando ainda mais a tarefa e elevando os custos de desenvolvimento.

Qualquer que seja a abordagem utilizada para o desenvolvimento de uma aplicação hipermídia, é necessário elaborar uma estrutura para as informações. Segundo Jonassen e Grabinger (1990), o problema mais importante no desenvolvimento de aplicações hipermídia é decidir como estruturar as informações. A resposta para essa questão depende, em parte, de como a aplicação será utilizada, pois as diversas aplicações exigem estruturas diferentes.

No caso de aplicaçбes hipermídia para ensino, é desejável uma estrutura que inclua o material essencial ou relevante, sem eliminar o secundário, o complementar, desde que este não seja conflitante com o anterior e que possa contribuir para os objetivos do aprendiz (Nunes \& Fortes, 1997). A estrutura também deve incluir informações que representem as estratégias pedagógicas utilizadas pela aplicação.

Dessa forma, é desejável que durante o desenvolvimento de uma aplicação hipermídia para ensino, o autor consiga depreender com clareza a estrutura da mesma, para que ele possa organizar as informações conforme as estratégias pedagógicas adotadas, de maneira a atingir os seus objetivos (e também os do aprendiz). Portanto, existe a necessidade de prover mecanismos adequados para auxiliar o autor nesse sentido, e de trazer ganhos de produtividade e redução dos custos de desenvol vimento. 
A utilização de um modelo de representação para o domínio da aplicação pode auxiliar o autor na atividade de autoria porque permite que ele trabalhe em um nível de abstração mais próximo a este domínio, entre outras vantagens (Garzotto et al., 1993). Geralmente, esse modelo está inserido no contexto de um método, que pode oferecer uma abordagem mais sistemática e estruturada para realizar essa atividade.

Entretanto, os métodos disponíveis atualmente para hipermídia (por exemplo, HDM, RMM, EORM, OOHDM, HMBS/M) procuram a generalização de domínio, perdendo informações importantes sobre as características de um domínio mais específico, que, para o caso do ensino, é de fundamental importância. Além disso, ao aceitar qualquer domínio, esses métodos tendem a utilizar modelos de representação que são estranhos aos autores, fazendo com que estes tenham dificuldade em modelar o material instrucional.

\subsection{Motivação e Objetivos}

O protótipo de ambiente de autoria denominado Sistema de Autoria e Suporte Hipermídia para Ensino (SASHE) (Nunes et al., 1997; Santos, 1997; Santos et al., 1997), desenvolvido no Instituto de Ciências Matemáticas e de Computação (ICMC), proporciona ao autor a capacidade de estabelecer um equilíbrio entre o controle do aprendiz e do sistema através da autoria de roteiros (guided tours) com escopos variados de liberdade de navegação pelo aprendiz (Nunes \& Fortes, 1997).

A confeç̧ão dos roteiros é realizada sobre um hiperdocumento previamente construído por um ou mais autores. A navegação proporcionada para o aprendiz incorpora estratégias pedagógicas (tutoriais) baseadas na contextualização e qualificação dos componentes do hiperdocumento, ou hiperbase, conforme terminologia do modelo de dados utilizado na implementação, o Modelo de Contextos Aninhados (MCA) (Casanova et al., 1991; Soares et al., 1994, 1995b). Durante a construção do hiperdocumento, o autor utiliza uma ferramenta fornecida pelo SASHE, que oferece recursos de autoria que utilizam diretamente os conceitos do MCA.

As dificuldades encontradas para utilizar esses conceitos durante a autoria motivaram a idéia de incluir uma ferramenta de modelagem do domínio de hipermídia para ensino no processo de autoria de hiperdocumentos do SASHE. Com o objetivo de fornecer uma base para o desenvolvimento dessa ferramenta, foi definido um método que propõe uma série de etapas de 
projeto, além de oferecer modelos de representação adequados para descrever o domínio de conhecimento e os aspectos navegacionais de hiperdocumentos para ensino.

Este trabalho apresenta o Método para Projeto de Hiperdocumentos para Ensino, ou EHDM (Educational Hyperdocuments Design Method), que foi definido inicialmente como uma ferramenta de modelagem para o SASHE, mas que posteriormente mostrou-se útil para apoiar o desenvolvimento de hiperdocumentos educacionais para outros sistemas e/ou ambientes, por exemplo, para a World Wide Web.

Além da definição do EHDM, este trabalho também apresenta o protótipo da ferramenta que suporta o método definido e um exemplo de sua utilização, permitindo avaliar a possibilidade de uso do EHDM num contexto real. O protótipo foi desenvolvido como uma ferramenta de suporte automatizado integrada ao SASHE, proporcionando um ambiente de modelagem para auxiliar a autoria de hiperdocumentos para ensino neste sistema.

\subsection{Organização}

Neste capítulo foram apresentados o problema a ser investigado, a motivação e os objetivos deste trabalho. O Capítulo 2 aborda o desenvolvimento de aplicações hipermídia. O Capítulo 3 descreve os principais métodos para projeto de aplicações hipermídia da literatura. O Capítulo 4 é dedicado à apresentação do Sistema de Autoria e Suporte Hipermídia para Ensino (SASHE).

O Capítulo 5 apresenta o Modelo de Michener e Mapas Conceituais, que constituem a base teórica utilizada na definição do Método para Projeto de Hiperdocumentos para Ensino (EHDM). O Capítulo 6 apresenta as etapas do EHDM e os trabalhos relacionados. No Capítulo 7 é apresentada a ferramenta desenvolvida para o SASHE e um exemplo de hiperdocumento desenvolvido com este suporte. Finalmente, o Capítulo 8 apresenta as conclusões, enfocando as contribuições e os trabalhos futuros. 


\section{Capítulo 2}

\section{Desenvolvimento de Aplicações Hipermídia}

\subsection{Considerações Iniciais}

A utilização de abordagens de engenharia de software no desenvolvimento de aplicações hipermídia oferece diversas vantagens, mas as peculiaridades da hipermídia exigem o desenvolvimento de novos métodos, específicos para as suas características (Garzotto et al., 1993).

O objetivo deste capítulo é apresentar as principais diferenças envolvendo o desenvolvimento de software tradicional e o desenvolvimento de aplicaçōes hipermídia, e levantar subsídios para a proposta de um método para projeto de aplicações hipermídia destinadas ao ensino.

A Seção 2.2 apresenta o processo de desenvolvimento de software. A Seção 2.3 diferencia alguns termos da engenharia de software, de maneira a uniformizar a terminologia empregada neste trabalho e evitar várias interpretaçōes. A Seção 2.4 apresenta as particularidades que envolvem o desenvolvimento de aplicações hipermídia. A Seção 2.5 descreve os aspectos cognitivos de aplicações hipermídia, apresentando diversas diretrizes de projeto para essas aplicações.

\subsection{Desenvolvimento de Software}

A literatura especializada em engenharia de software proporciona várias metodologias para o desenvolvimento de software (clássica ou cascata, prototipação, desenvolvimento incremental, espiral etc.), cada uma delas oferecendo potencialidades e fragilidades. Em muitos casos, porém, as metodologias podem e devem ser combinadas de forma que as potencialidades de cada uma possam ser obtidas num único projeto, sendo que a natureza da aplicação deve ditar a abordagem a ser tomada (Pressman, 1995). 
O processo de desenvolvimento de software, independentemente da metodologia escolhida, contém três fases genéricas: definição, desenvolvimento e manutenção (Pressman, 1995). A fase de definição compreende três etapas:

- Análise do sistema: define o papel de cada elemento num sistema baseado em computador, atribuindo o papel do software no sistema;

- Planejamento do projeto de software: estabelece o escopo do software, analisa os riscos, aloca os recursos, estima os custos e define as tarefas e a programação de trabalho;

- Análise de requisitos: define detalhadamente o domínio da informação e a função do software.

A fase de desenvolvimento também compreende três etapas:

- Projeto de software: traduz os requisitos do software num conjunto de representações (modelos) que descrevem a estrutura de dados, a arquitetura, o procedimento algorítmico e as características de interface;

- Implementação: converte as representações do projeto numa linguagem que resulte em código executável;

- Realização de testes do software: testa a forma executável do software para descobrir defeitos de função, lógica e implementação.

A fase de manutenção concentra-se nas mudanças que estão associadas à correção de erros, adaptações e ampliações, reaplicando os passos das fases de definição e desenvolvimento, mas dentro do contexto do software existente.

\subsection{Terminologia}

É importante, nesse contexto, distinguir alguns conceitos, como metodologia, método e modelo, para uniformizar a terminologia empregada neste trabalho e evitar várias interpretações. Os termos aqui definidos são baseados principalmente em Yourdon (1993), sendo que outros autores podem divergir dessas definições.

Uma metodologia é um "plano de batalha", passo a passo, para atingir algum resultado desejado (Yourdon, 1993). Geralmente, uma metodologia identifica as atividades principais (por exemplo, análise, projeto, codificação e teste) a serem executadas, indicando quais pessoas (usuários, gerentes, técnicos) devem ser envolvidas em cada atividade e qual papel elas desempenham. O termo "ciclo de vida" é um sinônimo para metodologia (Yourdon, 1993). 
Um método consiste em uma abordagem essencialmente técnica, passo a passo, para executar uma ou mais atividades principais identificadas em uma metodologia (Yourdon, 1993). Portanto, metodologias diferentes podem utilizar um mesmo método em uma determinada atividade. Por exemplo, as metodologias para desenvolvimento de software clássica (ou cascata) e espiral podem utilizar o mesmo método durante a atividade de projeto e implementação (projeto orientado a objetos, por exemplo).

Um modelo ${ }^{3}$ é uma representação abstrata de uma entidade real (Pressman, 1995). Alguns métodos propõem a criação de modelos para obter uma melhor compreensão da entidade real a ser construída. Portanto, um método pode utilizar um ou mais modelos em uma determinada atividade (fase). Em muitos casos, os modelos utilizam uma notação gráfica para descrever as características da entidade sendo modelada. Por exemplo, a Object Modeling Technique (OMT) (Rumbaugh et al., 1991) utiliza três tipos de modelos para descrever um sistema: o modelo de objeto, que descreve os objetos no sistema e seus relacionamentos; o modelo dinâmico, que descreve as interações entre os objetos no sistema; e o modelo funcional, que descreve as transformações dos dados no sistema.

\subsection{Desenvolvimento de Aplicações Hipermídia}

As aplicações hipermídia envolvem muitos componentes diferentes, como navegação, interface de usuário e armazenamento de dados. Conseqüentemente, os modelos de dados como os diagramas de entidade-relacionamento $(E-R)$ e as hierarquias orientadas a objetos não conseguem representar os detalhes das aplicações hipermídia (Bieber \& Isakowitz, 1995).

Além disso, várias dimensões diferem os projetos de hipermídia dos projetos de desenvolvimento de software tradicionais (Isakowitz et al., 1995). Os projetos de hipermídia podem envolver pessoas com muitas habilidades diferentes: autores, bibliotecários, ilustradores, artistas, músicos e programadores (Streitz, 1995). O projeto de aplicações hipermídia envolve capturar e organizar a estrutura de um domínio complexo e torná-la clara e acessível aos usuários (Garzotto et al., 1993). Os aspectos de multimídia das aplicações hipermídia criam numerosas dificuldades (Hardman et al., 1994).

Por outro lado, a utilização de modelos no projeto de aplicações hipermídia apresenta diversas vantagens (Garzotto et al., 1993):

\footnotetext{
"Muitas vezes, o termo "modelo" é utilizado para referir a técnica empregada na construçāo de um modelo, por exemplo, o modelo orientado a objetos
} 
- Melhora a comunicação entre os profissionais envolvidos no desenvolvimento e o usuário final;

- Fornece uma base para o desenvolvimento, análise e comparação de metodologias de projeto e de estilos de autoria, em um alto nível de abstração;

- Permite o reuso da estrutura principal das aplicações;

- Ajuda a evitar inconsistências e erros;

- Fornece uma base para o desenvolvimento de ferramentas que suportam um processo de desenvolvimento estruturado e esquemático, permitem ao projetista trabalhar em um nível de abstração próximo ao domínio de aplicação e fornecem um processo de tradução sistemático ao nível de implementação.

Da mesma forma que os métodos de desenvolvimento de software tradicionais, as abordagens atuais para o desenvolvimento de aplicações hipermídia (descritos no Capítulo 3) podem oferecer uma série ordenada de etapas, além de fornecer novos conceitos e notações convenientes (modelos) para representar o domínio de hipermídia. As etapas geralmente identificadas em métodos formais são as seguintes: modelagem do domínio, modelagem da navegação, projeto da interface, implementação e realização de testes (Nanard \& Nanard, 1995).

A observação do trabalho de desenvolvedores de aplicações hipermídia mostra que o processo de desenvolvimento real não segue simplesmente os passos de um método formal, mas também envolve vários processos mentais (fatores humanos) (Nanard \& Nanard, 1995): geração de material, organização e estruturação, reorganização e alteração, avaliação.

Para um ambiente de desenvolvimento suportar as atividades citadas acima, Nanard e Nanard (1995) propð̃em o uso de laços de realimentação ("feedback loops") rápidos e de prototipação para facilitar a avaliação, de abordagens bottom-up e'top-down para estimular as atividades de estruturação e alteração, e de replicação (cloning) ao nível de instância para a geração dé material.

A Figura 2.1 ilustra as abordagens bottom-up e top-down. O processo abstrai modelos genéricos a partir de exemplos (instâncias) em um sentido e, no outro, instancia modelos para a implementação e construção de aplicações.

O processo de desenvolvimento também necessita suportar a realização de testes intensivos (Isakowitz et al., 1995; Nanard \& Nanard, 1995; Bieber \& Vitali, 1997), pois não existe atualmente uma teoria válida para avaliar se um modelo conceitual hipermídia pode ser compreendido pelos leitores, e as métricas tradicionais de software não podem avaliar adequadamente a estrutura de um hiperdocumento (Nanard \& Nanard, 1995). Alguns pesquisadores têm trabaihado no desenvolvimento de métricas e métodos de avaliação de 
hiperdocumentos (Rivlin et al., 1994; Garzotto et al., 1995; Hatzimanikatis et al., 1995; Fortes, 1996).

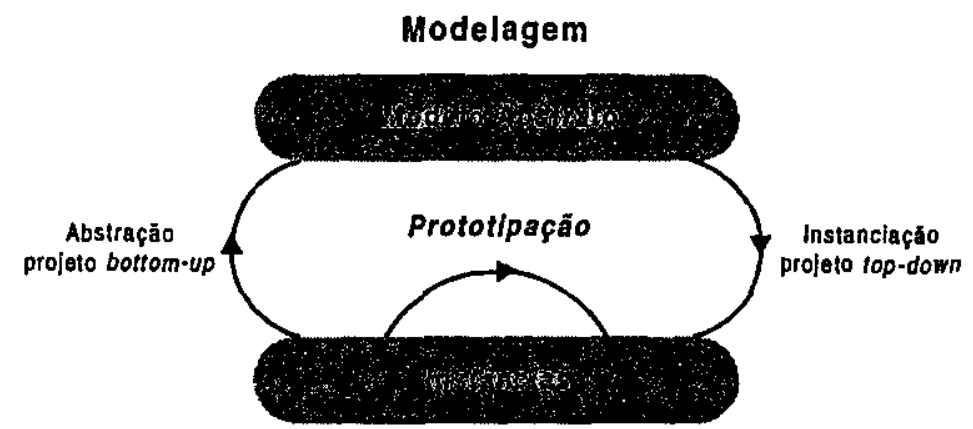

Figura 2.1: Abordagens bottom-up e top-down (Nanard \& Nanard, 1995)

\subsection{Aspectos Cognitivos de Aplicações Hipermídia}

Na ciência cognitiva, a compreensão é freqüentemente caracterizada como a construção de um modelo mental que representa os objetos e as relações semânticas descritas em um texto. A legibilidade (readability) de um documento pode ser definida como o esforço mental gasto no processo de construção. Para aumentar a legibilidade de um hiperdocumento (aplicação hipermídia) deve-se auxiliar os leitores através do fortalecimento dos fatores que suportam esse processo e enfraquecendo os que o impedem. Thüring et al. (1995) aponta dois fatores críticos que influenciam a compreensão: a coerência, como fator positivo; e a sobrecarga cognitiva (Conklin, 1987), como fator negativo.

Um documento é coerente se um leitor pode construir um modelo mental a partir dele que corresponda a fatos e relações em um mundo possível. -Para obter coerência em hiperdocumentos, os autores devèm proporcionar recursos ou pistas (cues) em dois níveis: ao nível de nó (dentro dos nós) e ao nível de rede (entre os nós). Ao nível de nó, os autores podem contar com suas habilidades de escrita usuais, mas ao nível de rede, eles necessitam de habilidades além daquelas utilizadas para escrever textos lineares.

Para aumentar a coerência entre os nós, os autores devem limitar a fragmentação característica de hipertexto (Thüring et al., 1995). A fragmentação pode resultar em uma falta de contexto interpretativo e levar à impressão que o hiperdocumento é uma agregaçāo de pedaços de informação em vez de um todo coerente. Para reduzir essa impressão, os autores podem representar explicitamente os relacionamentos semânticos entre os nós, e também podem fornecer um contexto no qual o nó atual é apresentado junto com o seu predecessor. A 
preservação do contexto proporciona um sentido de continuidade através dos nós que é muito importante para a compreensão (Thüring et al., 1995).

Outra forma de aumentar a coerência entre os nós consiste na utilização de recursos para ajudar o leitor a identificar os principais componentes do hiperdocumento e a maneira pela qual eles constituem sua estrutura global. Os autores podem agregar as informações em unidades de ordem mais alta (através de nós de composição) e fornecer urna visão geral dos componentes e de suas relações na forma de browsers gráficos.

A sobrecarga cognitiva é o esforço e concentração adicionais necessários para manter várias tarefas ou trilhas ao mesmo tempo (Conklin, 1987). Como a capacidade humana de processarnento de informação é limitada, cada esforço adicional para a leitura reduz os recursos mentais disponíveis para a compreensão. Em hiperdocumentos, esses esforços correspondem principalmente à orientação, navegação e adaptação à interface de usuário (user-interface adjustment) (Thüring et al., 1995).

Os termos "orientação" e "navegação" sugerem a concepção de hiperdocumentos como "espaços de informação" onde os leitores podem mover-se de uma parte para outra. Essa idéia certamente contribui para caracterizar o mais citado problema dos leitores de hipertexto, a "desorientação", que ocorre quando os leitores não sabem onde eles estão, como eles chegaram lá ou onde eles deveriam ir.

Para minimizar a "desorientação", os autores devem fornecer recursos para permitir aos leitores identificar a sua posição corrente em relação à estrutura global, reconstruir o caminho que o levou a esta posição, e distinguir entre as diferentes opções para mover-se a partir desta posição. Por exemplo, a manutenção do histórico de navegação (isto é, o caminho percorrido pelo usuário) auxilia o leitor a reconstruir o caminho até a sua posição atual.

Enquanto os recursos de orientação ajudam os leitores a "encontrar" o seu caminho, os recursos de navegação permitem a eles realmente "fazer" o seu caminho. Os autores devem fornecer recursos para reduzir o esforço dos leitores na tomada de decisões de navegação, cobrindo uma certa quantidade de movimentos possíveis sem impor uma série de ações complicadas. Os aspectos de direção e distância da navegação são importantes nesse contexto (Thüring et al., 1995).

Em relação à direção, a questão é diferenciar a navegação "para frente" (informação nova) e a navegação "para trás" (informação antiga), além da navegação na vertical, no caso de estruturas aninhadas. Com relação à distância, os recursos devem proporcionar a diferença entre "andar", isto é, mover-se de um nó para outro diretamente conectado; e "saltar", isto é, atingir um nó que 
não está diretamente conectado à sua posição atual (através de índices ou tabelas de conteúdo, por exemplo).

Além de suportar a orientação e a navegação, uma interface também deve superar uma terceira fonte de sobrecarga cognitiva: a adaptação dos leitores à interface. $O$ esforço exigido para essa atividade pode ser influenciado por várias características de interface, por exemplo, as operações e layouts de janelas. Para minimizar o esforço de adaptação, os autores devem considerar cuidadosamente quais tarefas são indispensáveis e quais devem ser evitadas, através de um projeto de interface apropriado (Thüring et al., 1995).

\subsection{Considerações Finais}

As principais diferenças envolvendo o desenvolvimento de aplicaçōes hipermídia e o desenvolvimento de software tradicional foram apresentadas neste capítulo. Nesse contexto, é importante diferenciar um "sistema hipermídia" de uma "aplicação hipermídia" (Isakowitz et al., 1995). Um sistema hipermídia é um ambiente que facilita a criação de uma aplicação hipermídia. Uma aplicação hipermídia pressupõe a existência de um sistema hipermídia que forneça os recursos para autoria, apresentação e navegação.

Os modelos para sistemas hipermídia visam apresentar uma arquitetura genérica que possa ser utilizada para diferentes implementações desses sistemas (Fortes, 1996). O Hypertext Abstract Machine (HAM) (Campbell \& Godman, 1988), o Dexter hypertext model (Halasz \& Schwartz, 1994), o Amsterdam Hypermedia Model (AHM) (Hardman et al., 1994), o Modelo de Contextos Aninhados (Soares et al, 94), são exemplos de modelos para sistemas hipermídia.

Um modelo para úm sistema hipermídia detalha sua arquitetura, mas é de pouco valor na modelagem de aplicações hipermídia porque a atividade de descrever o layout de uma máquina (engine) de propósito geral é totalmente diferente da atividade de modelar um domínio de aplicação; um tipo de modelo diferente é necessário para este propósito (Isakowitz et al., 1995).

Os métodos para projeto de aplicaçōes hipermídia fornecem modelos adequados para descrever os dados do domínio e os aspectos de navegação das aplicações hipermídia, além de propor uma abordagem mais sistemática para o desenvolvimento dessas aplicações. O próximo capítulo apresenta os principais métodos para projeto de aplicaçőes hipermídia da literatura. 


\section{Capítulo 3}

\section{Métodos para Projeto de Aplicações Hipermídia}

\subsection{Considerações Inicials}

Neste capítulo são apresentados os principais métodos da literatura que têm sido propostos para descrever o processo de desenvolvimento e os aspectos de domínio e de navegação das aplicações hipermídia. A Seção 3.2 apresenta o HDM (Hypertext Design Model), considerado como o primeiro modelo para o domínio de hipermídia. A Seção 3.3 apresenta o RMM (Relationship Management Methodology), que é um método para o desenvolvimento de aplicações hipermídia baseado em diagramas entidade-relacionamento.

A Seção 3.4 apresenta o OOHDM (Object-Oriented Hypermedia Design Method), a Seção 3.5, o EORM (Enhanced Object-Relationship Model) e a Seção 3.6, o HMBS/M (Hypertext Model Based on Statecharts / Method). Esses métodos utilizam uma abordagem orientada a objetos para a construção de aplicaçōes hipermídia.

\subsection{HDM - Hypertext Design Model}

O Hypertext Design Model (HDM) (Garzotto et al., 1993) é um modelo para descrever aplicações hipermídia. Uma aplicação (hiperdocumento) no HDM consiste de estruturas de informação chamadas entidades, que denotam um objeto físico ou conceitual do domínio, e são agrupadas em tipos de entidades (entity types). Por exemplo, "motor elétrico" é uma entidade do tipo "equipamento".

Uma entidade é uma hierarquia de componentes. Os componentes são compostos de unidades, sendo que cada unidade corresponde a um componente associado com uma perspectiva específica, ou seja, uma unidade mostra o conteúdo de um componente sob uma perspectiva. As hierarquias de componentes podem ser deduzidas por vários critérios semânticos, por exemplo, a relação "é-parte-de" é um dos critérios mais utilizados. No HDM, esse recurso é puramente 
sintático, servindo apenas para organizar a informação em blocos de construção homogêneos dentro de uma aplicação.

As entidades derivam seu conteúdo a partir de seus componentes que, por sua vez, derivam de suas unidades. As unidades são os menores conjuntos de informação que podem ser visualizados, e são semelhantes à noção de nós em hipertexto. A perspectiva é um recurso sintático para organizar as informações que devem ser apresentadas de formas alternativas, por exemplo, uma mesma informação pode ser visualizada em português e inglês, ou utilizando mídias diferentes como texto, gráfico, imagem, vídeo, áudio etc.

As estruturas de informação (entidades, componentes e unidades) podem ser conectadas por três categorias de elos (links): os elos estruturais conectam os componentes de uma mesma entidade; os elos de perspectiva conectam as unidades de um mesmo componente; e os elos de aplicação indicam os relacionamentos dependentes do domínio, e conectam componentes e entidades de maneira arbitrária e definida pelo autor. Os elos de aplicação são organizados em tipos, que são especificados através de um nome, do tipo das entidades origem e destino, e de um atributo (simétrico ou assimétrico) indicando se o tipo possui um elo inverso.

A Figura 3.1 mostra um exemplo das estruturas de informação e dos elos do HDM. Esse exemplo possui duas entidades, $A$ e $B, \mathrm{com}$ um elo de aplicação indicando um relacionamento entre estas entidades. A entidade $A$ possui os componentes $A l$ e $A 2$, conectados à entidade através de elos estruturais; o mesmo para a entidade $B$. O componente $B 3$ possui três unidades conectadas através de elos de perspectiva, que corresponde à possibilidade de apresentar informação sobre o componente na forma de foto, texto e mapa.

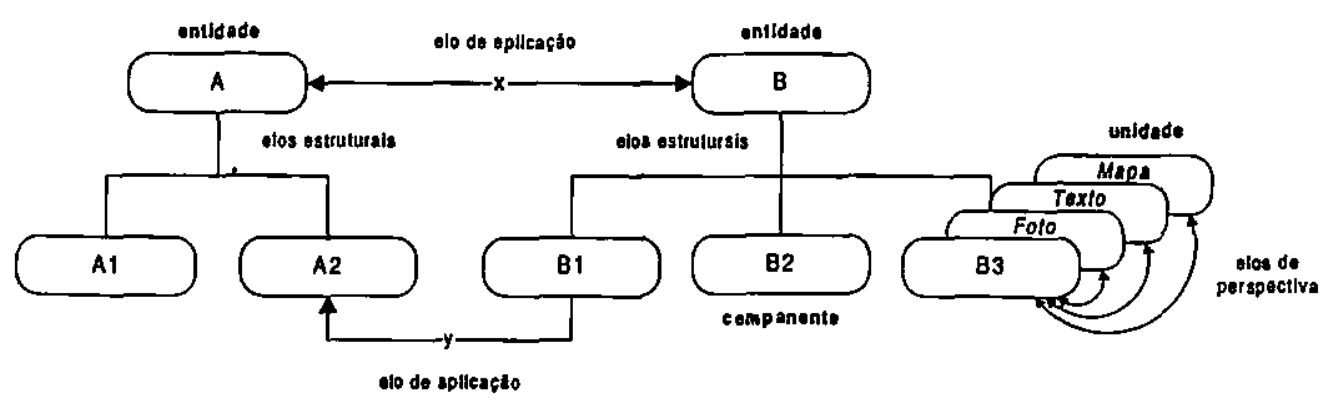

Figura 3.1: Exemplo de estruturas de informação e elos do HDM

As categorias de elos e os tipos de elos de aplicação são utilizados com o objetivo de simplificar o trabalho de projeto, induzir o uso consistente de elos, criar padrões de navegação e possibilitar a derivação automática de um núrnero significativo de elos a partir da especificação.

O modelo HDM faz uma distinção entre as noções de esquema (schema) e instância de esquema. Um esquema é uma coleção de definições de tipos (entidades e elos de aplicação) que 
descrevem uma aplicação em nível global; uma instância de um esquema é uma coleção de entidades, componentes, unidades, e elos que satisfazem as definições do esquema. Essa característica pode permitir a reutilização do mesmo esquema para diferentes aplicações do mesmo domínio.

A Figura 3.2 mostra um exemplo de esquema que procura descrever a informação manipulada em uma organização de crédito, na qual os documentos são manipulados conforme procedimentos. Os documentos e procedimentos são definidos de acordo com leis, regulamentos e normas informais.

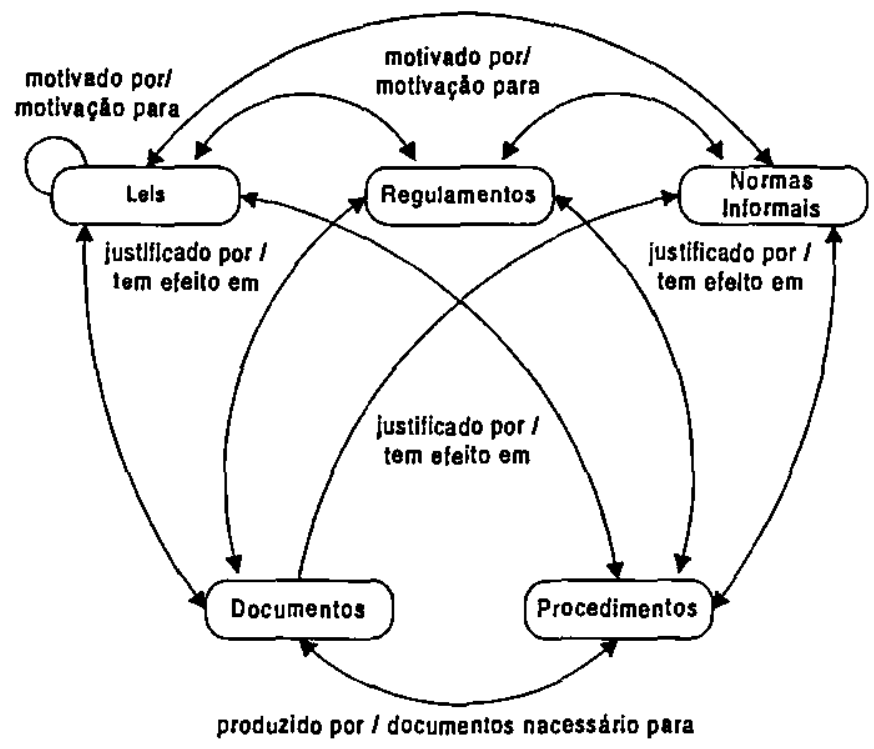

Figura 3.2: Exemplo de esquema HDM (Garzotto et al., 1993)

Apesar do HDM ser utilizado principalmente para a modelagem de aplicações, ele fornece uma semântica de navegação padrão, derivada diretamente da especificação e compatível com a navegação comum de nós e elos encontrada em muitos sistemas. Entretanto, é possível definir semânticas de navegação específicas para um determinado sistema alvo da aplicação.

A navegação pode ser realizada percorrendo-se os elos definidos em uma instância de esquema. Entretanto, para acessar diretamente as estruturas de informação, são utilizadas as estruturas de acesso (outlines), que fornecem pontos de entrada apropriados (como um índice, por exemplo) e não são especificadas no esquema, sendo livremente adicionadas ou modificadas em uma aplicação. 


\subsection{RMM - Relationship Management Methodology}

O Relationship Management Methodology (RMM) (Isakowitz et al., 1995) é um método de desenvolvimento de aplicações hipermídia indicado principalmente para as aplicações que apresentam uma estrutura regular do domínio e que necessitam de frequientes atualizações (um catálogo de produtos, por exemplo).

O método compreende sete etapas: projeto de entidade-relacionamento (E-R design), projeto de entidade (entity design), projeto de navegação (navigation design), projeto de protocolo de conversão (conversion protocol design), projeto de tela de interface de usuário (user-interface screen design), projeto de comportamento de tempo de execução (run-time behavior design) e construção (construction). Essas etapas podem ser visualizadas na Figura 3.3, dentro de um ciclo de desenvolvimento completo.

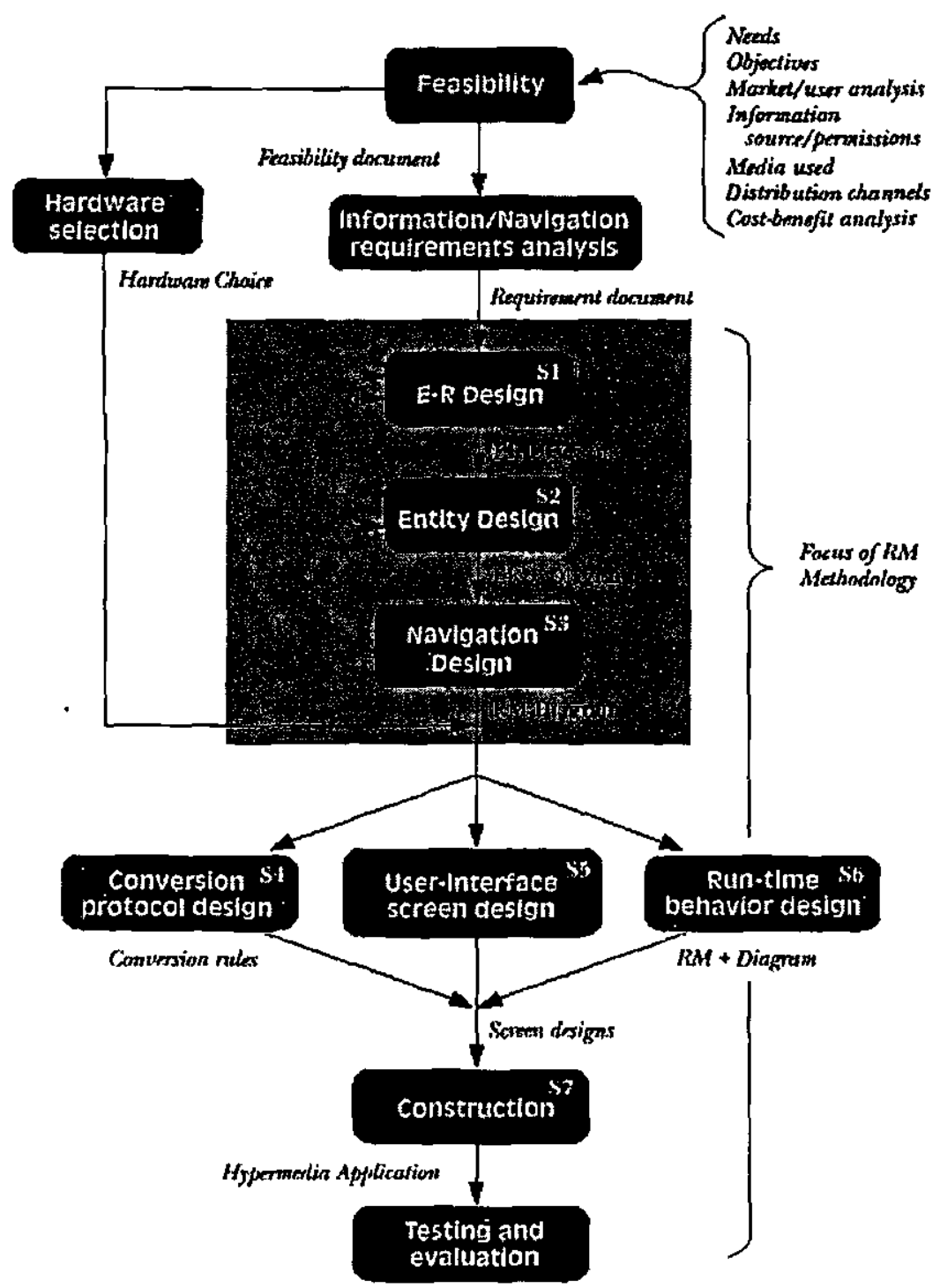

Figura 3.3: A metodologia RMM (Isakowitz et al., 1995) 
A eira etapa, o projeto de entidade-relacionamento (E-R), tem como objetivo representar o do , da aplicação através de um diagrama E-R. Essas entidades e seus relacionamentos asso os formam a base da aplicação hipermídia, correspondendo a nós e elos (links) na apli final.

ura 3.4 mostra um exemplo de diagrama E-R. Neste exemplo, as entidades "Faculty" e " $C s$ " são representadas por retângulos, enquanto que os relacionamentos "Teach", "1 t_by", "Has_Co-Requisite" e "Has_Pre-Requisite" são indicados por linhas tracejadas. A $\mathrm{n}$ । Jráfica também mostra a aridade de cada relacionamento, sendo que, quando uma linha a $\quad \mathrm{n}$ três linhas, a aridade é "muitos" naquele lado do relacionamento. As aridades possíveis n lacionamentos são: um-para-um, um-para-muitos e muitos-para-muitos. (representada por c elacionamentos um-para-muitos, como "Teach" e "Taught_by").

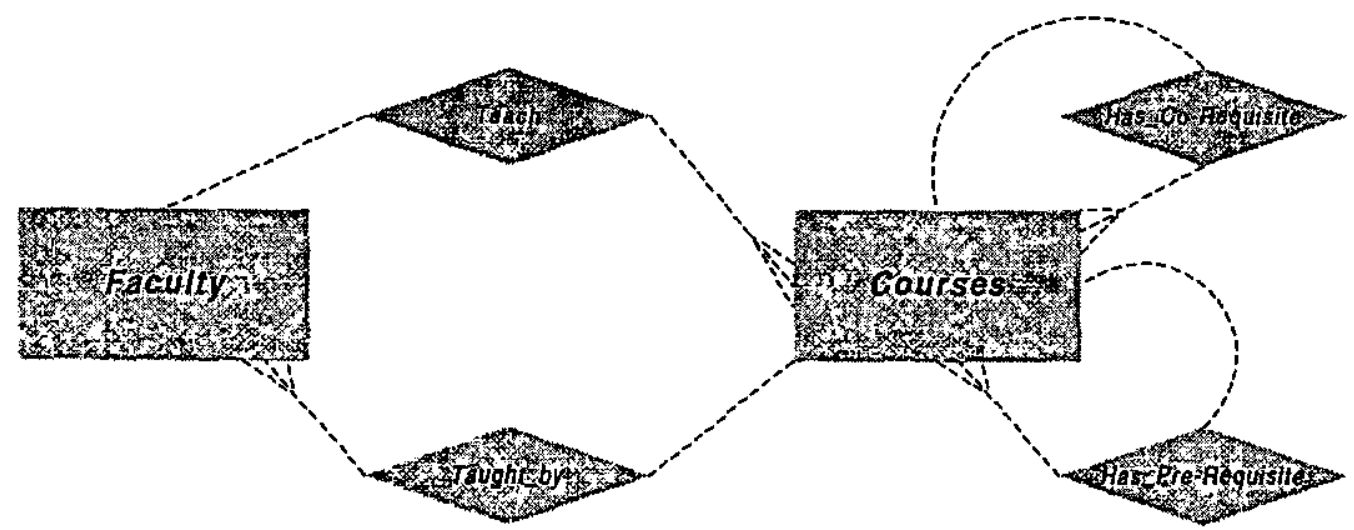

Figura 3.4: Exemplo de diagrama entidade-relacionamento (Isakowitz et al., 1995)

O projeto de entidade determina como a informação das entidades identificadas na etapa unterior será apresentada aos usuários. Essa etapa pode envolver a divisão de cada entidade em unidades ou "fatias" (slices) significativas, que podem ser apresentadas de forma separada, mas inter-relacionadas através de relacionamentos estruturais (similar aos elos estruturais do HDM). Por exemplo, a entidade "Faculty" pode ser subdividida em quatro slices, contendo informação geral, uma biografia, os interesses de pesquisa e um videoclip. $\mathrm{O}$ diagrama $\mathrm{E}-\mathrm{R}$ mais a descrição das slices de cada entidade formam o diagrama E-R+.

O projeto de navegação analisa os relacionamentos associativos do diagrama $E-R+e$ descreve os objetos de informação e os mecanismos de navegação através do modelo de dados denominado Relationship Management Data Model (RMDM) (Isakowitz et al., 1995). Cada relacionamento associativo é substituído por uma das estruturas de acesso do RMDM: índice condicional (conditional index), roteiro condicional (conditional guided tour) e roteiro indexado condicional (conditional indexed guided tour). Além disso, estruturas de acesso de alto nível 
(menus, por exemplo) podem ser especificadas através do agrupamento (grouping) de itens de interesse.

A Figura 3.5 mostra um exemplo de diagrama RMDM. Neste exemplo, o relacionamento "Teach" entre "Faculty" e "Courses" pode ser navegado através do índice condicional "Course Index"; o mesmo para os demais relacionamentos. No topo da Figura 3.5 está especificado um agrupamento (menu) com opções de acesso a "Faculty" e "Courses" através de roteiros condicionais. Isakowitz et al. (1995) fomece uma descrição mais detalhada das primitivas do RMDM.

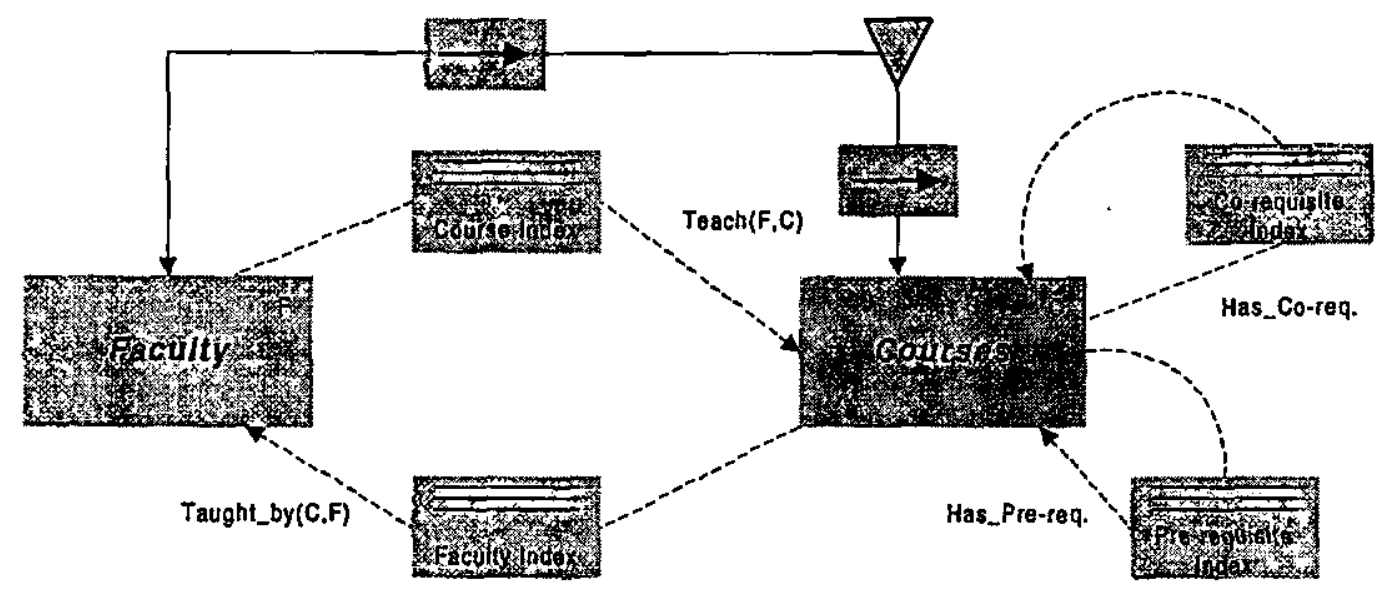

Figura 3.5: Exemplo de diagrama RMDM (Isakowitz et al., 1995)

A etapa de projeto de protocolo de conversão utiliza um conjunto de regras de conversão para transformar cada elemento do diagrama RMDM em um objeto da plataforma destino (HyperCard, ToolBook, HTML etc.).

O projeto de tela de interface de usuário envolve o projeto do layout das telas para cada objeto do diagrama RMDM obtido no projeto de navegação. Isso inclui o layout de botões, aparência de nós e índices, e a localização do auxílio à navegação. No projeto de comportamento de tempo de execuçāo são tomadas as decisões sobre como percorrer os elos e como os mecanismos de navegação, histórico e backtracking são implementados. A última etapa, a construção, tem como objetivo implementar a aplicação e é executada da mesma forma que em projetos tradicionais de engenharia de software. 


\subsection{OOHDM - Object-Oriented Hypermedia Design Method}

O Object-Oriented Hypermedia Design Method (OOHDM) (Rossi, 1996; Schwabe et al., 1996) é um método para construção de aplicações hipermídia, compreendendo quatro atividades diferentes: modelagem conceitual (ou análise de domínio), projeto navegacional, projeto da interface abstrata e implementação. Esse processo suporta uma mistura dos estilos de desenvolvimento incremental, iterativo e baseado em protótipo. Cada atividade produz ou enriquece um modelo orientado a objetos enfocando um determinado interesse de projeto. A Figura 3.6 resume as atividades, produtos, mecanismos e interesses de projeto do OOHDM.

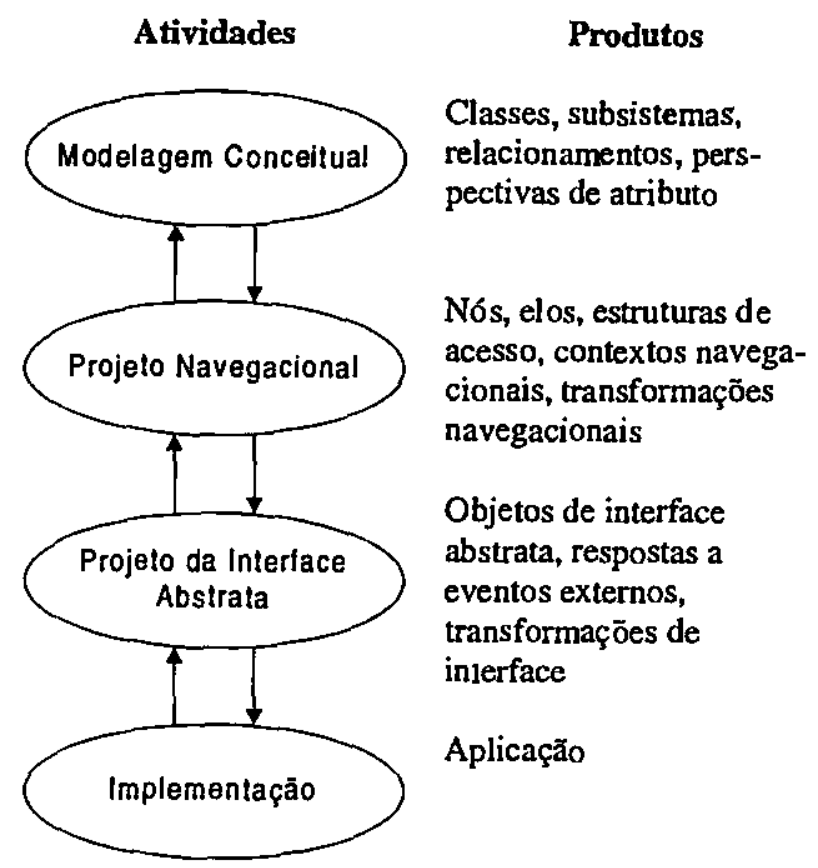

Mecanismos

Classificação, composiçāo, generalização e especialização

Mapeamento entre objetos conceituais e objetos navegacionais

Mapeamento entre objetos navegacionais e objetos perceptíveis ao usuário

Aqueles fornecidos pelo ambiente alvo
Interesses de Projeto

Modelar a semântica do domínio da aplicação

Levar em conta o perfil do usuário e a tarefa; ênfase nos aspectos cognitivos

\section{Modelar os objetos} perceptiveis, implementar as metáforas escolhidas; descrever a interface para os objetos navegacionais

Desempenho, completitude

Figura 3.6: Resumo da metodologia OOHDM (Schwabe \& Rossi, 1995)

Durante a modelagem conceitual, um modelo do domínio da aplicação é construído utilizando-se os princípios da modelagem orientada a objetos, ampliada com algumas primitivas como as perspectivas de atributo (atributos multi-valorados, similar às perspectivas do HDM) e os subsistemas (abstrações de um sistema conceitual completo). As hierarqquias de composição e de generalização / especialização típicas da orientação a objetos são utilizadas para construir as classes conceituais. A principal preocupação da etapa de modelagem conceitual é capturar a semântica do domínio da aplicação, com pouco interesse para os tipos de usuários e tarefas. $\mathrm{O}$ produto desta etapa é um esquema de classes e objetos construído a partir de subsistemas, classes e relações. 
A Figura 3.7 mostra uma versão simplificada do esquema conceitual de uma aplicação que apresenta informações sobre o pintor Cândido Portinari. Nesse exemplo, a classe "Obra" possui o atributo "Description" que tem duas perspectivas, "Text" e "Image", correspondendo às representações textual e gráfica da obra. A seta entre "Referência" e a caixa tracejada indica que "Referência" está relacionada com todas as outras classes dentro da caixa tracejada através da relação "referencia"; o mesmo para "Comentários históricos".

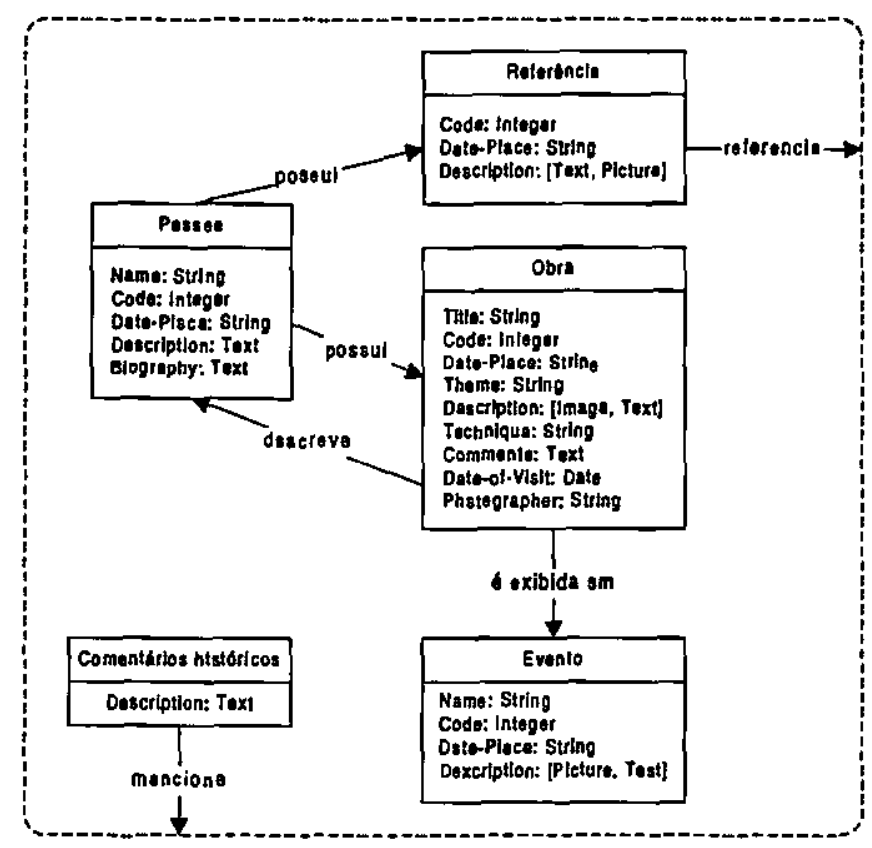

Figura 3.7: Exemplo simplificado de esquema conceitual (Schwabe et al., 1996)

No OOHDM, para obter uma aplicação é necessário definir um modelo navegacional para o modelo conceitual. Esse modelo navegacional é uma visão do modelo conceitual, e diferentes modelos navegacionais podem ser construídos para expressar diferentes visões do mesmo domínio. Essa visão é construída durante o projeto navegacional observando-se o tipo dos usuários e as tarefas que serão realizadas por eles.

O projeto navegacional é descrito em dois esquemas: o esquema de classe navegacional e o esquema de contexto navegacional. Os objetos navegáveis (objetos que serão visualizados) de uma aplicação hipermídia são definidos por um esquema de classe navegacional, cujas classes refletem a visão escolhida sobre o domínio da aplicação. No OOHDM, existe um conjunto prédefinido de tipos de classes navegacionais: nós, elos e estruturas de acesso (índices e guided tours). Os nós são definidos como visões orientadas a objetos das classes conceituais definidas durante o projeto conceitual e os elos refletem os relacionamentos a ser explorados pelo usuário final, também definidos como visões sobre os relacionamentos do esquema conceitual. 
O esquema de contexto navegacional especifica as várias maneiras que as informações de uma aplicação hipermídia podem ser exploradas pelo usuário, por exemplo, por tema ou por ordem cronológica. Um contexto navegacional é um conjunto de nós, elos, classes de contexto e outros contextos navegacionais (aninhados), produzido a partir das classes navegacionais (nós, elos, índices e guided tours).

Os contextos navegacionais podem ser especificados através da definição de uma propriedade que todos os nós e elos no contexto possuem, ou através da enumeração dos seus membros. As classes de contexto complementam a definição de uma classe navegacional (um nó) indicando qual informação é mostrada e quais âncoras estão disponíveis quando o objeto é apresentado em um determinado contexto. A definição das transformações navegacionais que ocorrem quando um usuário percorre os elos (por exemplo, os nós fonte e destino permanecem ativos) completa a especificação da dinâmica da estrutura navegacional.

O projeto da interface abstrata define a estrutura navegacional que pode ser vista pelo usuário através da definição de um modelo de interface abstrata. Isso significa definir quais objetos que podem ser vistos (perceptíveis) pelo usuário. No OOHDM, é utilizada a abordagem de projeto Abstract Data View (ADV) para descrever a interface de uma aplicação hipermídia.

ADVs são modelos formais, orientados a objetos, de objetos de interface (menus, campos de texto, botões etc.) que permitem especificar as metáforas de interface e descrever suas propriedades estáticas (relacionamentos com os objetos navegacionais) e dinâmicas (comportamento frente a eventos externos), de uma forma independente de implementação.

Finalmente, a implementação realiza um mapeamento dos modelos de interface abstrata e navegacional para objetos concretos disponíveis no ambiente de implementação escolhido, de maneira a obter uma aplicação pronta para ser executada.

\subsection{EORM - Enhanced Object-Relationship Model}

O Enhanced Object-Relationship Model (EORM) (Lange, 1994) é uma abordagem orientada a objetos para o projeto de aplicaçōes hipermídia. A abordagem utiliza como base uma metodologia de análise orientada a objetos, a Object Modeling Technique (OMT) (Rumbaugh et al., 1991), e estende esta metodologia com construções para capturar a semântica das interaçбes entre objetos. 
A idéia central da metodologia é representar, explicitamente, os relacionamentos semanticamente ricos no modelo orientado a objetos. Esses relacionamentos são definidos como classes que têm estrutura e comportamento próprios. Desta forma, os relacionamentos são capazes de capturar não apenas as restrições estruturais básicas dos relacionamentos OMT, mas também as propriedades complexas destes relacionamentos, como por exemplo, a semântica de ligações hipermídia. A semântica hipermídia de um relacionamento é modelada em uma aplicação definindo-se classes e hierarquias de ligações e associando as semânticas dessas ligações aos relacionamentos.

A Figura 3.8 mostra as três fases do método de projeto EORM: a estrutura de classes, a estrutura de composição e a estrutura de interface gráfica de usuário (GUI).

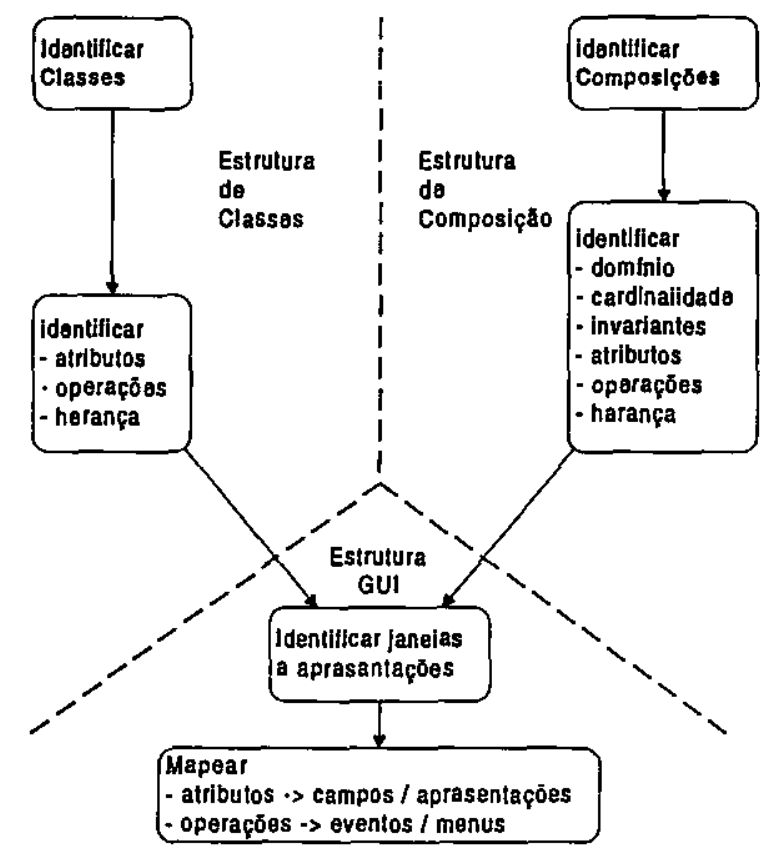

Figura 3.8: Visão geral do método de projeto EORM (Lange, 1994)

A estrutura de classes é formada por uma biblioteca reusável de definições de classes e possui duas atividades relacionadas: identificação e refinamento de classes. A primeira atividade consiste em identificar as classes relevantes a partir do domínio da aplicação. As classes irrelevantes, não específicas e redundantes, bem como relacionamentos, atributos e operaçōes devem ser evitados nesta fase.

A segunda atividade consiste no detalhamento da informação de cada classe pela definição de seus atributos, operações e relacionamentos de herança. Nessa atividade, os atributos são adicionados representando as propriedades da classe. As operaçōes também são adicionadas e definem os aspectos funcionais da classe, isto é, o comportamento local da classe, excluindo a interação do comportamento que é capturada pela composição. Finalmente, deve ocorrer a 
introdução de herança, que representa as situações nas quais classes distintas são combinadas para formar uma nova classe virtual. A herança pode ser considerada como uma generalização de classes existentes em novas superclasses ou como uma especialização de classes existentes em novas subclasses.

A estrutura de composição consiste na especificação de uma biblioteca reusável de definiçōes de composições. A construção desta estrutura envolve duas atividades: a identificação de composições e o refinamento das composiçōes identificadas.

A primeira atividade identifica as composições dentro do domínio da aplicação. Composiçōes são constituídas por um relacionamento, pelas classes participantes deste relacionamento e suas cardinalidades, e por uma classe de ligação especificando a semântica de navegação do relacionamento.

A segunda atividade envolve o refinamento das composições identificadas através da definição explícita dos domínios e das cardinalidades dos participantes, pela definição das restrições de integridade e pela definição da semântica da ligação associada à composição. A definição da semântica das ligaçōes resulta em uma hierarquia de classes de ligações definidas com base em critérios como: direção, propriedades estáticas e dinâmicas, densidade da população dos conjuntos conectados, comportamento etc.

A estrutura GUI é formada por uma biblioteca reusável de definições de apresentação. As atividades relacionadas a essa estrutura são: a identificação das janelas e das apresentações, e o mapeamento de classes e composições para apresentações.

Uma apresentação consiste de um ou mais widgets (botões, strings etc.) no qual um objeto pode apresentar seu conteúdo. A definição de uma apresentação envolve ainda a especificação de eventos e de funções que podem ser associadas a estes eventos. Uma janela mostra uma apresentação na tela. As janelas também podem conter menus que são utilizados para atribuir comportamento à janela, fazendo-a aparecer e atuar como um programa de aplicação independente.

A atividade de mapeamento considera como os atributos e as operações de classes são mapeados para a apresentação, como os eventos são conectados às operações e como a funcionalidade é atribuída aos menus. 


\subsection{HMBS/M - Hypertext Model Based on Statecharts / Method}

O Hypertext Model Based on Statecharts / Method (HMBS/M) (Carvalho, 1998) é um método para apoiar o projeto e o desenvolvimento estruturado de aplicações hipermídia. O HMBS/M é composto por quatro fases, sendo que o produto de cada fase é incrementado ou melhorado na fase posterior. As melhorias introduzidas no(s) modelo(s) de uma das fases devem ser especificadas no(s) modelo(s) da(s) fase(s) anterior(es), permitindo assim um desenvolvimento interativo. A Figura 3.9 apresenta as fases do método: Modelagem Conceitual, Modelagem Navegacional, Modelagem da Interface, Implementação e Teste.

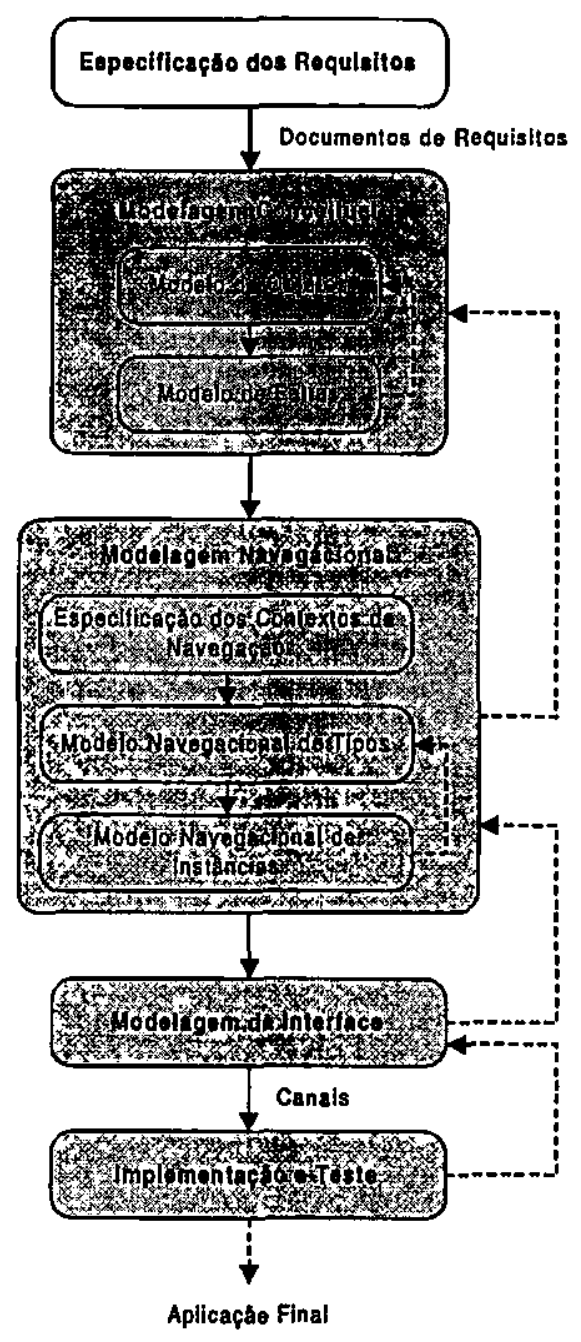

Figura 3.9: Fases do método HMBS/M

A Modelagem Conceitual tem como objetivo analisar o domínio e representar a sua semântica em modelos que ajudem a identificar as informações relevantes da aplicação hipermídia. $O$ modelo conceitual é composto de dois modelos: o modelo de objetos e o modelo de fatias. 
O modelo de objetos utilizado adota os princípios do método de desenvolvimento de software orientado a objetos Fusion (Coleman et al., 1994). As classes são utilizadas para representar os objetos do domínio, os atributos representam as propriedades intrínsecas ou conceituais dos objetos, e os relacionamentos associativos representam as ligações entre eles. Somente o conceito original "atributo" do Fusion foi estendido para fornecer suporte a atributos multitipados, ou seja, um mesmo atributo pode ter vários tipos de dados associados (número, texto, imagem, vídeo, por exemplo), que especificam as diferentes formas de apresentação. Cada aparência de um atributo é denominada "perspectiva do atributo" (conceito derivado do HDM e do OOHDM).

A Figura 3.10 mostra uma versão simplificada do modelo de objetos para o Parque Ecológico de São Carlos, que possui as classes "Parque_Ecológico" e "Animal", e o relacionamento "abriga / é_abrigado".

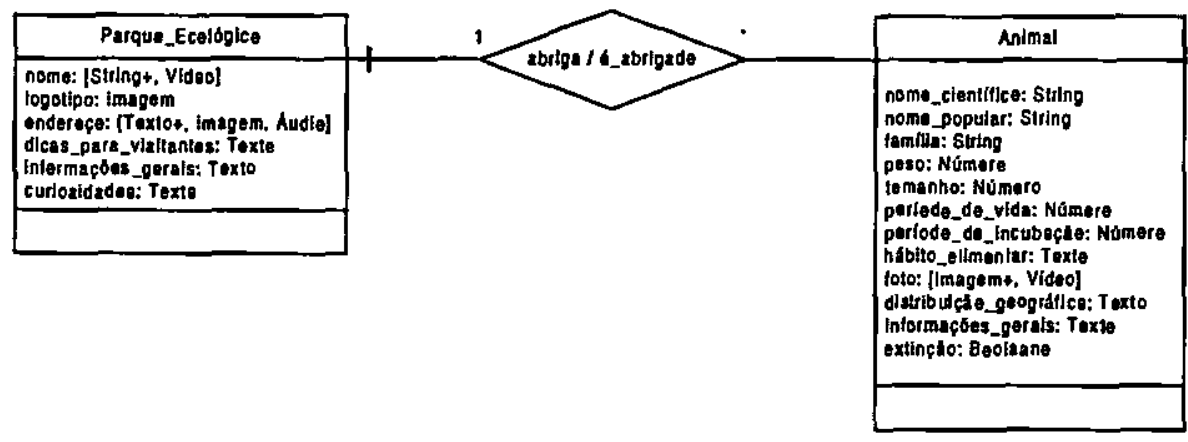

Figura 3.10: Exemplo simplificado de modelo de objetos (Turine, 1998)

O atributo "endereço" da classe "Parque_Ecológico" é representado por "endereço: [Texto+, Imagem, Áudio]", indicando que a informação associada ao atributo pode ser apresentada de três formas: a perspectiva "Texto" contém uma descrição textual da localização do parque; a perspectiva "Imagem" contém um mapa de sua localização; e a perspectiva "Áudio" contém uma versão sonora da descrição textual. O sinal " + " indica que a perspectiva "Texto" é a default, ou seja, é a perspectiva sob a qual o atributo será inicialmente mostrado.

O modelo de fatias determina como a informação numa classe escolhida é agrupada para ser apresentada ao usuário. Uma fatia (conceito introduzido pelo RMM) agrupa um ou mais atributos de uma dada classe. Há dois tipos fundamentais de fatias: fatia Principal e fatia de Ligações. A fatia Principal é aquela a ser inicialmente apresentada quando uma determinada classe for acessada. A fatia de Ligaçōes agrupa os relacionamentos de cada classe. Outras fatias podem ser criadas conforme os atributos que cada classe possui.

Por exemplo, os atributos da classe "Animal" podem ser agrupados em três fatias: a fatia Principal "Descrição" contendo os atributos que descrevem o animal textualmente; a fatia 
"Foto_Imagem" com os atributos que identificam o animal através de imagem; e a fatia "Foto_Vídeo" com os atributos que identificam o animal através de um vídeo.

A Modelagem Navegacional tem como objetivo reorganizar os modelos da fase anterior, considerando o perfil do usuário e as tarefas que o autor pretende apoiar. Durante esta fase são especificados os contextos de navegação e são criados o modelo navegacional de tipos e o modelo navegacional de instâncias.

Os contextos de navegação (conceito introduzido pelo OOHDM) permitem reunir informações do domínio de aplicação que estão relacionadas segundo alguns critérios, por exemplo, todos os animais da família "Réptil". As estruturas de acesso são utilizadas para especificar os contextos de navegação no modelo navegacional de tipos.

O modelo navegacional de tipos é uma visão orientada à navegação do modelo de fatias e inclui a especificação dos contextos de navegação e das estruturas de acesso. Os relacionamentos do modelo de fatias são substituídos por uma ou mais estruturas de acesso, que especificam os diferentes caminhos de navegação disponíveis para acessar as informações do hiperdocumento. As estruturas de acesso utilizadas são: ligação, índice, roteiro guiado, roteiro guiado indexado e agrupamento.

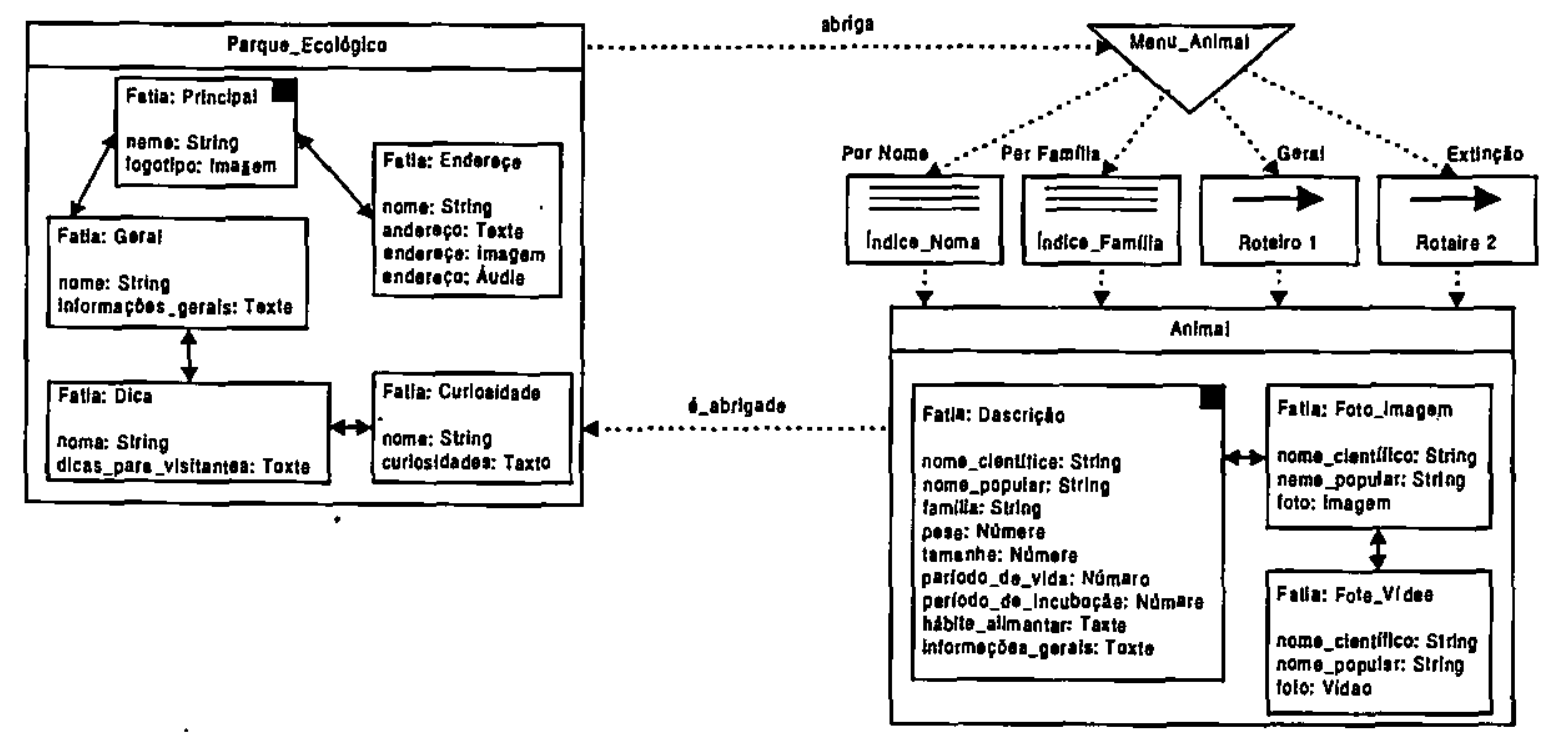

Figura 3.11: Exemplo simplificado de modelo navegacional de tipos (Turine, 1998)

A Figura 3.11 apresenta uma versão simplificada do modelo navegacional de tipos para o Parque Ecológico de São Carlos. Neste exemplo, existem quatro contextos para obter informações sobre os animais: duas estruturas indice que apresentam os animais em ordem alfabética de nome ("Índice_Nome") e de família ("Índice_Família"), e dois roteiros guiados, o "Roteiro l" especifica um caminho linear por todos os animais em uma ordem arbitrária e o "Roteiro 2" especifica um caminho por todos os animais em extinção. 
O modelo navegacional de tipos retrata a estrutura navegacional estática do hiperdocumento. Os padrões dinâmicos e comportamentais são especificados no modelo navegacional de instâncias, que adota o Hyperdocument Model Based on Statecharts (HMBS) (Turine, 1998) para especificar precisamente o comportamento navegacional do hiperdocumento. O HMBS utiliza a estrutura e a semântica operacional de Statecharts (Harel, 1987) para especificar a estrutura organizacional e a semântica de navegação de hiperdocumentos. As instâncias das classes e dos relacionamentos do modelo navegacional de tipos são modeladas em termos de estados e transições.

Na Modelagem da Interface são especificados os objetos navegacionais (páginas, âncora, ligação) e os objetos de apresentação (canais) que definem a aparência dos mesmos. Durante a Implementação e Teste os modelos navegacional e de interface são mapeados em objetos concretos de um determinado ambiente, cujo resultado é a aplicação final.

\subsection{Considerações Finais}

Neste capítulo foram apresentados os principais métodos para projeto de aplicações hipermídia da literatura. Essa revisão constitui um embasamento teórico importante para a definição de um método específico para o ensino. No Capítulo 6, a Seção 6.6 apresenta uma comparação desses métodos com o método proposto neste trabalho segundo vários critérios.

O próximo capítulo descreve o Sistema de Autoria e Suporte Hipermídia para Ensino (SASHE). As dificuldades encontradas pelo autor durante a construção de hiperdocumentos nesse sistema constituem a principal motivação para este trabalho. 


\section{Capítulo 4}

\section{SASHE - Sistema de Autoria e Suporte Hipermídia para Ensino}

\subsection{Considerações Iniciais}

O Sistema de Autoria e Suporte Hipermídia para Ensino (SASHE) (Nunes et al., 1997; Santos, 1997; Santos et al., 1997) é um ambiente de autoria e navegação de hiperdocumentos para aplicações no ensino desenvolvido no Instituto de Ciências Matemáticas e de Computação (ICMC). O Modelo de Contextos Aninhados (MCA), o modelo de dados utilizado na implementação do SASHE, é apresentado na Seção 4.2.

O protótipo do SASHE, acrescido de novas funcionalidades, foi denominado de SASHE Versão 2.0. A Seção 4.3 apresenta a nova arquitetura desse protótipo. As Seções 4.4 e 4.5 descrevem os recursos de autoria disponíveis na versão anterior e mantidos na atual, com o objetivo de destacar as dificuldades encontradas pelo autor durante a construção de um hiperdocumento. Os recursos de navegação não são comentados, mas podem ser encontrados com detalhes em Nunes et al. (1997) e Santos (1997).

\subsection{MCA - Modelo de Contextos Aninhados}

O Modelo de Contextos Aninhados (MCA) (Casanova et al., 1991; Soares et al., 1994, 1995b) é um modelo conceitual para a definição, apresentação e navegação de hiperdocumentos. As próximas subseções apresentam as estruturas de dados do MCA básico e o modelo de apresentação de uma forma intuitiva. Uma formalização maior do modelo e detalhes sobre o controle de versões pode ser encontrada em Casanova et al. (1991) e Soares et al. (1994, 1995b). 


\subsubsection{Definições do Modelo Básico}

A definição de hiperdocumentos no MCA é baseada nos conceitos usuais de nós e elos. O modelo distingue duas classes básicas de nós, chamados de nós terminais e nós de composição, sendo estes últimos o ponto central do modelo. A Figura 4.1 ilustra a hierarquia de classes do MCA.

Uma entidade é um objeto que tem como atributos um identificador único, uma lista de controle de acesso e um descritor de entidade. $O$ identificador único tem o significado usual. Para cada atributo da entidade, a lista de controle de acesso tem uma entrada que associa um usuário ou um grupo de usuários aos seus direitos de acesso ao atributo. $O$ descritor de entidade contém informação que determina como a entidade deve ser apresentada ao usuário.

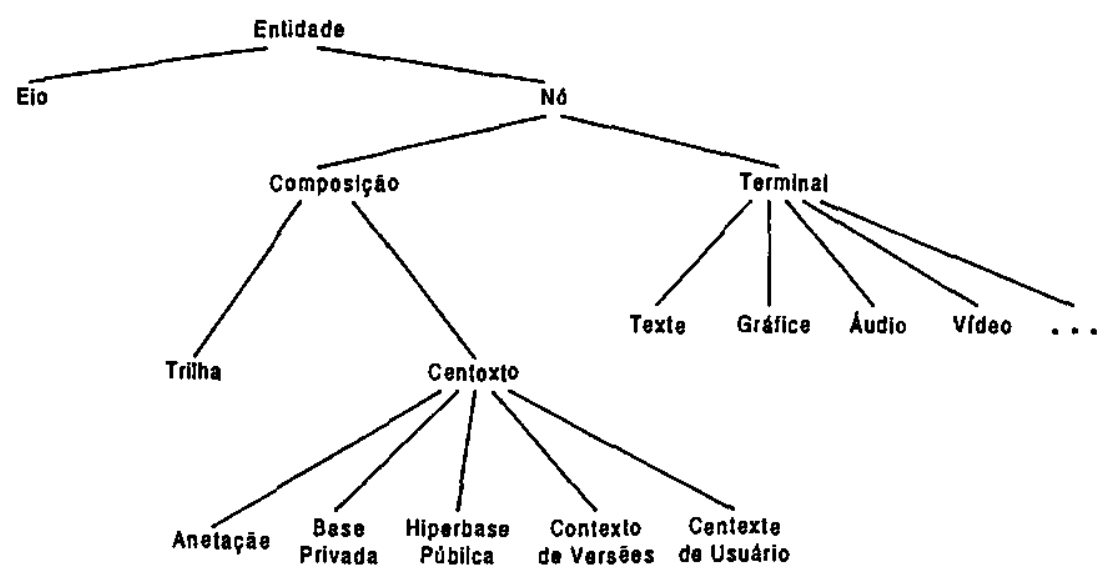

Figura 4.1 - Hierarquia de classes do MCA (Soares et al., 1994)

Um nó é uma entidade que tem como atributos adicionais um conteúdo e um conjunto de âncoras. Cada elemento do conjunto de âncoras é chamado de âncora do nó e é um objeto que tem como atributos um identificador, uma região e um conjunto de pares condição/ação. A exata definição do conteúdo do nó e da região da âncora depende da classe do nó.

Um nó terminal é um nó cujo conteúdo e conjunto de âncoras é dependente da aplicação. $\mathrm{O}$ modelo permite a especialização da classe de nós terminais em outras classes (texto, gráfico, ádio, vídeo etc.). Intuitivamente, uma região da âncora define um segmento dentro do conteúdo do nó terminal.

Um nó de composição agrupa entidades, chamadas de componentes, incluindo outros nós de composição. Os componentes não formam necessariamente um conjunto, podendo uma entidade ser incluída mais de uma vez em um nó de composição. A classe de nós de composição pode ser especializada em duas outras classes: nós de contexto e trilhas. 
Um nó de contexto é utilizado para agrupar um conjunto que pode ser formado por elos, trilhas, nós terminais e de contexto, recursivamente. A classe de nós de contexto pode ser especializada em outras classes: nós de anotação, contexto de versões, base privada, hiperbase pública e contexto de usuário.

Um nó de contexto de usuário é utilizado para agrupar um conjunto de elos, nós terminais e de contexto de usuário. Como todo nó de composição, os nós de contexto de usuário podem ser aninhados em qualquer profundidade, permitindo organizar, de maneira hierárquica ou não, conjuntos de nós.

Um elo é uma entidade com dois atributos especiais, o conjunto de extremidades origem e o conjunto de extremidades destino. A definição permite relacionamentos "muitos-para-muitos", que são necessários para suportar aplicações onde, por exemplo, a seleção de um elo pode levar à apresentação simultânea de vários nós. Os elos são sempre unidirecionais, embora possam ser seguidos em ambas as direções.

Os nós do tipo trilha são especializações de nós de composição que contém uma lista ordenada de nós, incluindo nós do tipo trilha, sendo que um nó pode estar na lista em mais de uma posição. Os nós do tipo trilha são utilizados para dar suporte à navegação.

Uma hiperbase é qualquer conjunto $H$ de nós tal que, para qualquer nó $N$ pertencente a $H$, se $N$ é um nó de composição, então todos os nós contidos em $\mathrm{N}$ também pertencem a $H$.

\subsubsection{Modelo de Apresentação}

O MCA básico trata hiperdocumentos como estruturas de dados essencialmente passivas. $O$ modelo de apresentação do MCA trata os aspectos de edição, apresentação e navegação através da estrutura dos hiperdocumentos.

Em geral, os descritores mencionados anteriormente definem métodos para exibir ou editar entidades. $\mathrm{O}$ modelo de apresentação do MCA fornece métodos específicos somente para editar atributos do sistema, e para navegar e editar o conteúdo de nós de contexto.

$\mathrm{O}$ modelo de apresentação do MCA oferece mecanismos genéricos de navegação. $\mathrm{O}$ sistema HyperProp (Soares et al., 1995a), uma implementação de sistema hipermídia que utiliza o MCA como modelo conceitual, suporta esses mecanismos, além de possuir primitivas de apresentação para definir formas específicas de navegação.

Os mecanismos de navegação oferecidos pelo modelo são: navegação por elos, idéia essencial de hipermídia; navegação por consulta, que permite ao usuário atingir um nó específico 
descrevendo propriedades que o nó satisfaz; navegação em profundidade, que é a ação de seguir o aninhamento de nós de composição, movendo-se para cima e para baixo na hierarquia de composição; a navegação através de browsers, que utiliza uma visão gráfica do hiperdocumento (ou de partes dele); e navegação através de trilhas, que permite ao usuário seguir trilhas preestabelecidas ou definidas como default no hiperdocumento.

\subsection{Arquitetura do SASHE}

A Figura 4.2 apresenta a arquitetura do SASHE Versão $2.0 \mathrm{com}$ os novos módulos desenvolvidos para auxiliar a autoria: Modelagem e Importação. Esses dois módulos, mais o módulo de Edição, que engloba os recursos de autoria existentes na versão anterior, compõem a camada de Autoria. O módulo de Modelagem é apresentado neste trabalho, no Capítulo 6. O módulo de Importação, que importa e adapta documentos HTML para a representação interna do SASHE, é apresentado em Haber (1999).

A camada de Autoria e Navegação utiliza as funções da camada Hip/Windows*, que é uma extensão do ambiente HIP/Windows (Nunes et al., 1996). As setas da figura indicam que os módulos (Modelagem, Importação e Edição) utilizam diretamente as funções da camada Hip/Windows*, não existindo nenhum módulo (ou interface) intermediário. Essa camada é composta por funções que manipulam a Hiperbase (MCA), que consiste do hiperdocumento armazenado segundo o Modelo de Contextos Aninhados.

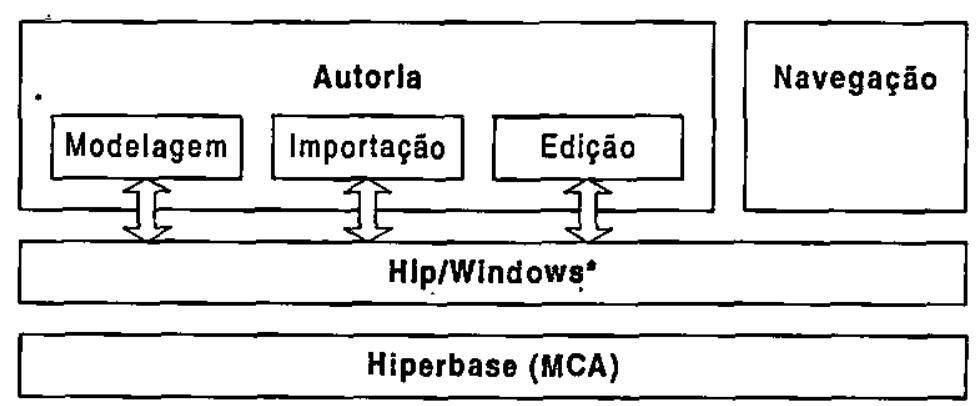

Figura 4.2: Arquitetura do SASHE Versão 2.0 


\subsection{Autoria da Estrutura do Hiperdocumento}

O módulo de Edição permite a construção de hiperdocumentos estruturados de acordo com o MCA, utilizando os conceitos de nó terminal (texto, gráfico, áudio e vídeo), nó composição (trilha, contexto de usuário e hiperbase pública) e elo.

A interface de edição utiliza o termo "Informação" para referir-se a um nó terminal devido à sua associação com um conteúdo (fragmento de informação) armazenado segundo uma mídia de representação. As informações (nós terminais) são classificadas quanto à sua função didática (introdução, exercício, motivação, definição, bibliografia, exemplo, resumo e ajuda), dificuldade (baixa, regular e alta) e palavras-chave relacionadas ao conteúdo. Essa classificação é utilizada pelas estratégias tutoriais durante a navegação.

Os nós de contexto de usuário são utilizados para estruturar o hiperdocumento (hiperbase pública), sendo denominados apenas de "Contexto" pela interface de edição. Um contexto representa um espaço de informação e pode conter outros contextos (aninhados). Essa característica permite a construção de hiperdocumentos hierárquicos, partindo de contextos (espaços) com informações mais gerais para contextos com informações mais específicas.

A Figura 4.3 mostra um pequeno exemplo de hiperdocumento no domínio da Química, através do browser estrutural, um recurso para visualizar a estrutura de um hiperdocumento ou parte dela. Pode-se observar a estrutura hierárquica através dos contextos "Matéria", "Estados físicos da matéria", "Sólido", "Líquido" e "Gasoso".

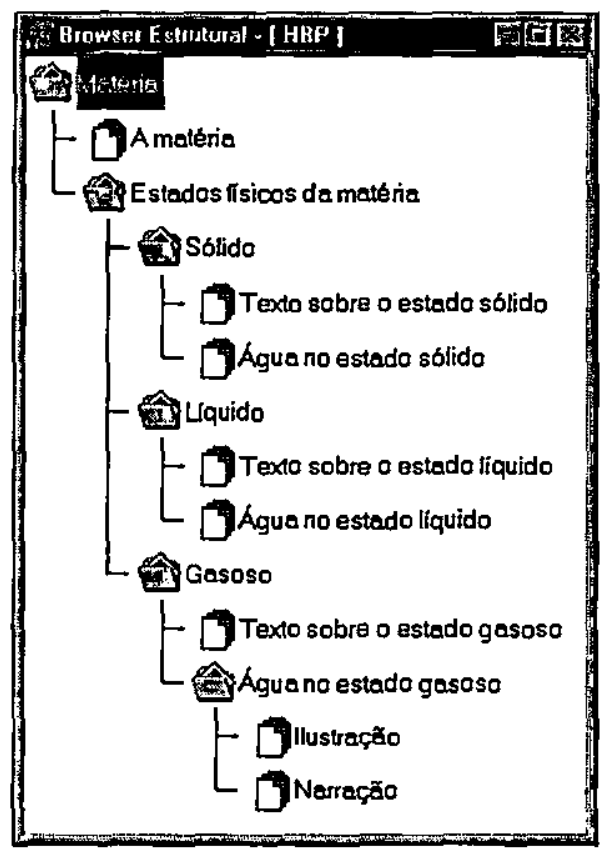

Figura 4.3: Exemplo de hiperdocumento 
É importante ressaltar que a estrutura hierárquica para um hiperdocumento pode ser difícil de ser conseguida dependendo do domínio de conhecimento. Muitas vezes, a obtenção dessa estrutura depende da habilidade e da experiência do autor. Nesse sentido, autores iniciantes podem encontrar dificuldades para realizar essa tarefa. Um modelo de representação do domínio de conhecimento pode auxiliar o autor a organizar a hierarquia de contextos do hiperdocumento.

As informações (nós terminais) são inseridas em contextos, indicando que pertencem ao espaço de informações correspondente ao contexto. A Figura 4.4 mostra a interface para inserir uma informação. Pode-se notar que cabe ao autor preencher todos os campos relacionados com a classificação da informação. Uma representação em alto nível das informações que serão inseridas no hiperdocumento pode auxiliar o autor nessa tarefa.

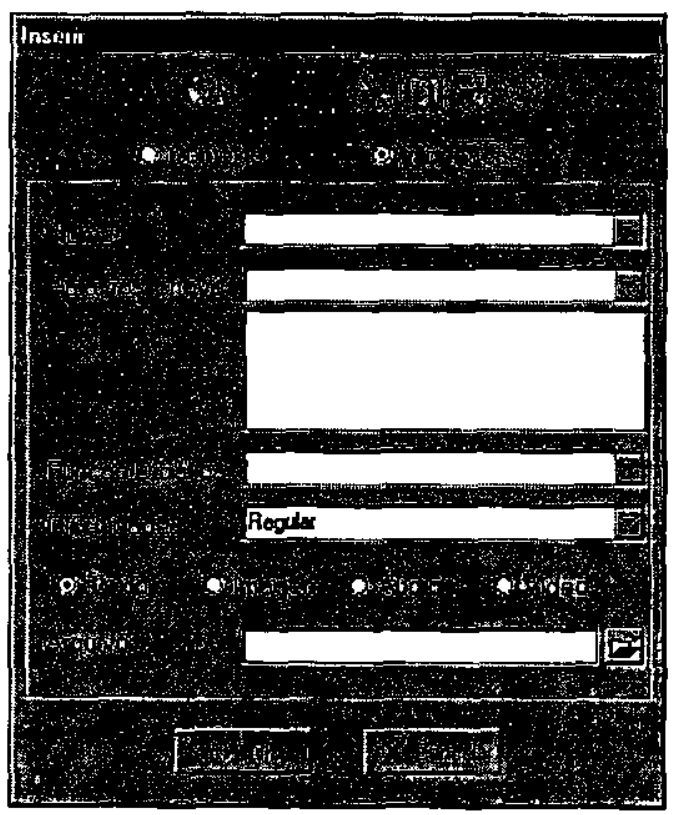

Figura 4.4: Interface para inserir uma informação

Os elos são utilizados para conectar informações que mantêm alguma relação entre si. Um elo pode conectar uma informação a outra informação ou a um contexto. A Figura 4.5 ilustra a interface utilizada para inserir elos. Neste caso, o elo inserido conecta uma informação a um contexto. A caixa "Apresentar todas as informações do destino" selecionada indica que todas as informações contidas no contexto "Água no estado gasoso" serão apresentadas quando o elo for acionado.

A outra caixa ("Apresentar origem e destino simultaneamente") selecionada indica que a apresentação da informação "Texto sobre o estado gasoso" será mantida depois que o elo for acionado, ou seja, a sua janela não será fechada quando o contexto "Água no estado gasoso" for apresentado. Esse recurso contribui para a preservação do contexto interpretativo, 
proporcionando um sentido de continuidade de exposição que é muito importante para a compreensão (Seção 2.4).

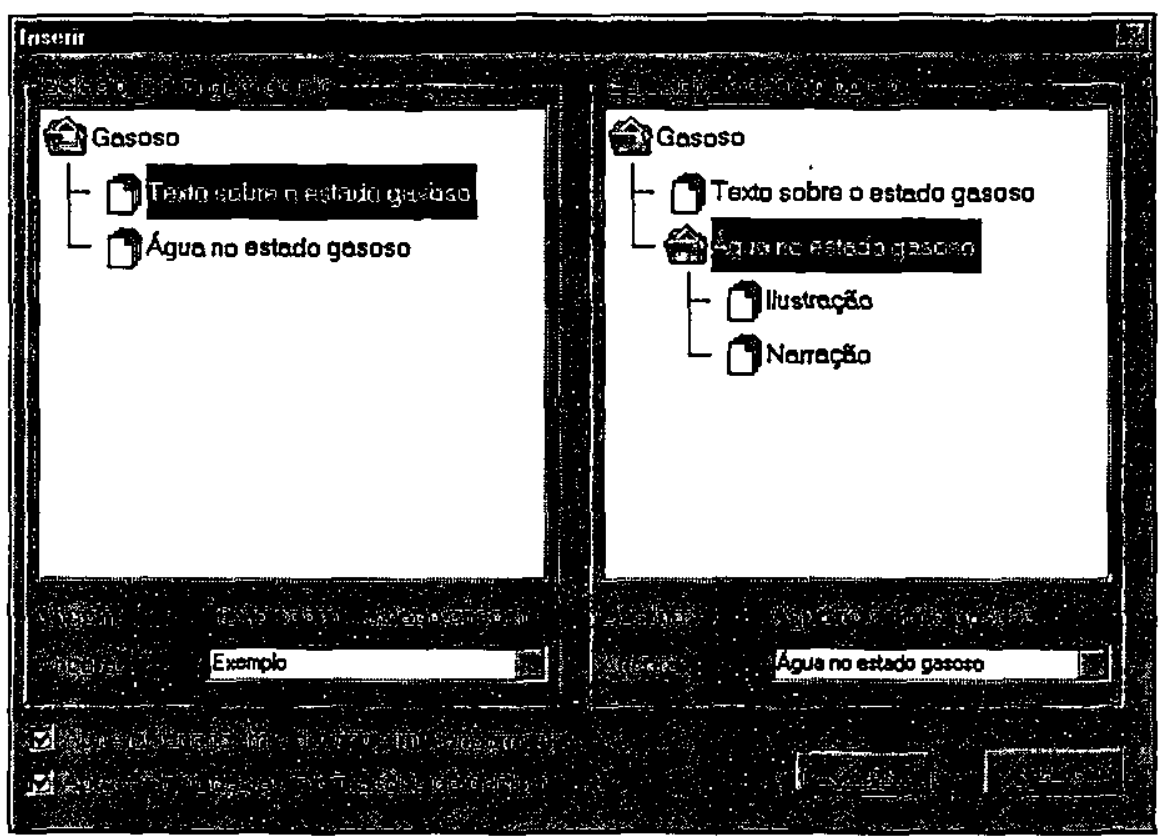

Figura 4.5: Interface para inserir elos

Esse exemplo ilustra algumas das dificuldades encontradas pelo autor durante a definição de elos utilizando os recursos do módulo de Edição. O autor deve tomar decisões sobre a apresentação que podem ser consideradas de "baixo nível", isto é, decisões tomadas em nível de sistema. A utilização de abstrações de alto nível adequadas em um modelo de representação para o hiperdocumento pode evitar decisões desse tipo.

O exemplo da Figura 4.5 também ilustra uma outra utilização de contextos. Além de organizar hierarquicamente o hiperdocumento, um contexto também pode ser utilizado para apresentar duas ou mais informações ao mesmo tempo. Nesse exemplo, a apresentação do contexto "Água no estado sólido" consiste na apresentação da imagem da informação "Ilustração" simultaneamente ao áudio da informação "Narraçăo". Esse comportamento é obtido selecionando a caixa "Apresentar todas as informações do destino".

A possibilidade de utilizar contextos para obter dois resultados diferentes adiciona dificuldades à tarefa de autoria porque o autor deve decidir quando utilizar uma ou outra forma para obter o efeito desejado. Novamente, a utilização de abstrações de alto nível adequadas para representar (ou esconder) as diferentes utilizações de contextos pode auxiliar o autor nessa tarefa. 


\subsection{Autoria de Roteiros}

Depois da autoria da estrutura, o autor pode definir um ou mais roteiros de navegação através do hiperdocumento. Um roteiro (nó composição do thipo trilha do MCA) é definido pela sequiência de informações e contextos que serão apresentados durante a navegação. Para cada elemento da sequiência do roteiro, o autor deve definir o grau de liberdade associado através da seleção de um dos contextos que contém o elemento (informação ou contexto). O grau de liberdade determina o maior contexto em que o aprendiz pode navegar a partir do elemento do roteiro. Essa característica distingue as aplicações criadas no SASHE daquelas criadas em outros sistemas. O objetivo desse comportamento é estabelecer um equilibrio entre o controle do aprendiz e do sistema, de modo a oferecer um certo grau de orientação para que o aprendiz possa atingir seu objetivo sem perder a flexibilidade da leitura (Nunes \& Fortes, 1997).

A Figura 4.6 mostra a interface para a definição de roteiros. $O$ autor define a seqüência do roteiro selecionando a informação ou contexto do hiperdocumento, auxiliado por funções de busca segundo a classificação das informações (botão "Selecionar").

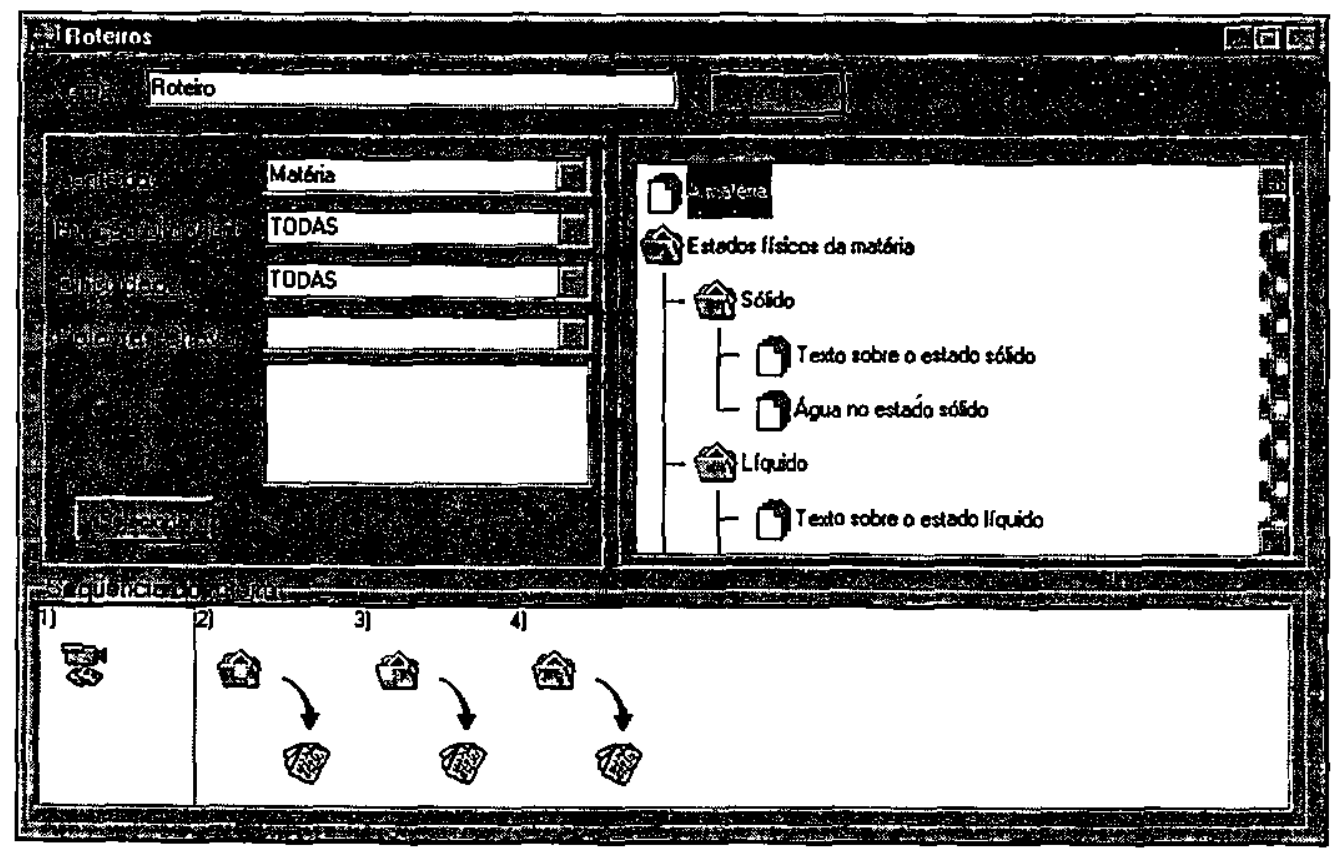

Figura 4.6: Interface para a definição de roteiros

Apesar do auxílio proporcionado pelas funções de busca, o autor não encontra uma base efetiva para definir a sequência do roteiro, bem como o grau de liberdade associado a cada elemento. Um modelo em alto nível do hiperdocumento com informações relativas às estratégias definidas para o domínio de conhecimento alvo pode ser utilizado para fornecer orientaçðes para o autor durante a autoria de roteiros. 


\subsection{Considerações Finais}

As dificuldades encontradas pelo autor para utilizar os conceitos do Modelo de Contextos Aninhados (MCA) durante a autoria constituem a principal motivação para incluir uma ferramenta de modelagem de hiperdocumentos para ensino no processo de autoria do SASHE.

Com o objetivo de fornecer um suporte para o desenvolvimento dessa ferramenta, foi definido um método que propõe uma série de etapas de projeto, além de oferecer modelos de representação adequados para modelar o domínio de conhecimento e os aspectos navegacionais de hiperdocumentos para ensino.

No próximo capítulo são apresentados o Modelo de Michener e os Mapas Conceituais, que constituem a base teórica para a fase de modelagem do domínio de conhecimento do método proposto neste trabalho. 


\section{Capítulo 5}

\section{Base Teórica para Modelagem do Domínio de Conhecimento}

\subsection{Considerações Iniciais}

Este capítulo apresenta a base teórica utilizada na definição de um modelo conceitual para descrever o domínio de conhecimento de uma aplicação hipermídia para ensino. $O$ modelo proposto por Michener (1978) para representar o conhecimento matemático, denominado neste trabalho de Modelo de Michener, e a teoria utilizada pela técnica de Mapas Conceituais (Moreira \& Buchweitz, 1987; Faria, 1995) constituem essa base teórica.

O modelo para a representação do domínio de conhecimento do Arqtema (Takehara, 1994), uma arquitetura genérica para sistemas tutores inteligentes em Matemática, é baseado na proposta de Michener. Essa arquitetura é utilizada pelo Protema (Nunes \& Hasegawa, 1997), um ambiente para desenvolver sistemas tutores inteligentes em Matemática.

Algumas propostas de metodologias para apoiar o desenvolvimento de aplicações hipermídia para ensino, por exemplo, MAPHE (Pimentel, 1997) e Daphne (Kawasaki \& Fernandes, 1996), utilizam a teoria de Mapas Conceituais como base para a modelagem do domínio. de conhecimento durante o processo de desenvolvimento dessas aplicações. Essas propostas são apresentadas como trabalhos relacionados na Seção 6.7.

O Modelo de Michener é apresentado na Seção 5.2 è a técnica de Mapas Conceituais, com ênfase na sua utilização como instrumento de ensino, na Seção 5.3.

\subsection{O Modelo de Michener}

Examinando como os matemáticos utilizam e explicam seu conhecimento, Michener (1978) concluiu que existem, no mínimo, três categorias de informações necessárias para representar o conhecimento matemático. A Figura 5.1 ilustra essas categorias. 


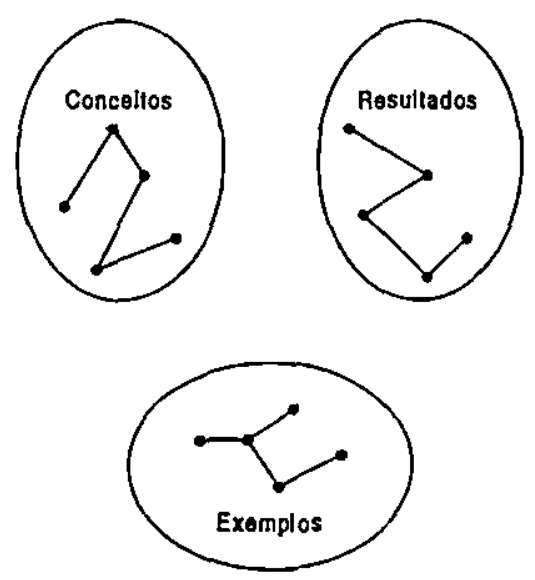

Figura 5.1: As três categorias do Modelo de Michener (Takehara, 1994)

Uma delas é a categoria de Conceitos, da qual fazem parte as definições e os princípios matemáticos. Outra categoria existente é a de Resultados que contém os aspectos lógicos tradicionais da Matemática, isto é, os teoremas e suas provas. Finalmente, a categoria de Exemplos, contendo o material ilustrativo.

Além da classificação em categorias, Michener estabeleceu classes epistemológicas, baseada no fato de que os itens da teoria desempenham funções distintas e que, portanto, existe uma divisão taxonômica para esses itens com relação a seu papel na nossa compreensão e às atribuições especiais que desempenham de forma única.

\subsubsection{Categoria de Conceitos}

Os conceitos, uma vez agrupados, podem ser estruturados por uma relação de ordem pedagógica, onde se, estabelece que um conceito A deve ser introduzido ou apresentado, ensinado, antes que um conceito B. Algumas vezes esta relação reflete o fato de que o conceito A faz parte da definição do conceito B; outras vezes, reflete preferências na ordem de exposição dos conceitos (opção didática). Em Álgebra Linear, por exemplo, alguns autores definem um auto-valor $\lambda$ de uma matriz $A$ em termos da equação $A v=\lambda v$, enquanto outros o definem como raiz da equação característica $\operatorname{det}(\mathrm{A}-\lambda \mathrm{D})=0$. Logo, duas abordagens diferentes, respectivamente, geométrica e algébrica. Para a primeira definição, o conceito de auto-valor é mais intuitivo, sendo necessário um pré-conhecimento sobre áuto-vetores. Já na segunda abordagem, não necessariamente é preciso sab̉er o que é um auto-vetor, mas é preciso conhecimento sobre determinantes e polinômios. 
A categoria de conceitos possui três classes epistemológicas: Definições, Mega-Princípios e Contra-Princípios. A classe de Definições, como o nome indica, fornece as definições contidas na teoria tratada.

Os Mega-Princípios fornecem núcleos de conhecimento na forma de fortes sugestões ou heurísticas. Por exemplo, "matrizes simétricas são boas" é um Mega-Princípio da Álgebra Linear. Este mega-princípio é, de certa forma, um resumo de muitos resultados que mostram que matrizes simétricas são diagonalizáveis e bem-condicionadas.

Contra-Princípios são avisos que indicam possíveis fontes de erros ou problemas. Por exemplo, "não dividir por zero" é um contra-princípio bem familiar. A Figura 5.2 ilustra a categoria de conceitos.

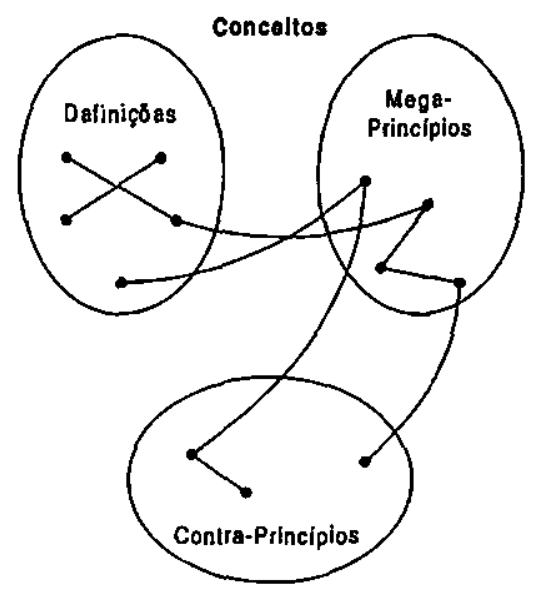

Figura 5.2: A categoria de conceitos (Takehara, 1994)

\subsubsection{Categoria de Resultados}

Os resultados podém ser estruturados pela relação de dedução lógica, pela qual um resultado A precedendo um resultado B significa que o resultado A é utilizado para provar o resultado B. A categoria de resultados possui duas classes epistemológicas, denominadas Resultados Básicos e Resultados Culminantes.

Resultados Básicos estabelecem propriedades elementares, mas importantes, de conceitos, enquanto que Resultados Culminantes são aqueles para os quais a teoria se direciona, ou seja, são os pontos principais da teoria. Um resultado básico da Álgebra Linear seria, por exemplo, $\lambda$ é um auto-valor da matriz $A$ se, e somente se, $\operatorname{det}(A-\lambda I)=0$. Um resultado culminante no estudo de polinômios seria, por exemplo, o Teorema Fundamental da Álgebra. 
A Figura 5.3 ilustra a estrutura da categoria de resultados tendo a dedução lógica como relação entre seus itens.

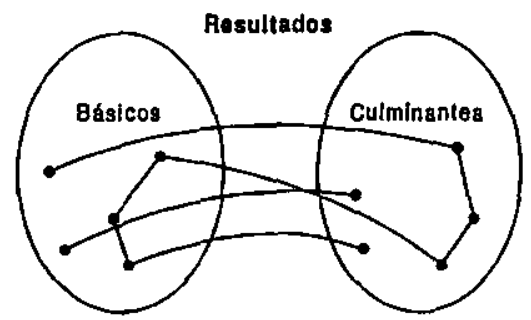

Figura 5.3: A categoria de resuitados (Takehara, 1994)

\subsubsection{Categoria de Exemplos}

Os exemplos podem ser organizados pela relação de derivação fabricacional, pela qual um exemplo A precedendo um exemplo B significa que o exemplo A é utilizado para construir o exemplo B. Por exemplo, a partir dos números naturais, pode-se gerar os inteiros (pela inclusão de números negativos), dos quais pode-se gerar os racionais (pela formação dos quocientes), dos quais pode-se construir os números reais (completando a sequiência de Cauchy).

A categoria de exemplos possui quatro classes epistemológicas, denominadas de Exemplos Iniciais, Exemplos de Referência, Exemplos Modelos e Contra-Exemplos. A Figura 5.4 ilustra a estrutura da categoria exemplos, onde seus itens são relacionados via derivação fabricacional.

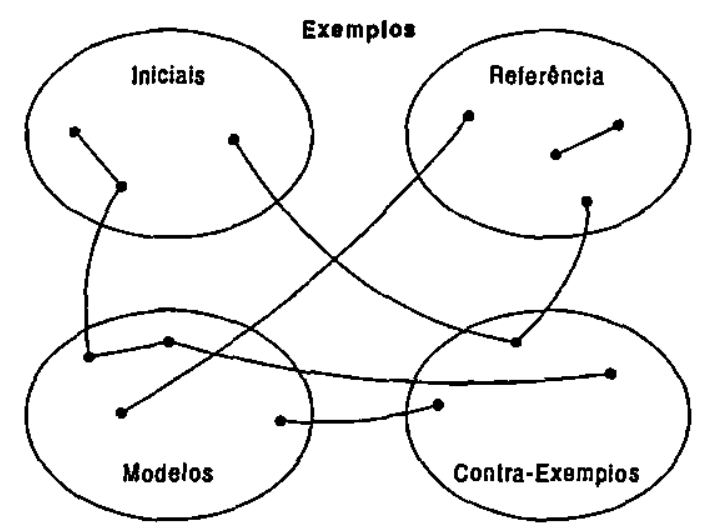

Figura 5.4: A categoria de exemplos (Takehara, 1994)

Exemplos Iniciais são aqueles que auxiliam a introduzir um novo assunto, motivando suas definições e resultados básicos. Um exemplo inicial no estudo de curvatura de curvas planas seria o seguinte: mostrar um segmento de reta, um círculo e outro círculo menor.

Exemplos Modelos são situações-padrão que sugerem a essência de um resultado ou conceito. Eles indicam situações genéricas que geralmente devem ser adequadas às especificidades do 
problema em questão. Exemplos Modelos para a idéia de inclusão de conjuntos e triângulo retângulo são mostrados na Figura 5.5.
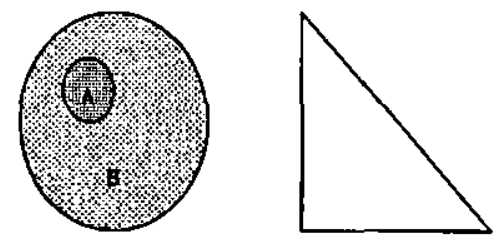

Figura 5.5: Modelos para exemplificar inclusão de conjuntos e triângulo retângulo

Exemplos de Referência fornecem um nó comum através do qual vários resultados e conceitos são ligados. Portanto, são exemplos referidos várias vezes durante o desenvolvimento de uma teoria. Por exemplo, na Teoria dos Números, os inteiros são sempre referenciados para facilitar o entendimento. Contra-Exemplos são muito conhecidos e mostram que uma asserção não é verdadeira. Assim como os Contra-Princípios, os Contra-Exemplos nos advertem sobre os limites das propriedades de uma teoria.

Vistas em detalhes as três categorias que representam uma teoria matemática, pode-se fazer algumas considerações: Exemplos Modelos, Mega-Princípios e Resultados Culminantes representam os itens mais importantes de uma teoria; Contra-Exemplos e Contra-Princípios mostram os limites de uma teoria; Resultados Básicos e Exemplos Iniciais săo pontos de entrada para introduzir uma teoria. Adicionalmente a essas analogias, pode-se considerar relações específicas entre itens de diferentes categorias, apresentadas na próxima subseçăo.

\subsubsection{Relacionamentos entre as Categorias}

No modelo proposto por Michener, a representação de um item também considera os itens fora da categoria a qual ele pertence. A idéia "dual" realça as relações entre os três espaços de representaçōes. Estes são considerados "espaços epistemológicos duais" de cada outro. Assim, cada uma dàs três categorias (conceitos, exemplos e resultados) possui itens duais nas outras duas categorias.

Por exernplo, seja $C$ um item da categoria de conceitos, $R$ um item da categoria de resultados e $\mathrm{E}$ um item da categoria de exemplos:

- Um exemplo (E) possui como itens duais (Figura 5.6): os conceitos $\left(C_{1}\right)$ e resultados $\left(R_{1}\right)$ necessários para sua discussão ou fabricação, e os conceitos $\left(C_{2}\right)$ e resultados $\left(R_{2}\right)$ motivados por ele. 


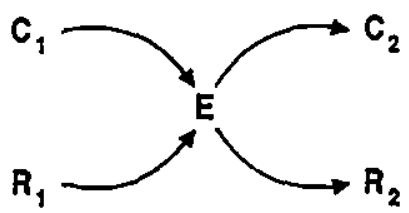

Figura 5.6: Itens duais da categoria exemplo (Takehara, 1994)

- Um resultado (R) possui como itens duais (Figura 5.7): os exemplos ( $\left.E_{l}\right)$ que o motivam e os conceitos $\left(C_{1}\right)$ necessários para ele e para sua prova, e os conceitos $\left(C_{2}\right)$ e exemplos $\left(\mathrm{E}_{2}\right)$ derivados dele.

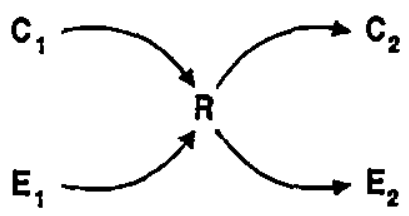

Figura 5.7: Itens duais da categoria resultado (Takehara, 1994)

- Um conceito (C) possui como itens duais (Figura 5.8): os exemplos $\left(\mathrm{E}_{\mathrm{l}}\right)$ que o motivam e os resultados $\left(R_{1}\right)$ que preparam sua base, e os exemplos $\left(E_{2}\right)$ que o ilustram e os resultados $\left(\mathrm{R}_{2}\right)$ que provam coisas sobre ele.

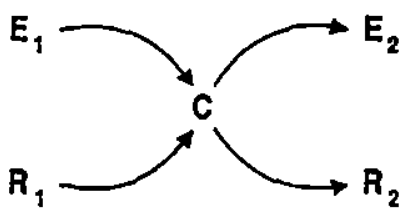

Figura 5.8: Itens duais da categoria conceito (Takehara, 1994)

A Figura 5.9 ilustra, através das relaçōes duais, as ligações entre as três categorias de conhecimento. Cada relação dual pode ser de um tipo (ilustra, prepara, deriva, constrói, motiva, entre outras).

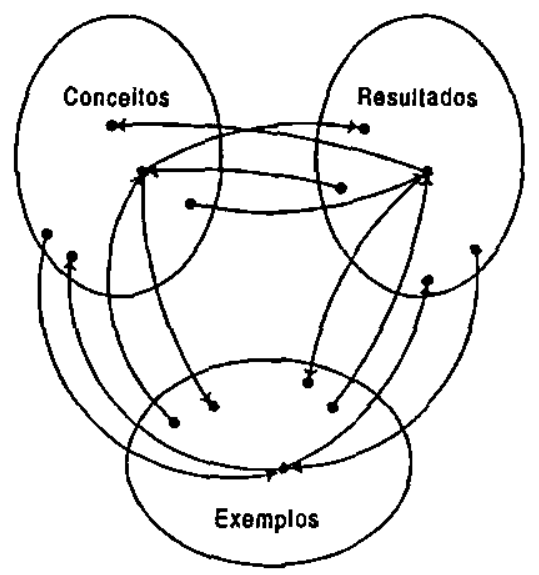

Figura 5.9: Os relacionamentos entre as três categorias (Takehara, 1994) 


\subsection{Mapas Conceituais}

Mapeamento conceitual (Moreira \& Buchweitz, 1987; Faria, 1995) é uma técnica de análise que pode ser utilizada para ilustrar a estrutura conceitual de uma fonte de conhecimento. Essa ilustração é chamada de mapa conceitual. A forma e representação dos mapas conceituais dependem dos conceitos e das relações incluídas, de como os conceitos são representados, relacionados e diferenciados e do critério utilizado para organizar esses conceitos. Portanto, mapas conceituais são diagramas hierárquicos que indicam os conceitos e as relações entre esses conceitos (Moreira \& Buchweitz, 1987).

A teoria da aprendizagem significativa de Ausubel ${ }^{4}$ forneceu os princípios teóricos para elaboração dos mapas conceituais, ou seja, o critério orientador de seleção dos itens que deverão compor os mapas e os princípios de organização dos mesmos (Faria, 1995). As Subseções 5.4.1 e 5.4.2 apresentam esses princípios. A Subseção 5.4.3 descreve a utilização dos mapas conceituais como instrumentos de ensino devido à relevância desta aplicação para este trabalho.

\subsubsection{Seleção dos Itens Relevantes}

A teoria de Ausubel recomenda que os itens relevantes a serem selecionados para compor um mapa conceitual são (Ausubel apud Faria, 1995):

"aqueles conceitos e proposições unificadores de uma dada disciplina que tenham maior poder explicativo, inclusividade, possibilidade de generalização e de relacionamento com o conteúdo do assunto daquela disciplina".

O significado do termo "conceito" é definido por Ausubel como:

“objetos, eventos, situações ou propriedades que possuem atributos criteriais comuns, e que são designados por algum signo ou símbolo, tipicamente uma palavra com significado genérico".

Quanto ao termo "proposição", Ausubel define seu significado como consistindo de:

\footnotetext{
^Uma descrição completa dessa teoria pode ser encontrada na segunda ediçāo do livro Psicologia Educacional (Ausubel et al., 1980).
} 
"uma idéia composta, expressa verbalmente numa sentença, contendo tanto um sentido denotativo quanto um sentido conotativo e as funções sintáticas e relações entre palavras".

Por exemplo, o conceito de quadrado é representado pelo signo "Quadrado" e o seu significado pode ser definido da seguinte forma: "Polígono que possui quatro lados iguais e todos os ângulos retos". Pode-se notar que os critérios para identificar os objetos do tipo "Quadrado" são: "possuir quatro lados iguais" e "todos os ângulos retos".

Uma proposição é formada por dois ou mais conceitos ligados à estrutura de uma sentença. A sua aprendizagem implica o domínio do significado dos conceitos que a compõem. Por exemplo, a proposição "A soma das medidas dos ângulos internos de um triângulo é igual a $180^{\circ}$ ", que é uma propriedade dos ângulos de um triângulo, possui na sua formação os conceitos de "Ângulo interno" e "Triângulo".

Outras formas de configurações estruturadas que as proposiçōes podem assumir são as seguintes:

- Princípios e generalizaçōes, que são abstrações que sintetizam observações particulares de fenômenos (por exemplo, os princípios essenciais do comportamento de elementos da natureza, como o princípio de que "Todo metal dilata-se sob a ação do calor");

- Regras, que são formulaçōes prescritivas que determinam ou indicam como agir ou pensar em determinados contextos (por exemplo, as regras utilizadas para falar e escrever corretamente);

- Critérios, que são semelhantes às regras, mas podem ter um faixa de aplicação mais geral (por exemplo, os critérios pelos quais o valor nutritivo de um alimento pode ser julgado).

\subsubsection{Princípios Organizacionais dos Mapas}

A teoria da aprendizagem significativa de Ausubel forneceu também os princípios básicos para a organizaçāo dos itens selecionados: os princípios da diferenciação progressiva e da reconciliação integrativa.

O princípio da diferenciação progressiva refere-se a uma orientação para organizar o conteúdo, devendo-se proceder hierarquicamente, partindo das idéias (conceito e proposição) mais gerais para as idéias sucessivamente mais específicas.

O princípio da reconciliação integrativa consiste, basicamente, no delineamento explícito das relações entre idéias, ou seja, assinalar e evidenciar as diferenças e semelhanças, reais ou 
aparentes, existentes entre essas idéias. A aplicação desse princípio, aparentemente simples, tem implicações profundas na programação da sequiência do conteúdo e na apresentação do mesmo ao aprendiz. O seu desconhecimento pode gerar problemas de aprendizagem, como os conflitos cognitivos. Algumas das situações que podem provocar esses conflitos são as seguintes (Faria, 1995):

- Quando dois ou mais rótulos conceituais são utilizados para expressar o mesmo conceito;

- Quando o mesmo rótulo conceitual é utilizado para expressar mais de um conceito;

- Conceitos aparentemente semelhantes, cujas diferenças não foram explicitadas, correm o risco de serem percebidos e retidos como se fossem idênticos.

Caso essas reconciliações integrativas não forem destacadas pelo professor, os alunos podem enfrentar dificuldades de aprendizagem. Os mapas conceituais podem constituir instrumentos importantes para o professor na orientação das reconciliações integrativas, porque situam graficamente os conceitos pertencentes a uma determinada fonte de conhecimento em uma rede conceitual, indicando as reconciliações a serem feitas. Assim, a percepção gráfica dessa rede pelo aluno facilitaria a compreensão das explicações do professor.

\subsubsection{Mapas Conceituais como Instrumentos de Ensino}

Os mapas conceituais destinados ao planejamento da apresentação do ensino devem assinalar as reconciliações integrativas, para evitar eventuais conflitos cognitivos dos alunos. Os conceitos e proposições são selecionados através do critério apresentado na Subseção 5.4.1, e organizados de acordo com o princípio da diferenciação progressiva.

Um mapa deverá conter boxes com um rótulo conceitual em cada um, ou, no caso de proposições, somente as palavras-chave que evoquem o princípio ou regra, se forem estes os casos. Os boxes devem ser ligados com linhas cheias ou setas que indiquem a direção da diferenciação progressiva dos conceitos. Pode-se ainda diferenciar os boxes que contenham conceitos, traçados com linhas cheias, dos boxes que contenham proposições, com linhas tracejadas.

$\mathrm{Na}$ apresentação das idéias, o professor poderá iniciar com um conceito mais amplo, mas deverá descer no mapa a exemplos e ilustrações de conceitos situados na base, para depois voltar aos conceitos mais gerais, situados no topo do mapa. 
A Figura 5.10 mostra um exemplo de aplicação de mapeamento conceitual à subunidade "Poesia: nível rítmico", para iniciar os estudos da unidade "Poesia: forma e conteúdo". Os números que aparecem no exemplo indicam um roteiro para atingir a reconciliação integrativa.

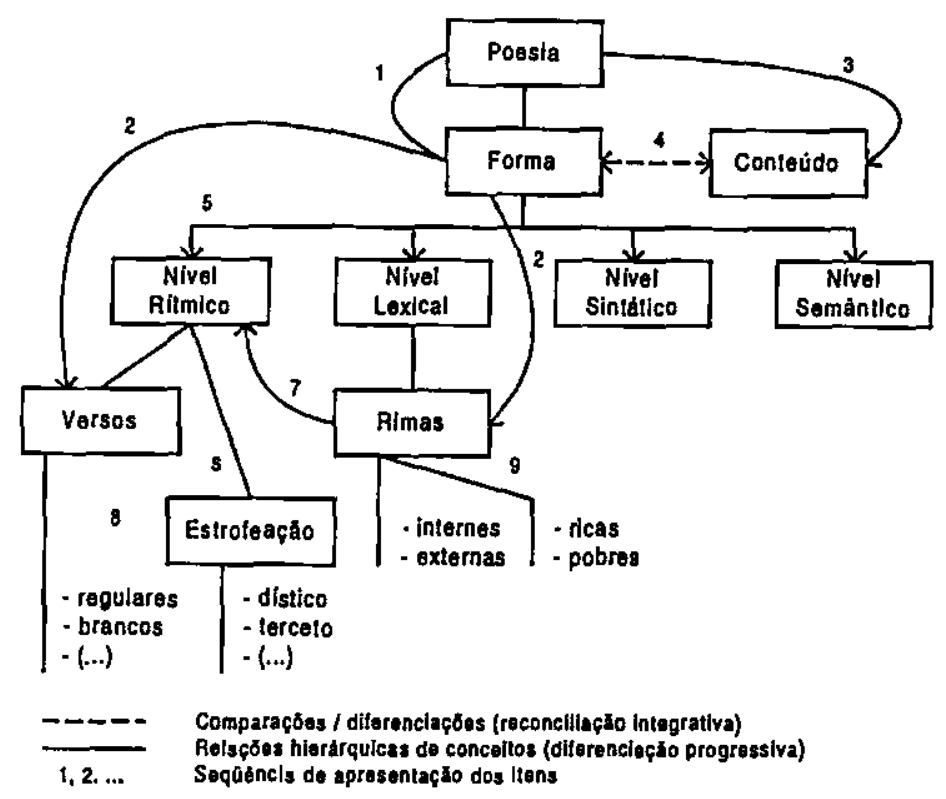

Figura 5.10: Mapa de hierarquia conceitual de unidades com possíveis sequiências instrucionais (Faria, 1995)

A sequiência indicada sugere que o professor inicie a aula com a concepção de "Poesia" (1), mostrando que a mesma não se restringe somente a rimas e versos (2). Essa abordagem pressupõe que seja essa concepção a predominante entre os alunos. O conceito de poesia como um tipo determinado de conteúdo literário é introduzido (3) e diferenciado de poesia como "Forma" (4). Segue-se um retorno ao conceito "Forma" e suas subdivisões, destacando o "Nível Rítmico" (5) e seus desdobramentos.

O mapa conceitual apresentado na Figura 5.10 exemplifica itens consistentemente interrelacionados de uma disciplina. Outras disciplinas desse tịo são a Física, Química, Biologia, Sociologia. Existem disciplinas em que os conhecimentos factuais, constituídos por descrições de objetos, paisagens e eventos específicos, têm um peso maior do que os conceitos. É o caso de disciplinas como História e Geografia. No entanto, mesmo esśas disciplinas têm uma base conceitual relevante que proporciona organicidade e sustentação. Competirá ao professor discernir a base conceitual, pois esta possibilitará uma interpretação adequada dos significados dos conhecimentos factuais.

Um segundo exemplo, mostrado na Figura 5.11, refere-se a uma unidade de estudo denominada "Massa de ar", na área da Geografia Física. O mapa intercala as explicações de conceitos com a apresentação de informações factuais ("Localização geográfica das massas de ar no Brasil"). As setas com linhas cheias indicam a diferenciação progressiva de conceitos e as 
setas com linhas tracejadas a reconciliação integrativa. Os números indicam a seqüência de apresentação das idéias. O ponto de partida é o conceito denominado "Massa de ar".

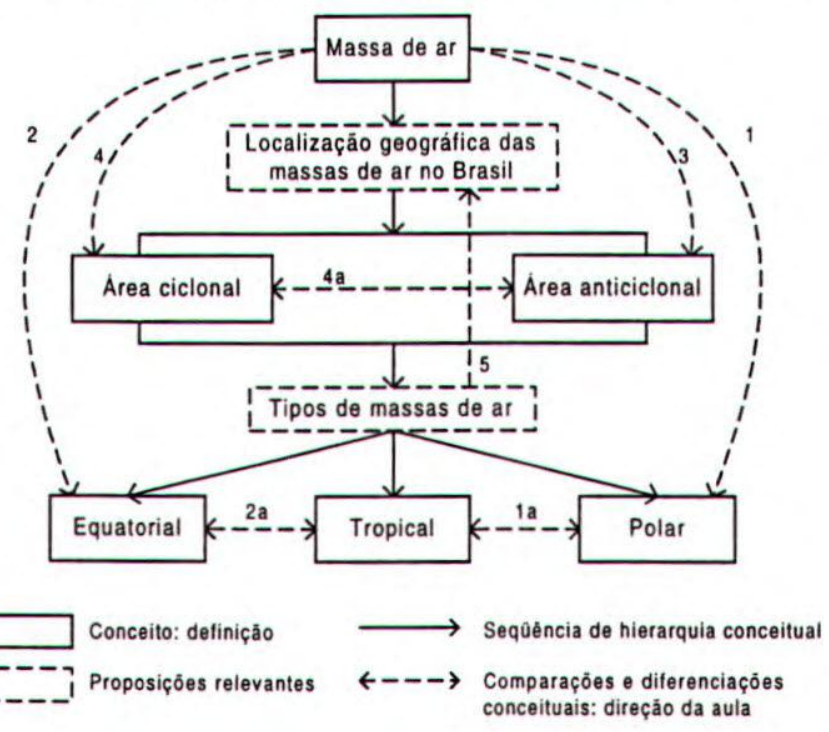

Figura 5.11: Exemplo de seqüência de ensino na disciplina Geografia Física - Climatologia (Faria, 1995)

\subsection{Considerações Finais}

Neste capítulo foram apresentados o Modelo de Michener e a técnica de Mapas Conceituais, que constituem a base teórica utilizada neste trabalho para definir um modelo conceitual com o objetivo de descrever o domínio de conhecimento de uma aplicação hipermídia para ensino.

Esse modelo conceitual é definido no contexto do Método para Projeto de Hiperdocumentos para Ensino, ou EHDM (Educational Hyperdocuments Design Method), que é apresentado no próximo capítulo. 


\section{Capítulo 6}

\section{EHDM - Educational Hyperdocuments Design Method}

\subsection{Considerações Iniciais}

Os métodos para projeto de aplicações hipermídia descritos no Capítulo 3 fornecem primitivas para modelar o domínio da aplicação baseadas em diagramas E-R (RMM, por exemplo) ou em uma abordagem orientada a objetos (OOHDM, por exemplo). Portanto, esses métodos procuram abranger domínios genéricos e não cobrem todos os aspectos de um domínio mais específico, como o domínio de ensino. Além disso, os autores de hiperdocumentos educacionais encontram dificuldades para utilizar esses métodos porque seus modelos de representação não proporcionam uma linguagem adequada para essas aplicaçőes.

De acordo com Isakowitz et al. (1995), o método RMM é mais adequado para o projeto de hiperdocumentos com estruturação e freqüência de atualizações altas, por exemplo, um catálogo de produtos. Esta afirmação também é válida para os demais métodos, pois todos possuem paradigmas semelhantes. Os conceitos de navegação propostos por esses métodos são direcionados para a indexação de uma quantidade grande de informações (instâncias) relativamente simples e organizadas em coleções (classes ou entidades, por exemplo).

No entanto, um hiperdocumento destinado ao ensino é mais diretamente vinculado à resolução de um problema específico e bastante estruturado (Thüring et al., 1995). Esse tipo de hiperdocumento procura guiar intencionalmente os leitores através de um espaço de informações sobre um domínio de conhecimento.

O Método para Projeto de Hiperdocumentos para Ensino, ou EHDM (Educational Hyperdocuments Design Method), tem como principal objetivo auxiliar o projeto de hiperdocumentos educacionais. A característica principal do EHDM é a utilização de primitivas de categorias de conhecimento e relacionamentos para modelar o domínio de conhecimento do hiperdocumento.

O EHDM utiliza características do Modelo de Michener (Seção 5.2), da técnica de Mapas Conceituais (Seção 5.3), e dos principais métodos para projeto de aplicações hipermídia 
encontrados na literatura, descritos no Capítulo 3. Portanto, o EHDM pode ser considerado como o resultado do emprego de várias idéias oriundas dos métodos genéricos e do domínio de ensino, conforme ilustrado pela Figura 6.1.

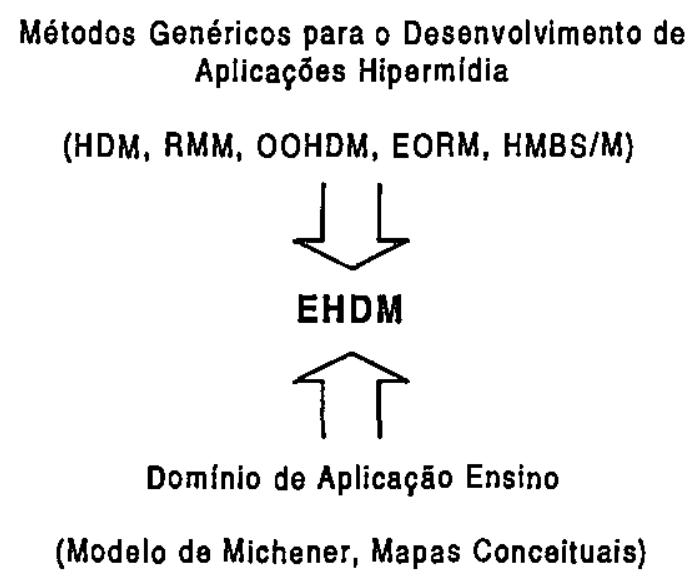

Figura 6.1: Ilustração do EHDM como o resultado do emprego de várias idéias

A Seção 6.2 apresenta uma visão geral do processo do EHDM e situa o método em um ciclo de desenvolvimento. As Seções 6.3, 6.4 e 6.5 apresentam as fases do método em detalhes. Alguns exemplos são apresentados com o objetivo de ilustrar os modelos utilizados pelo método. A Seção 6.6 apresenta uma comparação do EHDM com os demais métodos descritos no Capítulo 3. A Seção 6.7 apresenta os trabalhos relacionados.

\subsection{Fases do Método EHDM}

O EHDM é composto por três fases distintas: (1) modelagem conceitual hierárquica, (2) projeto navegacional de contextos, (3) construção e teste. Essas fases podem ser visualizadas na Figura 6.2. As setas de linhas cheias indicam a sequiência do processo e as setas com linhas pontilhadas os possíveis laços de realimentação ("feedback loops").

A fase de modelagem conceitual hierárquica consiste em estruturar o domínio de conhecimento, através da classificação de partes da teoria em categorias de conhecimento prédefinidas, e do estabelecimento de relações entre estas partes. O projeto navegacional de contextos deriva um modelo navegacional de contextos do modelo conceitual hierárquico criado na fase anterior. Contextos navegacionais, nós, elos, e estruturas de acesso são definidos durante o projeto navegacional de contextos. $\mathrm{Na}$ fase de construção, um hiperdocumento real é obtido 
através de um processo de tradução do modelo navegacional de contextos para uma plataforma hipermídia. Nessa fase também ocorrem os testes, que procuram identificar os erros ocorridos na construção do hiperdocumento.

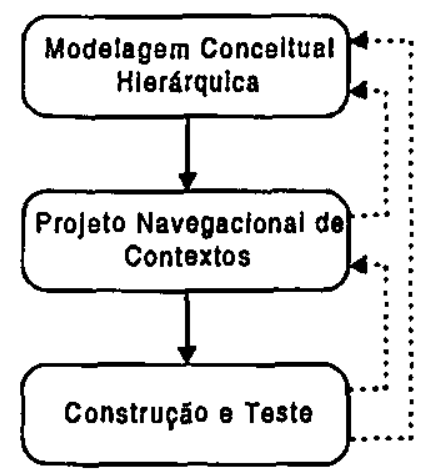

Figura 6.2: Fases do método EHDM

O EHDM pode ser incorporado por várias metodologias. Por exemplo, o Ciclo de Vida por Prototipação Evolutiva, sugerido por Fortes (1996) para o desenvolvimento de hiperdocumentos, possui as etapas básicas esquematizadas na Figura 6.3; o EHDM pode ser utilizado durante a etapa de "Autoria" para a elaboração de um projeto rápido e a construção de um protótipo.

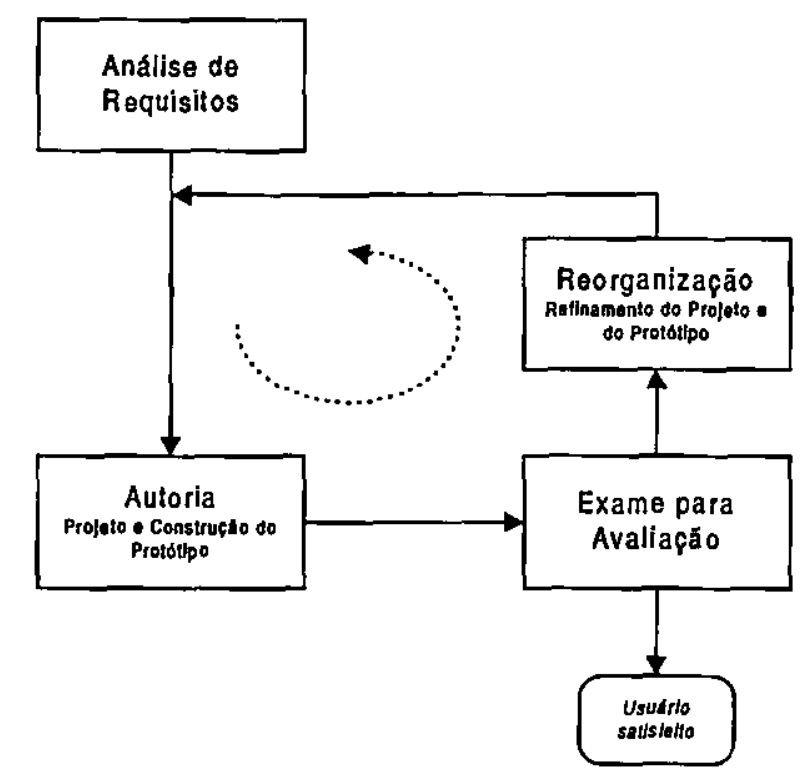

Figura 6.3: Etapas do Ciclo de Vida por Prototipaçāo Evoluliva (Fortes, 1996)

\subsection{Modelagem Conceitual Hierárquica}

A fase de modelagem conceitual hierárquica tem como objetivo descrever o domínio de conhecimento escolhido para o hiperdocumento. Durante essa fase, um modelo conceitual 
hierárquico é construído para representar as partes relevantes do domínio de conhecimento e suas relações.

O modelo conceitual hierárquico foi baseado no Modelo de Michener (Seção 5.2) e na teoria de Mapas Conceituais (Seção 5.3). Michener identifica três categorias fundamentais de conhecimento matemático (conceito, resultado e exemplo), fornece uma estrutura para cada categoria e discute associações entre elas. Um dos seus objetivos é propor uma representação desse domínio de conhecimento, que pode ser utilizado em várias aplicações computacionais. Apesar de Michener ter trabalhado no domínio da Matemática, suas idéias podem ser estendidas para domínios diferentes, por exemplo, História e Geografia.

Mapas conceituais são diagramas hierárquicos utilizados para ilustrar a estrutura conceitual de uma fonte de conhecimento. Em um mapa conceitual, os conceitos mais abrangentes ou gerais são colocados no topo do mapa. À medida que se desce, conceitos intermediários menos abrangentes (subordinados) são encontrados. Finalmente, na parte inferior do mapa, aparecem os conceitos mais específicos. Essa idéia, baseada no princípio da diferenciação progressiva de Ausubel, é utilizada pelo modelo conceitual hierárquico quando é necessário expandir um elemento conceitual mais geral em elementos conceituais mais específicos.

A seguir, na Subseção 6.3.I, as categorias de conhecimento e os relacionamentos que permitem estabelecer uma ordem dentro de cada categoria são definidas. Na Subseção 6.3 .2 são definidos os relacionamentos que podem ser estabelecidos entre as categorias de conhecimento. O EHDM fornece primitivas gráficas para representar as categorias e os relacionamentos de modo a facilitar a visualização do domínio de conhecimento modelado. É importante ressaltar que essas definições procuram extrapolar o domínio matemático com o objetivo de estender a modelagem para outros domínios.

\subsubsection{Categorias de Conhecimento e seus Relacionamentos de Ordem}

O modelo conceitual hierárquico permite a classificação de partes de uma teoria em três categorias de conhecimento: Conceito, Resultado e Exemplo. A categoria Conceito abrange as características, propriedades, atributos, regularidades e/ou observações de um objeto, fenômeno ou evento relativo a um domínio de conhecimento. De um modo geral, as descrições, definições, princípios e procedimentos podem ser considerados como conceitos.

Alguns exemplos de conceitos identificados em vários domínios são apresentados a seguir: o ponto, a reta e o plano da Geometria; as definições de velocidade e aceleração da Física; as leis 
das reações químicas, como a lei de Lavoisier e a de Proust, da Química; a sociedade, cultura e natureza da História. A primitiva gráfica para a categoria Conceito é apresentada na Figura 6.4.

Os conceitos podem ser estruturados através de relacionamentos indicando que um conceito $\mathrm{A}$ deve ser apresentado antes de um conceito B, refletindo uma relação de ordem pedagógica. Essa relação pode representar simplesmente uma preferência na sequiência de apresentação dos conceitos ou ainda que a seqüência é pedagogicamente necessária para o aprendizado (relação de pré-requisito). As primitivas gráficas de relacionamento "precedência preferencial" e "precedência necessária", apresentadas na Figura 6.4, são as abstrações do modelo para essas relações.

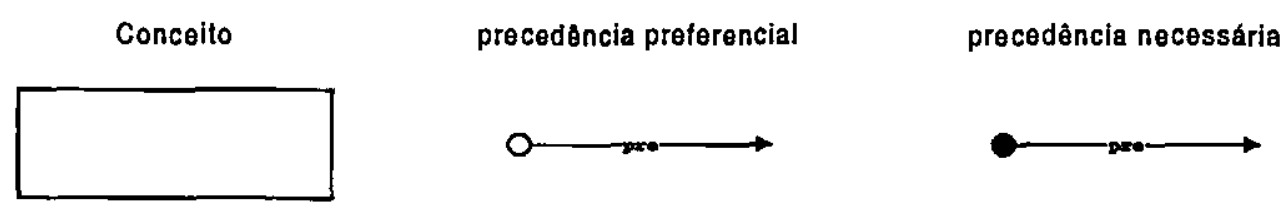

Figura 6.4: Primitivas para a categoria Conceito e seus relacionamentos de ordem

A Figura 6.5 mostra um exemplo de conceitos relacionados por "precedência necessária". O conceito "Átomo" deve ser apresentado antes do conceito "Molécula". A Figura 6.6 mostra um exemplo de conceitos relacionados por "precedência preferencial". Os conceitos referentes aos estados físicos da matéria são apresentados preferencialmente nesta sequiência: "Sólido", "Líquido" e "Gasoso".

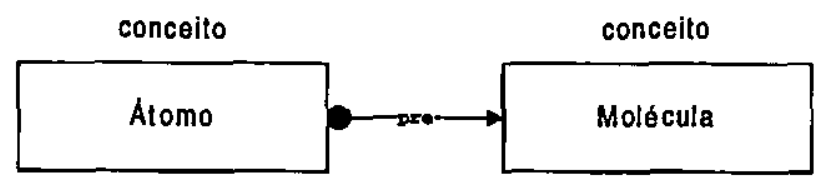

Figura 6.5: Exemplo de relação entre conceitos por "precedência necessária"

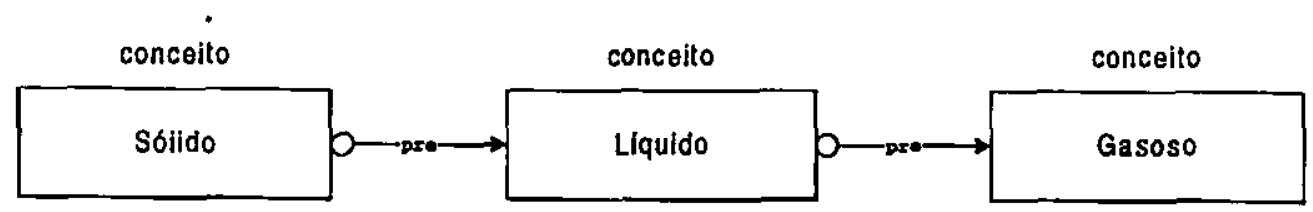

Figura 6.6: Exemplo de relação entre conceitos por "precedência preferencial"

A categoria Resultado abrange as consequêencias lógicas obtidas a partir de conceitos do domínio e de outros resultados previamente estabelecidos. Essa categoria inclui teoremas, deduções, generalizações, conseqüências e soluções.

Podem ser considerados como exemplos de resultados: os vários teoremas que podem ser estabelecidos a partir do conceito de triângulo retângulo, entre eles, o Teorema de Pitágoras; as equações dos movimentos da teoria de Mecânica, no domínio de Física; o Renascimento, no 
domínio de História, pois foi a conseqüência (ou resultante) de um complexo de causas (crescimento das cidades e do comércio, o desenvolvimento do humanismo, a influência das civilizações bizantinas e sarracenas etc.). A primitiva gráfica para a categoria Resultado é apresentada na Figura 6.7.

Os resultados podem ser estruturados através de uma relação de dedução, indicando que um resultado A deduz (ou deriva / causa) um resultado B. A primitiva gráfica para o relacionamento “dedução", apresentada na Figura 6.7, representa essa relação no modelo.

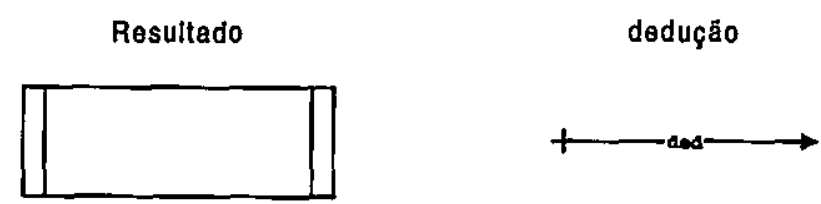

Figura 6.7: Primitivas para a categoria Resuitado e seu relacionamento de ordem

A Figura 6.8 mostra um exemplo de relação entre resultados. O resultado "Equação de Torricelli" pode ser deduzido a partir do resultado "Equações do MUV", uma vez que a equação de Torricelli é obtida das equações do movimento uniformemente variado, eliminando o tempo na equação horária do MUV, sendo que o tempo é isolado da equação da velocidade do MUV.

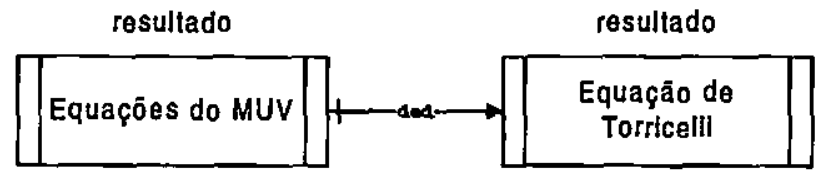

Figura 6.8: Exemplo de relaçāo entre resultados

A categoria Exemplo abrange as instâncias individuais relativas a um conceito ou resultado identificado no domínio. As ilustrações e instanciações de conceitos e resultados são classificadas como exemplos. Por exemplo: a seqüência formada pelos anos bissextos, que ocorrem de quatro em quatro anos, é um exemplo para a teoria de Progressão Aritmética, no domínio de Matemática; o conjunto dos dados resultantes de experimentos são exemplos para a Física e Química; os documentos históricos em geral, como cartas, livros, fotografias, filmes, construções arquitetônicas etc. são exemplos para a História. A primitiva gráfica para a categoria Exemplo é apresentada na Figura 6.9.

Os exemplos podem ser estruturados por relacionamentos que refletem uma ordem de complexidade. Essa relação indica que um exemplo A é menos complexo (ou mais simples) que um exemplo B. A primitiva gráfica para o relacionamento "complexidade", apresentada na Figura 6.9, representa a ordem de complexidade de exemplos no modelo. 


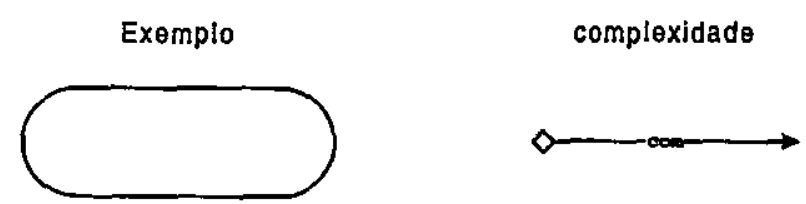

Figura: 6.9: Primitivas para a categoria Exemplo e seu relacionamento de ordem

A Figura 6.10 mostra exemplos relacionados por ordem de complexidade. $O$ átomo do Hidrogênio é um exemplo de átomo menos complexo que o do Alumínio, que por sua vez é menos complexo que o do Ferro (considerando-se o número de camadas eletrônicas de cada um).

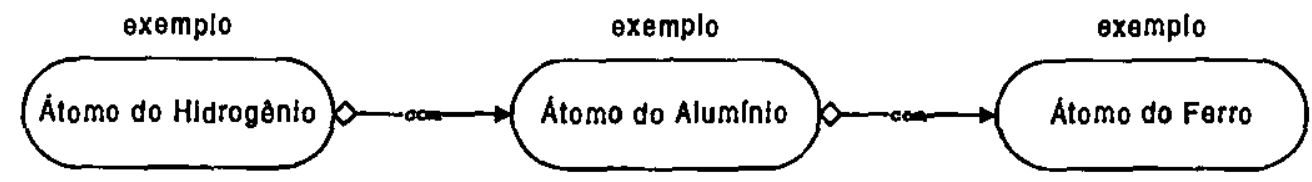

Figura 6.10: Exemplo de relação entre exemplos

\subsubsection{Relacionamentos entre as Categorias de Conhecimento}

Os relacionamentos que podem ser estabelecidos entre as categorias de conhecimento são baseados na idéia dual (dual idea) de Michener (1978), que destaca relações entre os espaços de representação definidos pelas três categorias junto com suas relações de estrutura. $O$ conjunto de todos os relacionamentos definidos no modelo contribui para que o resultado de uma modelagem possa ser vista como um grafo orientado.

O relacionamento "motivação / ilustração" relaciona a categoria Exemplo com as outras duas categorias (Conceito e Resultado). Quando o relacionamento parte de um exemplo, considera-se que este exemplo é utilizado para motivar um conceito ou resultado. Por outro lado, quando um exemplo é destino dó relacionamento, ele é utilizado para ilustrar um conceito ou resultado. A primitiva para o relacionamento "moti vação / ilustração" é apresentada na Figura 6.11.

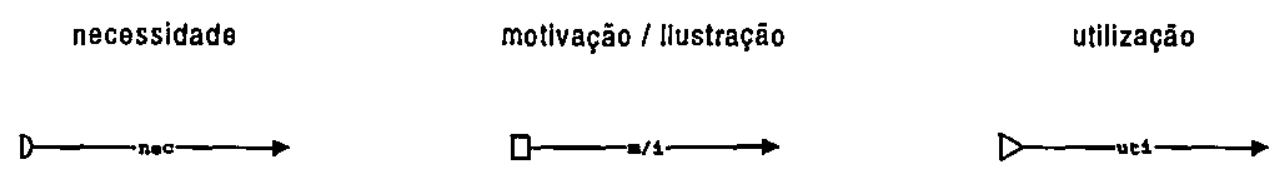

Figura 6.11: Primitivas para os relacionamentos entre as categorias de conhecimento

A Figura 6.12 mostra uma situação na qual ambas as formas do relacionamento foram utilizadas. O exemplo "Movimento da tartaruga" é utilizado para motivar o conceito "Movimento uniforme" (a tartaruga dificilmente varia sua velocidade), mas este conceito é ilustrado pelo exemplo "Carro em movimento", um exemplo clássico para esta teoria. 


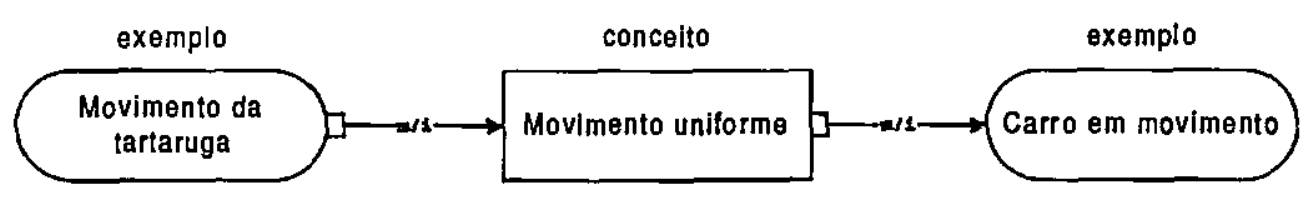

Figura 6.12: Exemplo para o relacionamento de "motivação / ilustração"

Os relacionamentos "necessidade" e "utilização" podem relacionar as três categorias de conhecimento. O relacionamento "necessidade" indica que um determinado item de uma categoria é necessário para discutir, descrever ou apresentar outro. A primitiva para o relacionamento "necessidade" é apresentada na Figura 6.11.

A Figura 6.13 mostra um exemplo desse relacionamento. O conceito "Velocidade" é necessário para descrever (ou provar) o resultado "Equação horária do Movimento Uniforme (MU)" (em uma abordagem de ensino onde a equação horária do MU é obtida a partir da definição do conceito de velocidade).

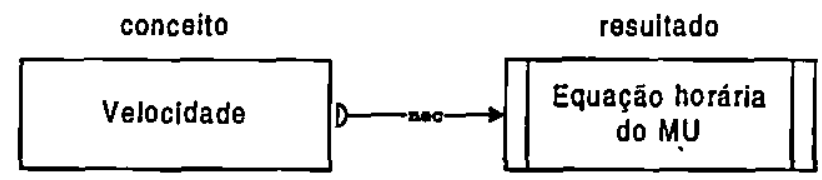

Figura 6.13: Exemplo para o relacionamento de "necessidade"

O relacionamento "utilização" indica que um item de uma categoria utiliza outro como base para sua construção ou definição. A primitiva para o relacionamento "utilização" é apresentada na Figura 6.11. Um exemplo para o relacionamento "utilização" é apresentado na Figura 6.14. O conceito "Condensação" é ilustrado pelo exemplo "Destilação", que utiliza o conceito "Vaporização" na sua exposiçã̃o. A destilação é um processo de purificação da água no qual é realizado uma condensação precedida por uma vaporização.

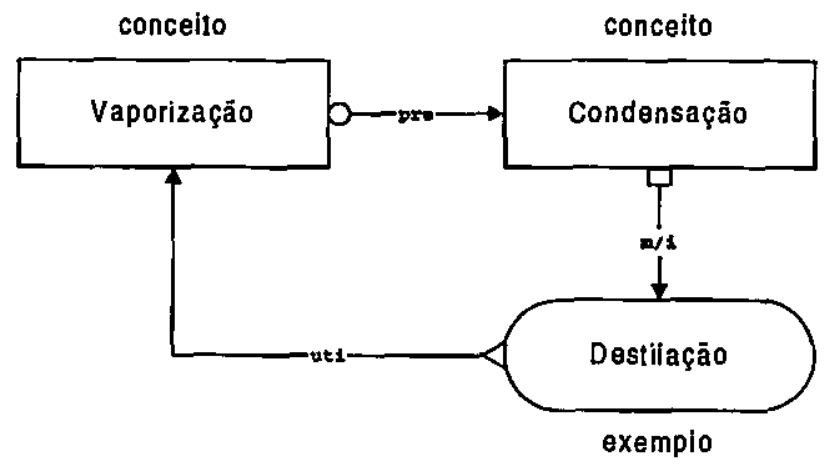

Figura 6.14: Exemplo para o relacionamento de "utilização"

A Figura 6.15 apresenta as três categorias de conhecimento e todos os relacionamentos do modelo em uma representação segundo a Unified Modeling Language (UML) (Rational, 1995), 
para esclarecer o significado dos relacionamentos que podem ser estabelecidos em cada categoria e entre as categorias.

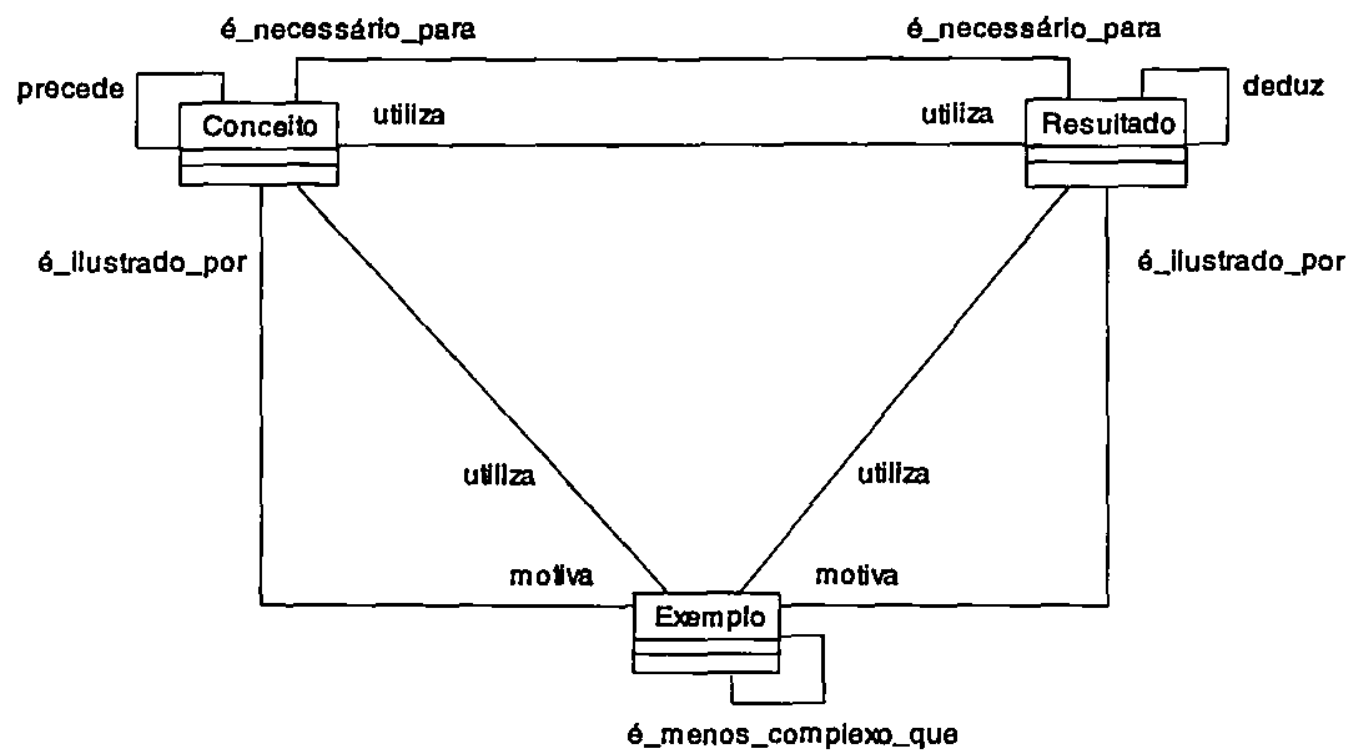

Figura 6.15: Representação das categorias e relacionamentos segundo a UML

Para uma visão mais geral da representação gráfica da modelagem, a Figura 6.16 mostra um exemplo de modelagem para a teoria de "Movimentos Retilíneos", que é parte da teoria de Mecânica, no domínio da Física. Segundo o exemplo, os conceitos "Repouso, movimento e trajetória", "Movimento uniforme", "Velocidade", "Movimento uniformemente variado" e "Aceleração" devem ser apresentados necessariamente nesta seqüência, devido aos relacionamentos de "precedência necessária". Essa não é a única modelagem possível; alguns autores podem decidir abordar os conceitos de "Velocidade" e "Aceleração" antes dos conceitos referentes aos movimentos. O exemplo "Movimento da tartaruga" é uma motivação para o conceito de "Movimento uniforme" e o exemplo "Carro em movimento" é uma ilustração para vários conceitos, como pode ser observado pelos relacionamentos "ilustração / motivação" cujo destino é este exemplo. Os conceitos "Movimento uniforme" e "Velocidade" são necessários para descrever o resultado "Equação horária do MU". Os conceitos "Velocidade", "Movimento uniformemente variado" e "Aceleração" são necessários para descrever o resultado "Equaçōes do MUV". O resultado "Equação de Torricelli" pode ser deduzido a partir do resultado "Equações do MUV", conforme descrito na subseção anterior. 


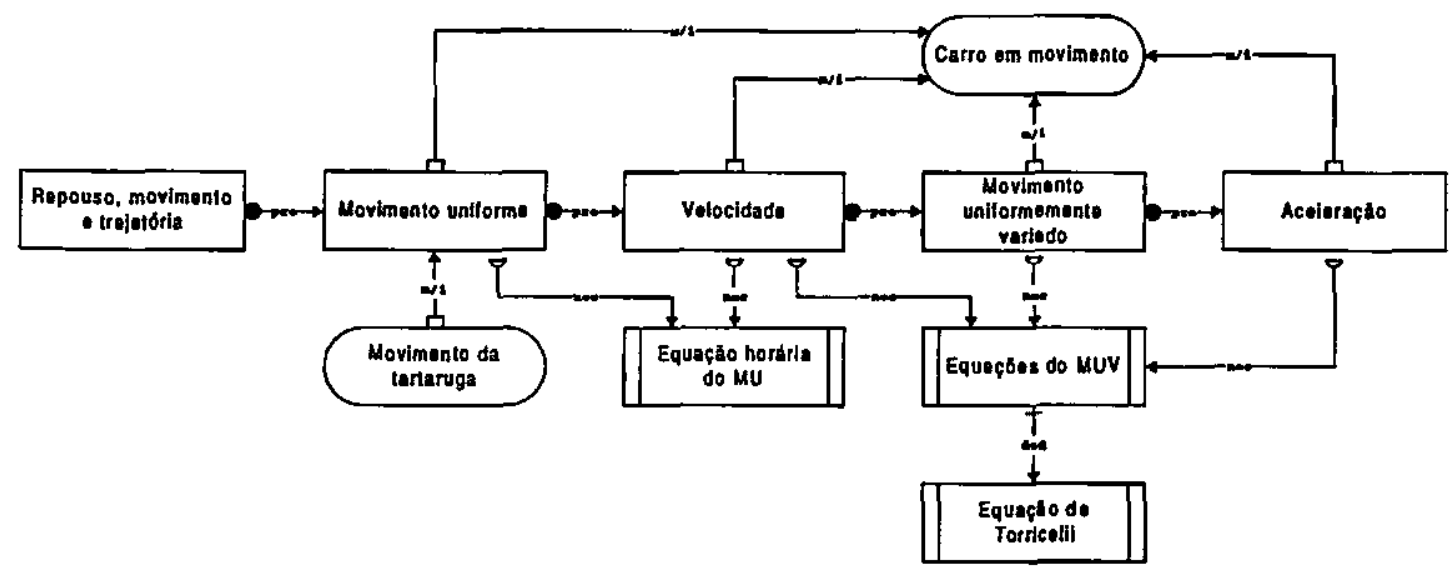

Figura 6.16: Exemplo de modelagem para a teoria "Movimentos Retilíneos"

Para ilustrar o uso do modelo em um domínio não matemático, a Figura 6.17 mostra uma modelagem para o conceito "Colonialismo no Brasil", no domínio de História. Os conceitos "Colonialismo", "Natureza e povos indígenas na visão do europeu", "Exploração econômica de recursos naturais pelos colonizadores" e "Trabalho entre os povos indígenas" estão ordenados por relacionamentos de "precedência necessária", indicando que esta sequiência é necessária para a aprendizagem. Esses conceitos, com exceção do conceito "Colonialismo", são necessários para apresentar o resultado "Diferentes formas de posse e propriedade da terra". Os resultados "Os grandes proprietários" e "A organização de trabalhadores", deduzidos como conseqüuencias do resultado "Diferentes formas de posse e propriedade da terra", derivam o resultado "Exodo rural" que, por sua vez, deriva o resultado "Reforma Agrária". Esse exemplo é baseado no livro de História de Marques et al. (1994) e nos Parâmetros Curriculares Nacionais de História (Brasil, 1998).

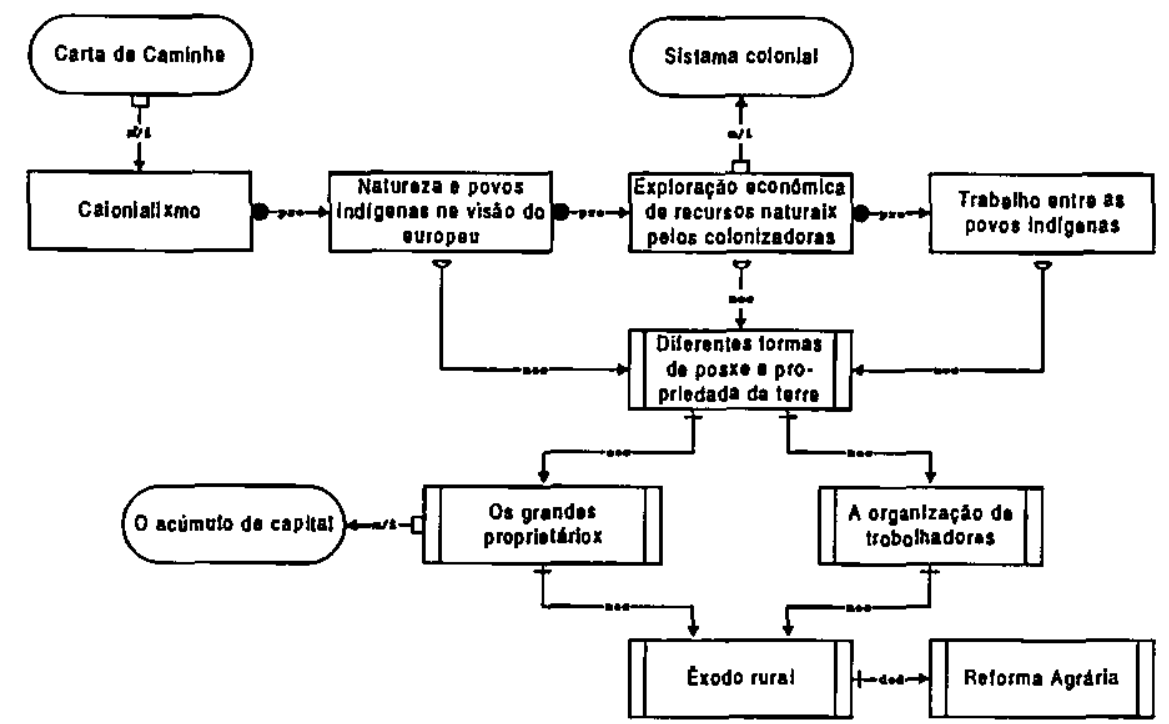

Figura 6.17: Exemplo de modelagem para o conceito "Colonialismo no Brasil" 


\subsubsection{Estruturação Hierárquica}

O modelo conceitual hierárquico permite estruturar o domínio de conhecimento através da classificação das suas partes em categorias de conhecimento pré-definidas e do estabelecimento de relacionamentos entre estas partes. Os relacionamentos do modelo possuem uma semântica que procura favorecer a criação de uma representação do domínio de conhecimento com o objetivo de ensino. Partes do domínio de conhecimento que correspondem a elementos mais gerais, mais inclusivos, podem ser expandidos em elementos mais específicos em termos de detalhe e especificidade, criando uma hierarquia de elementos conceituais. Esse mecanismo de expansão hierárquica é baseado no princípio da diferenciação progressiva utilizado pelos Mapas Conceituais.

A Figura 6.18 apresenta um exemplo de modelagem onde é utilizado o mecanismo de expansão hierárquica. A Figura 6.18(a) apresenta parte de uma modelagem para a teoria de "Matéria", do domínio da Química. Esse diagrama pode ser visto como o "topo" da hierarquia ou o diagrama de nível zero, semelhante ao conceito de expansão em níveis utilizado em diagramas de fluxo de dados (DFD) (Gane \& Sarson, 1983). A expansão do conceito "Estados físicos da matéria" pode ser visualizado na Figura 6.18(b) e a expansão do conceito "Mudanças de estado", na Figura 6.18(c).

(b) Parte de unte modelagem para a teoria de Hatéria, do dominjo da Oufmice

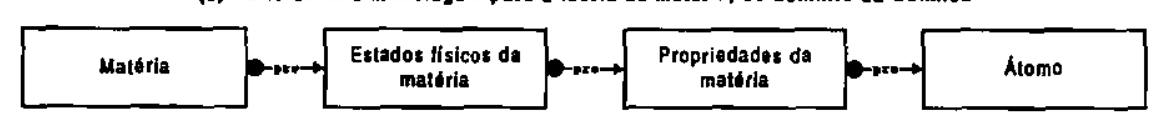

(b) Expenabo do concelto "Estados Ifsicos da matéria"

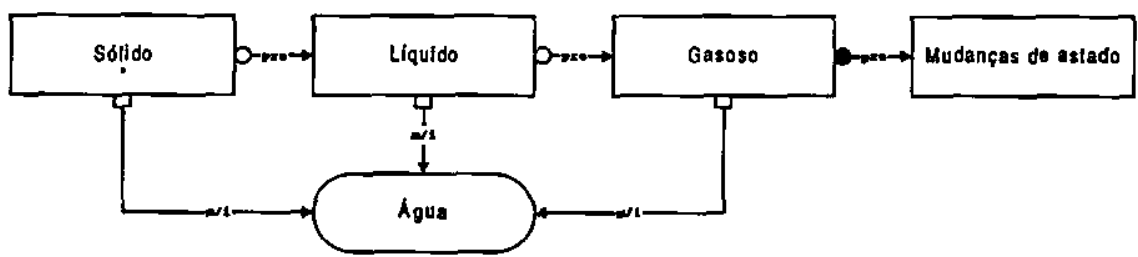

(c) Expansio do concel to "Hudançae de estado"

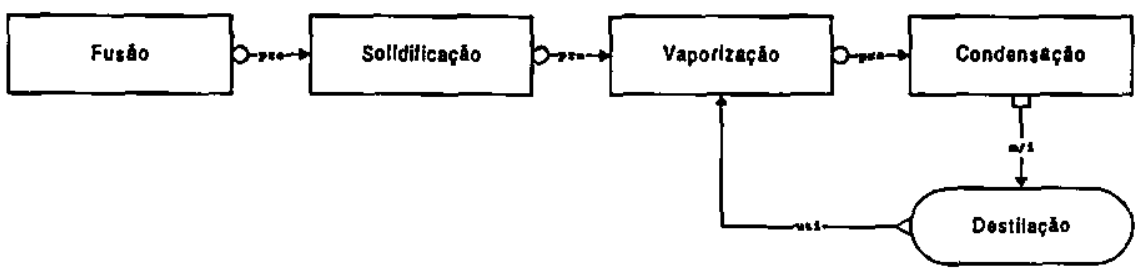

Figura 6.18: Exemplo de expansão hierárquica 


\subsubsection{Considerações sobre o Modelo Conceitual Hierárquico}

O papel que cada item possui na categoria a que pertence é um ponto importante a considerar. Michener (Seção 5.2) estabelece várias classes epistemológicas para cada categoria. A Figura 6.19 apresenta as classes como especializaçōes das categorias (classes) de conhecimento segundo a Unified Modeling Language (UML) (Rational, 1995). Essa especialização da categoria e a conseqüente associação com funções diferentes no modelo permitem registrar características importantes do domínio de conhecimento que podem ser utilizadas como suporte para processos e análises automatizadas. Além disso, a criação de classes adequadas e de relacionamentos com outras semânticas pode permitir a generalização para outros domínios de conhecimento.

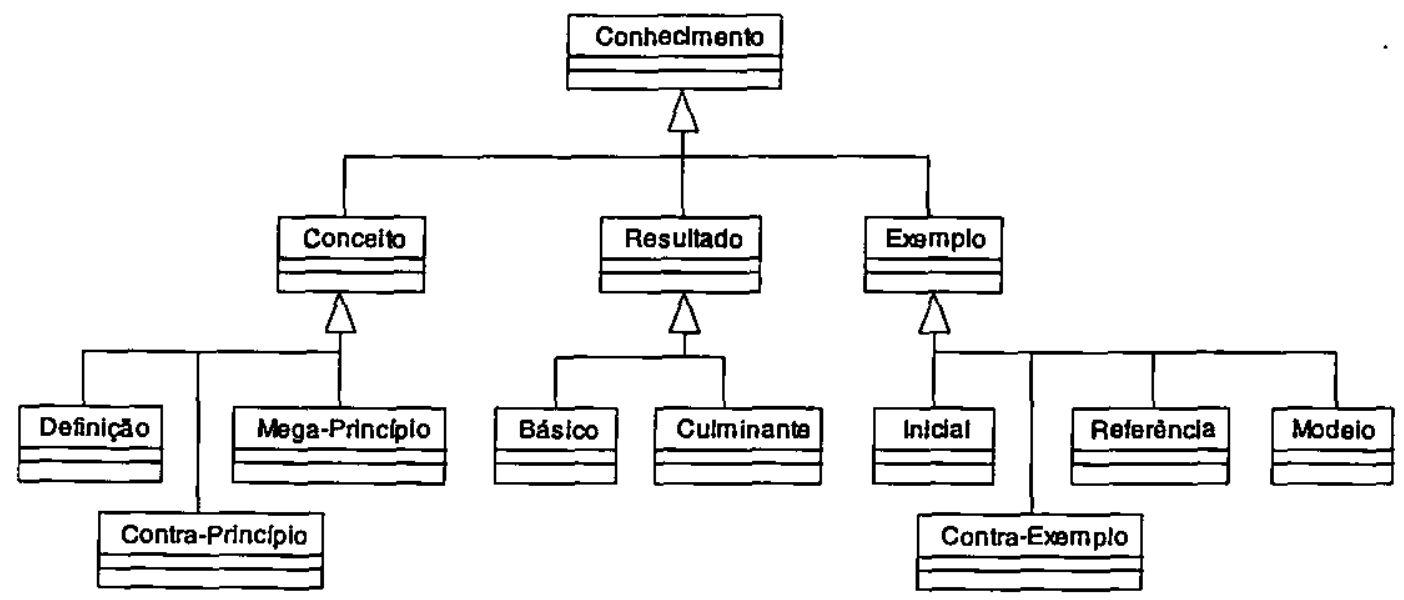

Figura 6.19: Classes epistemologicas para as categorias de conhecimento

\subsection{Projeto Navegacional de Contextos}

As aplicações hipermídia são projetadas para efetuar navegação através de um espaço de informações. Portanto, o projeto da estrutura de navegação dessas aplicações é a etapa crucial no empreendimento de desenvolvimento (Rossi, 1996). No EHDM, os`aspectos navegacionais de um hiperdocumento são modelados durante a fase de projeto navegacional de contextos. $\mathrm{O}$ resultado dessa fase é um modelo navegacional de contextos que representa um hiperdocumento.

$\mathrm{Na}$ fase de projeto navegacional de contextos, diferentes modelos navegacionais de contextos podem ser construídos, baseados no mesmo modelo conceitual hierárquico criado na fase anterior (modelagem conceitual hierárquica), e de acordo com propósitos educacionais diferentes. A motivação é permitir que usuários (aprendizes) diferentes vejam o mesmo conteúdo através de perspectivas diferentes. 
Por exemplo, considerando um hiperdocumento educacional sobre "Movimento" (da teoria de Mecânica, da Física), com os seguintes tipos de usuários: alunos de ensino médio, universitário e de pós-graduação. Esses usuários necessitam de abordagens de ensino diferenciadas e, possivelmente, de diferentes estruturas de navegação e diferentes mídias para apresentar o conteúdo. Para alunos de ensino médio pode ser necessária uma abordagem mais intuitiva da teoria, com exemplos na forma de vídeos e/ou animações. Para alunos universitários ou de pósgraduação, pode-se abordar a teoria de uma maneira mais formal, com discussões e exemplos mais abstratos.

Um desenvolvimento tradicional trataria cada uma dessas aplicações separadamente, dupplicando os esforços de desenvolvimento e manutenção. A construção de um modelo mais geral, que suporte todos os tipos de usuários, seria outra abordagem de desenvolvimento. Entretanto, o modelo obtido seria bastante complexo devido à necessidade de incorporar diversos mecanismos para abstrair todas as abordagens navegacionais possíveis.

No EHDM, vários modelos navegacionais de contextos podem ser derivados de um mesmo modelo conceitual hierárquico, enfatizando determinadas partes do domínio de conhecimento, e de acordo com o perfil do usuário a que se destina o hiperdocumento. Essa abordagem é semelhante à proposta pelo OOHDM (Seção 3.4), que utiliza visões navegacionais do modelo conceitual, cada uma delàs constituindo um tipo distinto de hiperdocumento. No OOHDM é utilizada uma linguagem de definição de visões orientada a objetos, enquanto que no EHDM somente é especificado um mapeamento de elementos conceituais em navegacionais.

Um modelo navegacional de contextos define um conjunto de contextos e entidades navegacionais. Os contextos navegacionais determinam a estrutura (organização hierárquica) do hiperdocumento, enquanto as entidades navegacionais, nó e elo, especificam os elementos que serão apresentados aơ usuário. A definição de estruturas de acesso (índices e roteiros) completa o modelo navegacional de contextos. A Figura 6.20 mostra as primitivas gráficas de modelagem navegacional.
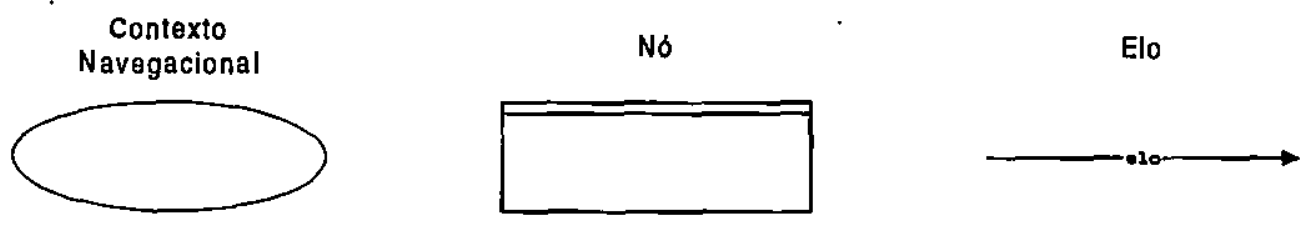

Figura 6.20: Primitivas gráficas de modelagem navegacional 


\subsubsection{Nós e Elos}

Em hiperdocumentos, os nós contêm as informações que serão apresentadas ao usuário. No modelo navegacional de contextos, os nós são descritos por um grupo de atributos e um conjunto de âncoras. Os, atributos representam as informações derivadas dos elementos conceituais (conceito, exemplo ou resultado) para o nó e as âncoras correspondem aos elos que partem do nó.

Os nós podem ou não ser derivados diretamente dos elementos conceituais. Em alguns casos, o modelo navegacional de contextos pode possuir nós com atributos derivados de mais de um elemento conceitual $\mathrm{e}$, em outros, vários nós com atributos derivados de um mesmo elemento conceitual. De qualquer forma, sempre é possível obter um mapeamento do tipo um-para-um, no qual cada elemento conceitual é mapeado em um nó com um único atributo. Para facilitar a compreensão, o mapeamento é indicado através de uma referência (no atributo) ao elemento conceitual que originou a informação representada pelo atributo.

Cada atributo deve ser associado a um tipo que indica a forma de apresentação da informação correspondente ao atributo. Por exemplo, um atributo do tipo "Vídeo" indica que a informação do atributo será apresentada através de um vídeo. Os tipos que um atributo pode assumir dependem do sistema hipermídia em que o hiperdocumento será construído, mas de um modo geral, pode-se considerar os tipos: texto, imagem, áudio e vídeo (incluindo animação).

Um atributo é representado da seguinte forma: <nome_atributo> (<elemento_conceitual $>$ ): $<$ tipo_atributo>, indicando que o atributo "nome_atributo", derivado do elemento conceitual "elemento_conceitual", é do tipo "tipo_atributo". Os atributos podem ser especificados no diagrama navegacional de contextos dentro de um colchete (bracket) situado abaixo do nó, ou documentados a parté, em um dicionário de dados.

Os atributos de um nó são divididos em duas classes: núcleo e satélite. Os atributos da classe núcleo representam as informações que são apresentadas quando o nó é visitado. O sinal “*” indica os atributos da classe núcleo. Os atributos da classe satélite correspondem às informaçōes que podem ser obtidas a partir das informações relativas aos atributos da classe núcleo.

A classificação dos atributos permite especificar as informações essenciais para apresentar um conteúdo e também as informações complementares que podem ser apresentadas ou não, dependendo da necessidade do usuário (aprendiz). Essa característica é interessante em aplicações no ensino, pois possibilita que a flexibilidade das informações contidas no hiperdocumento seja projetada para fornecer material adicional conforme a necessidade do aprendiz. 
A Figura 6.21 mostra dois exemplos de mapeamento de um modelo conceitual hierárquico para um modelo navegacional de contextos. A Figura 6.21(b) apresenta o resultado de um mapeamento um-para-um do modelo conceitual hierárquico da Figura 6.21(a). Pode-se notar que cada elemento conceitual foi mapeado para um nó com um atributo relativo ao elemento conceitual. A Figura 6.21(c) apresenta um mapeamento alternativo, no qual o elemento conceitual "Destilação" foi mapeado para o atributo "Exemplo" no nó "Condensação". Neste caso, "Definição" é um atributo núcleo e "Exemplo" é um atributo satélite.

(a) Modelo Conceltual Hlerárquico

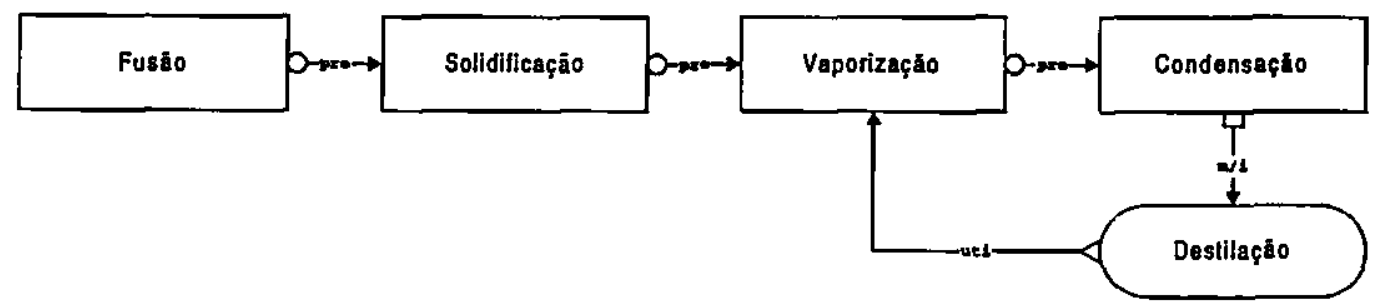

(b) Modelo Navegacional de Contextos com mapeamento um-pera-um

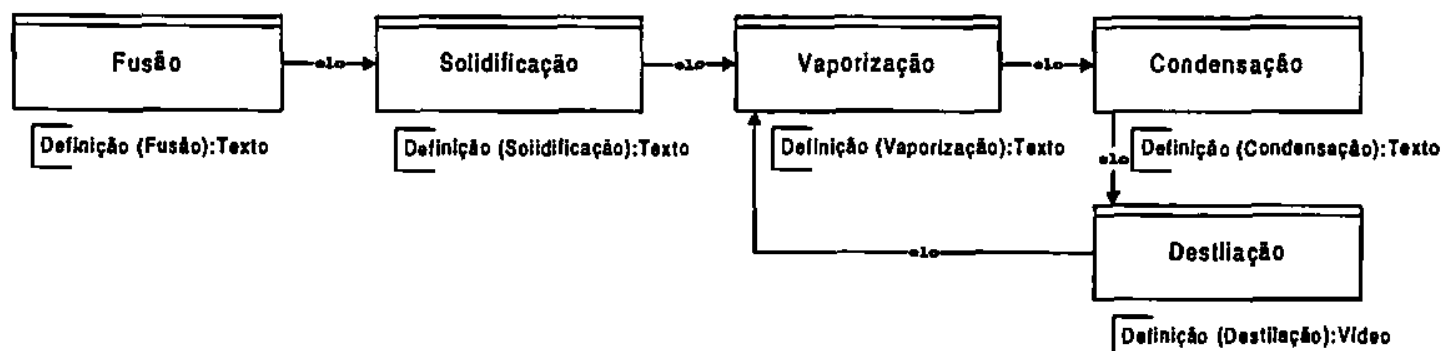

(c) Modelo Navegacional de Contextos alternativo

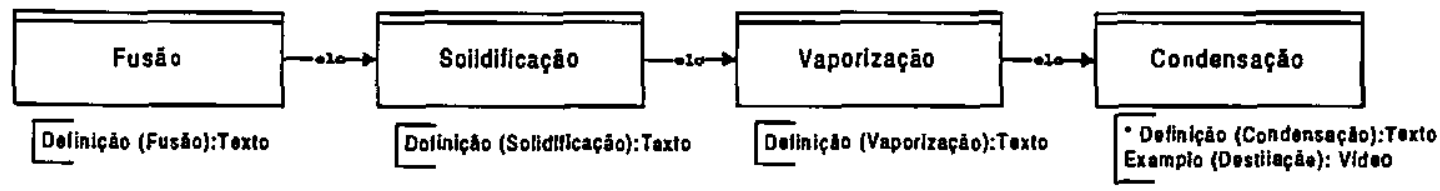

Figura 6.21: Exemplo de mapeamenıo

Os elos fazem a ligação entre os nós e somente podem ser unidirecionais. O suporte a elos bidirecionais é obtido através da definição de dois elos unidirecionais. $O$ resultado da navegação por um elo depende da especificação do tipo dos atributos do nó destino. Os elos são definidos a partir dos rel acionamentos do modelo conceitual hierárquico e são representados como setas no modelo navegacional de contextos. Para cada elo definido no diagrama navegacional deve existir uma âncora no seu nó origem. Uma âncờa pode ser representada no diagrama navegacional da seguinte forma: <nome_âncora> (<elemento_destino>), indicando que ao selecionar a âncora "nome_âncora", o elemento "elemento_destino" é apresentado.

A Figura 6.22 apresenta o diagrama da Figura 6.21(b) com a representação dos atributos e das âncoras correspondentes aos elos. O nó "Fusão" possui o atributo "Definição" (derivado do 
conceito "Fusão") do tipo "Texto", e a âncora "próximo" referente ao elo que parte deste nó com destino ao nó "Solidificação".

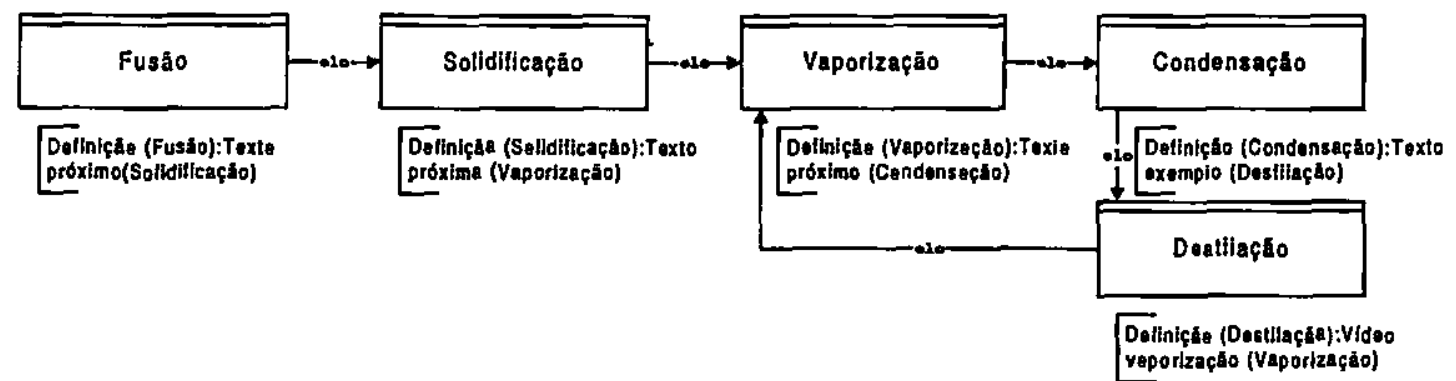

Figura 6.22: Exemplo de representação de âncoras

Os relacionamentos podem ser filtrados durante o mapeamento, isto é, nem todos os relacionamentos são necessariamente mapeados para elos. Além disso, novos elos podem ser adicionados ao modelo navegacional de contextos sem que seja mapeado a partir de um relacionamento. A Figura 6.23 apresenta o resultado de um mapeamento do modelo conceitual hierárquico da Figura 6.21(a), onde os relacionamentos de "preferência preferencial" não foram mapeados para elos.
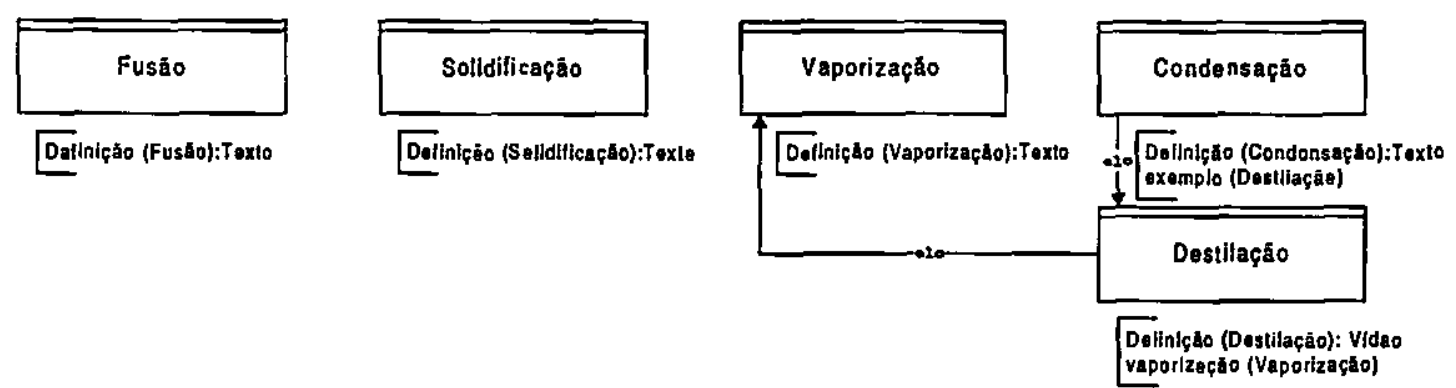

Figura 6.23: Exemplo de mapeamento com filtro de relacionamentos

\subsubsection{Contextos Navegacionais}

Um contexto navegacional é um conjunto de entidades navegacionais (nó e elo) e outros contextos navegacionais (aninhados). Os espaços de navegação representados pelos contextos navegacionais podem ser explorados utilizando as estruturas de acesso (índices ou roteiros), que estabelecem uma forma de navegação através desses espaços.

As entidades navegacionais (nó e elo) 'são organizadas em contextos navegacionais. Um contexto navegacional também pode conter outros contextos (aninhados), resultando em uma organização hierárquica de contextos. Nesse sentido, o contexto navegacional é um mecanismo 
para definir a estrutura de um hiperdocumento. O conceito de contexto navegacional utilizado pelo EHDM é baseado no Modelo de Contextos Aninhados (MCA) (Seção 4.2).

Os contextos navegacionais podem ser derivados diretamente do modelo conceitual hierárquico. A expansão de um elemento conceitual cria naturalmente um espaço de informação que pode ser interpretado como um contexto navegacional. Isso não é uma regra rígida, pois a organização dos contextos pode ser alterada e/ou novos contextos podem ser criados. A Figura 6.24 apresenta um exemplo de contextos navegacionais derivados do modelo conceitual hierárquico apresentado na Figura 6.18. O contexto navegacional "Estados físicos da matéria" foi derivado do elemento conceitual "Estados físicos da matéria" da Figura 6.18(a) devido à sua expansão na Figura 6.18(b); o mesmo ocorre para o contexto navegacional "Mudanças de estado".

(a) Modolo navegacional de contextos para o modelo conceftual hierárquico de Figura 6.18(a)
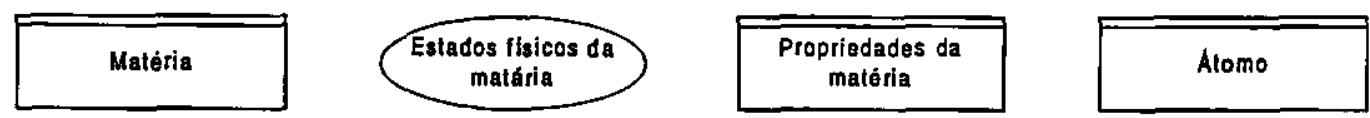

(b) Modelo ravegacional de contextos para o modejo conceitual hierárquico da Figura 6.18(b)
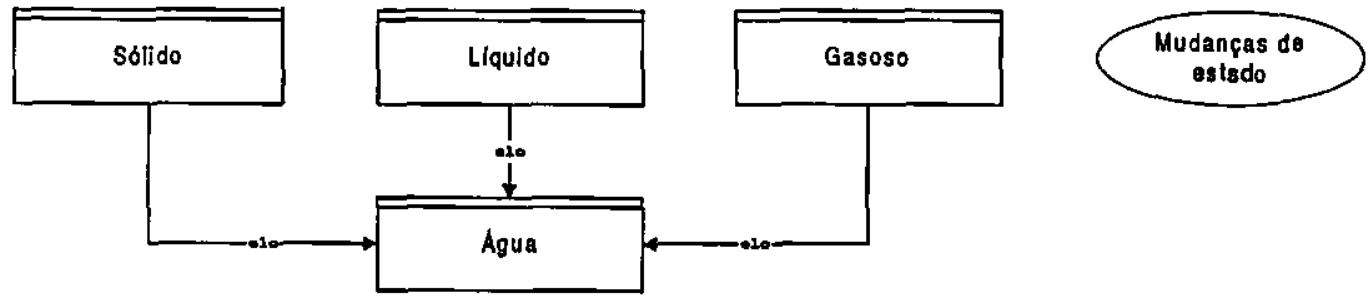

(c) Modelo navegacional de contextos para o modelo conceitusl hle rárqulco da Figura 6.18(c)
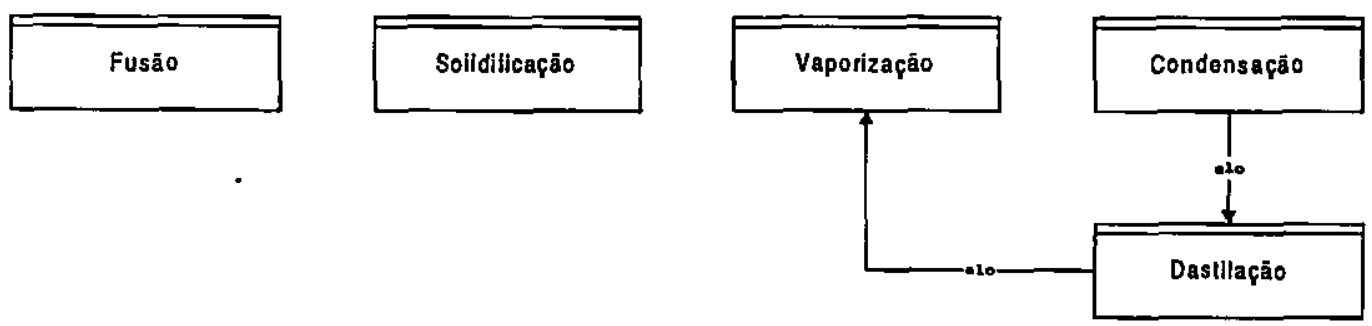

Figura 6.24: Exemplo de contextos navegacionais

Os elos também podem estabelecer ligações entre um nó e um contexto navegacional. Nesse caso, o contexto navegacional somente poderá ser o destino do elo. Navegar para um contexto navegacional significa que qualquer nó pertencente a esse contexto poderá ser explorado, ou seja, o usuário pode explorar o espaço navegacional representado pelo contexto. Isso pode provocar problemas de perda de continuidade de exposição se o contexto anterior não for preservado (Seção 2.4). A decisão de utilizar esse recurso deve ser cuidadosamente avaliada. 
A estruturação do hiperdocumento através dos contextos navegacionais permite a modificação da organização e da apresentação de uma aplicação sem que seja necessária a alteração das informações contidas nos nós. Portanto, um hiperdocumento existente pode ser reestruturado para atender uma necessidade específica, produzindo-se uma nova "versão" do hiperdocumento, isto é, um outro hiperdocumento.

\subsubsection{Estruturas de Acesso}

As estruturas de acesso são utilizadas para proporcionar uma navegação adicional à realizada através dos elos. O modelo navegacional de contextos fornece dois tipos de estrutura de acesso: índice e roteiro.

Um índice é um conjunto de nós e contextos navegacionais que permite a navegação direta a um elemento do hiperdocurnento especificado neste conjunto. Um índice pode ser definido através da especificação das entradas relativas aos nós e contextos que podem ser atingidos a partir do índice. Cada entrada do índice pode ser representada da seguinte forma: $<$ nome_entrada>: <elemento_destino>, indicando que ao selecionar a entrada "nome_entrada", o elemento "elemento_destino" é apresentado. A Figura 6.25(a) apresenta a especificação de índices para os nós do modelo da Figura 6.24(c).

Um roteiro é um conjunto de nós e contextos navegacionais que estabelece um caminho de navegação pelo hiperdocumento. Um roteiro pode ser definido através da especificação da sequiência dos nós e contextos selecionados para compor o roteiro. A Figura 6.25(b) apresenta a especificação de um roteiro para os nós do modelo da Figura 6.24(c).
(a) Índice
(b) Roteiro
fusão: Fusão
solidificação: Solidificação
vaporização: Vaporização
exemplo: Destilação
condensação: Condensação

Fusāo
Solidificação
Vaporização
Condensação
Destllação

Figura 6.25: Exemplo de definição de índice e roteiro

A semântica dos roteiros é diferente da semântica dos índices. O comportamento de um índice, quando uma das suas entradas é escolhida, é o mesmo dos nós quando uma âncora é selecionada. Um roteiro proporciona um caminho seqüencial pelo hiperdocumento incluindo operações como "Próximo" e "Anterior", que permite a navegação para frente e para trás no roteiro. A Figura 6.26 ilustra essa diferença utilizando elos para indicar as características 
navegacionais de cada estrutura de acesso. O modelo navegacional de contextos não pun... primitivas para as estruturas de acesso; os índices e roteiros são documentados à parte, no dicionário de dados do hiperdocumento.

(a) Indice

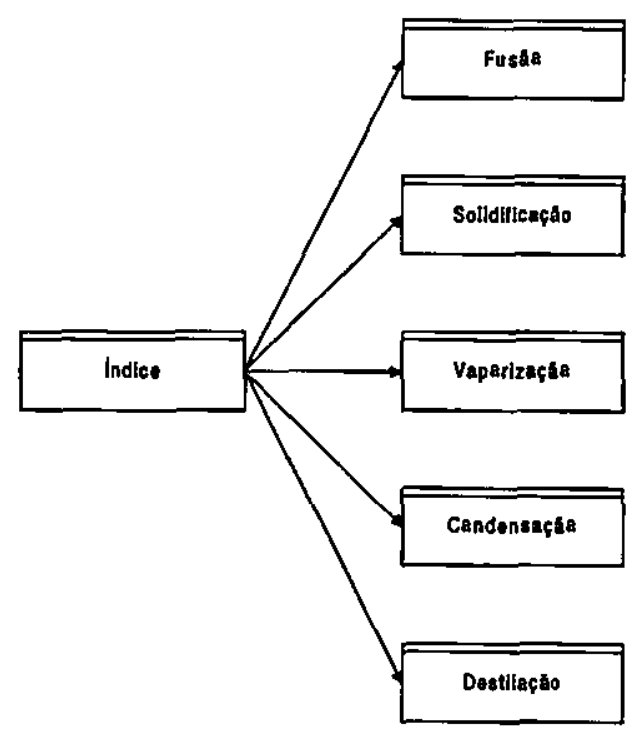

(b) Rotoiro

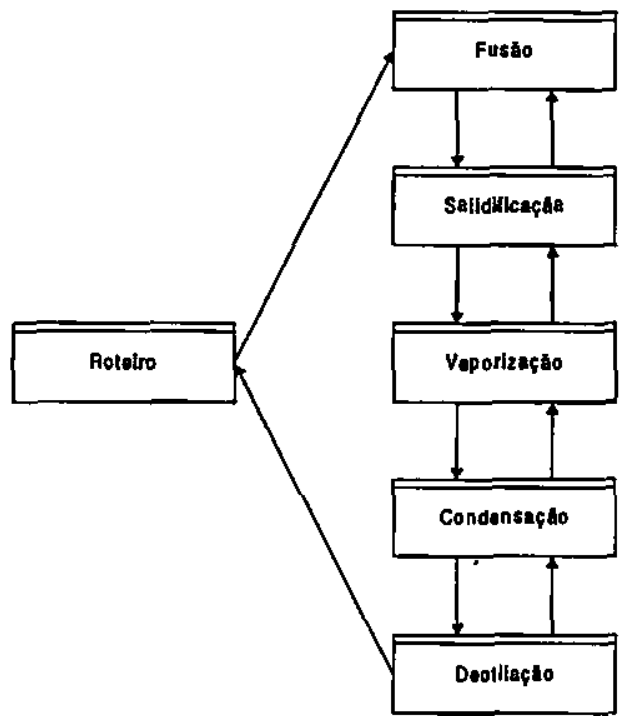

Figura 6.26: Diferença entre índice e roteiro

O EHDM sugere a construção de roteiros diferentes para atender objetivos de ensino diferentes, por exemplo: (a) introduzir um assunto novo, (b) aprofundar-se em uma teoria, (c) revisar uma teoria, (d) preparar-se para uma avaliação. A combinação da definição de múltiplos roteiros com a possibilidade de derivar mais de um modelo navegacional a partir do mesmo modelo conceitual é um recurso poderoso para proporcionar a flexibilidade necessária em hiperdocumentos destinados ao ensino.

Os roteiros também podem ser derivados do modelo conceitual hierárquico. Nesse caso, os componentes do roteiro são determinados pelos nós e contextos correspondentes e na ordem dos elementos conceituais resultantes de uma ordenação topológica do diagrama. Essa ordenação pode ser baseada na relação de precedência (necessária ou preferencial) dos conceitos. Os exemplos e resultados relacionados a esses conceitos podem estar ordenados em sequiência anterior ou posterior ao conceito correspondente, dependendo da estratégia de apresentação escolhida pelo autor. 


\subsection{Construção e Teste}

Durante a fase de Construção e Teste, o modelo navegacional de contextos é convertido em objetos disponíveis no ambiente de implementação escolhido. O resultado, a aplicação hipermídia final, pode ser obtido através de três possíveis tipos de implementação (Carvalho, 1998): interpretada, traduzida e de tradução livre.

A implementação interpretada requer um sistema capaz de interpretar e executar as especificações da aplicação desenvolvida. A implementação traduzida consiste em traduzir as especificações em artefatos de algum sistema de autoria de aplicações hipermídia como HyperCard, ToolBook, HTML (HyperText Language Markup) e apresentar a aplicação final utilizando um viewer ou um browser. A implementação com tradução livre não utiliza sistemas intermediários para interpretação, autoria ou apresentação.

\subsection{Comparação}

Os métodos atuais para projeto de aplicações hipermídia, descritos no Capítulo 3, possuem alguns pontos em comum:

- A definição de modelos para a descrição dos dados do domínio;

- A consideração da associação semântica que existe entre os relacionamentos do domínio e os elos hipermídia;

- A utilização de estruturas de acesso para modelar os aspectos navegacionais.

Essas características comuns dos métodos atuais foram consideradas durante a definição do EHDM. Entretanto, os métodos também possuem diversas diferenças. A Tabela 6.1 apresenta uma análise comparativa do EHDM com os demais métodos. Os critérios utilizados são os seguintes:

a) Metodologia: o método oferece uma série ordenada de etapas dentro de um processo de desenvolvimento?

b) Modelagem do domínio: qual o modelo base utilizado para analisar e descrever os dados do domínio?

c) Modelagem de navegação: quais os mecanismos utilizados para representar os aspectos navegacionais? 

d) Modelagem de interface: o método utiliza um modelo para especificar a interface do usuário?

e) Geração de protótipos: o método fornece regras de tradução automática da especificação do modelo para uma especificação executável por algum sistema?

Tabela 6.1: Comparação do EHDM com os demais métodos

\begin{tabular}{|l|l|l|l|l|l|}
\hline & Metodologia & $\begin{array}{l}\text { Modelagem do } \\
\text { dominio }\end{array}$ & $\begin{array}{l}\text { Modelagem de } \\
\text { navegacão }\end{array}$ & $\begin{array}{l}\text { Modelagem de } \\
\text { interface }\end{array}$ & $\begin{array}{l}\text { Geração de } \\
\text { protótipos }\end{array}$ \\
\hline HDM & $\begin{array}{l}\text { Enfase na } \\
\text { modelagem do } \\
\text { dominio }\end{array}$ & $\begin{array}{l}\text { Modelo entidade- } \\
\text { relacionamento }\end{array}$ & $\begin{array}{l}\text { Navegação default } \\
\text { e estruras de } \\
\text { acesso comuns }\end{array}$ & Não & Não \\
\hline RMM & Sim & $\begin{array}{l}\text { Modelo entidade- } \\
\text { relacionamento }\end{array}$ & $\begin{array}{l}\text { Estruturas de } \\
\text { acesso mais ricas }\end{array}$ & Não & Não \\
\hline OOHDM & Sim & $\begin{array}{l}\text { Modelo orientado } \\
\text { a objetos }\end{array}$ & $\begin{array}{l}\text { Estruturas de } \\
\text { acesso e contextos } \\
\text { navegacionais }\end{array}$ & $\begin{array}{l}\text { Modelo ADV } \\
\text { (Abstract Data } \\
\text { Views) }\end{array}$ & Não \\
\hline EORM & $\begin{array}{l}\text { Metodologia } \\
\text { orientada a objetos } \\
\text { estendida }\end{array}$ & $\begin{array}{l}\text { Modelo orientado } \\
\text { a objetos }\end{array}$ & $\begin{array}{l}\text { Composiçōes } \\
\text { Hã̃o }\end{array}$ & Não & HMBS \\
\hline EHDM & Sim & $\begin{array}{l}\text { Modelo orientado } \\
\text { a objetos }\end{array}$ & $\begin{array}{l}\text { Estruturas de } \\
\text { acesso e contextos } \\
\text { navegacionais }\end{array}$ & Canais & MCA \\
\hline
\end{tabular}

Quanto à metodologia (a), o EHDM oferece uma abordagem sistemática e abrangente, semelhante aos métodos RMM, OOHDM e HMBS/M; o HDM se concentra apenas na modelagem dos dados do domínio; o EORM estende uma metodologia orientada a objetos com uma fase de associação da semântica de ligações hipermídia aos relacionamentos.

O HDM possui abstrações mais simples para a modelagem do domínio (b), pois é considerado como o primeiro modelo para o domínio de hipermídia e foi utilizado como base para o RMM e o OOHDM; o RMM é baseado no modelo de dados entidade-relacionamento; o OOHDM, o EORM e o HMBS/M utilizam abstrações orientadas a objetos. O EHDM oferece um modelo orientado para o domínio de ensino, baseado no Modelo de Michener e em Mapas Conceituais.

Para a modelagem de navegação (c), o HDM e o RMM utilizam estruturas de acesso (índices e roteiros), mas o RMM fornece primitivas mais ricas em um modelo de dados (RMDM); o EORM utiliza composições para a modelagem da navegação; o OOHDM, além das estruturas de acesso comuns, também utiliza primitivas de alto nível chamadas de contextos navegacionais. $O$ HMBS/M utiliza estruturas de acesso (baseadas nas do RMM) e contextos de navegaçāo (conceito introduzido pelo OOHDM). O EHDM assemelha-se ao OOHDM, utilizando estruturas de acesso e o conceito de contextos navegacionais para estruturar o hiperdocumento. 
Quanto à modelagem de interface (d), o OOHDM é o único que fornece um método formal para descrever a interface; o HMBS/M permite definir somente as características genéricas da interface; o RMM e o EORM apenas reservam uma fase específica para esta tarefa. O EHDM não utiliza um modelo para especificar a interface do usuário.

O HDM, RMM, OOHDM e EORM não descrevem algum tipo de orientação efetiva a respeito de geração de protótipos (e), apesar de a maioria destes métodos considerar o desenvolvimento de ferramentas para este propósito, por exemplo, o OOHDM-CASE (Rossi, 1996), para o OOHDM, e o RMCase (Díaz \& Isakowitz, 1995), para o RMM. O HMBS/M fornece uma tradução do modelo navegacional de tipos para uma especificação segundo o modelo HMBS. O ambiente HySCharts (Hyperdocument System based on StateCharts) (Turine et al., 1998) permite criar, interpretar e executar especificações segundo o HMBS. O EHDM fornece uma tradução do modelo navegacional de contextos para uma especificação segundo o modelo MCA. Essa tradução é realizada através de uma ferramenta para modelagem e desenvolvimento de hiperdocumentos destinados ao SASHE, apresentada no Capítulo 7 deste trabalho. O SASHE (Capítulo 4) é um sistema para autoria e navegação de hiperbases MCA, ou seja, de especificações de hiperdocumentos segundo o MCA.

\subsection{Trabalhos Relacionados}

Nesta seção, duas abordagens existentes para projeto de aplicações hipermídia para ensino são apresentadas: a metodologia MAPHE (Metodologia de Apoio a Projetos de Hipertextos Educacionais) (Pimentel, 1997), na Subseção 6.7.1, e o modelo e metodologia Daphne (Definição de Aplicaçōes Hipermídia na Educação) (Kawasaki \& Fernandes, 1996), na Subseção 6.7.2. Essas metodologias utilizam a teoria de Mapas Conceituais como base para a modelagem do domínio de conhecimento. A Subseção 6.7.3 apresenta alguns comentários.

\subsubsection{MAPHE - Metodologia de Apoio a Projetos de Hipertextos Educacionais}

A metodologia MAPHE (Pimentel, 1997) propõe o desenvolvimento de hipertextos educacionais através de quatro etapas: Planejamento, Modelagem, Implementação e Teste. A etapa de planejamento visa estipular as estratégias a serem empregadas para o desenvolvimento 
do hipertexto. A etapa de modelagem visa investigar a natureza do hipertexto a ser construído. Os modelos definidos nesta etapa permitem implementar o hipertexto em uma plataforma específica, que é o objetivo da etapa de implementação. A etapa de testes objetiva identificar os erros ocorridos na etapa de implementação e verificar a validade educacional do hipertexto.

A etapa de modelagem, que é o foco desta metodologia, procura estruturar um hipertexto antes de sua implementação e consiste no desenvolvimento de quatro modelos: Modelo Orientado a Conceitos, Modelo de Páginas, Ferramentas Navegacionais e Modelo de Padrões.

O Modelo Orientado a Conceitos (MOC) (Pimentel, 1998) tem como finalidade elaborar uma estrutura coerente do conteúdo programático contido no hipertexto. O MOC pode ser entendido como uma extensão de Mapas Conceituais na qual incorpora notações mais rígidas a fim de eliminar ambigüidades; ou pode ser entendido como sendo uma modificação do Modelo Orientado a Objetos (Rumbaugh et al., 1991) cujo objetivo se volta para a estruturação e sistematização de conceitos.

No Modelo de Páginas, o conteúdo é mapeado para as páginas do hiperdocumento, utilizando o Modelo Orientado a Conceitos como guia para o desenvolvimento deste modelo. A navegação de uma página para outra também é definida no Modelo de Páginas. O Modelo de Padrões visa definir a interface-gráfica com o usuário cuidando de aspectos envolvidos na apresentação das páginas. As Ferramentas Navegacionais acrescentam outras formas de navegação, como índice, visita-guiada, mapas etc.

\subsubsection{Daphne - Definição de Aplicações Hipermídia na Educação}

Daphne (Kawasaki \& Fernandes, 1996) é um modelo criado para desenvolver cursos hipermídia baseado no HDM (Hypertext Design Model), Mapas Conceituais e na técnica de Mapeamento de Informações. Esse modelo é composto por três camadas: estrutura de acesso programado (EAP), hiperbase e estrutura de acesso direto (EAD).

A técnica de Mapeamento de Informaçōes (Horn apud Santibañez \& Fernandes, I998) consiste em dividir a informação em pedaços mais detalhados (blocos) para obter uma compreensão mais global do assunto (mapas). Os blocos de informação representam a menor porção de informação que pode ser recuperada individualmente. Quando esses blocos são organizados em estruturas maiores, são denominados mapas de informação.

$\mathrm{Na}$ camada EAP encontram-se os mecanismos que permitem selecionar e ordenar as informações para o aprendiz, de acordo com os objetivos do curso. A camada hiperbase contém 
as informações do curso, organizadas de acordo com a combinação de mapas conceituais, HDM e mapeamento de informações. A EAD permite localizar diretamente um determinado bloco de informação.

A metodologia de desenvol vimento de um curso hipermídia segundo o modelo Daphne tem as seguintes etapas (Santibañez \& Fernandes, 1998):

1. Descrição do curso

2. Elaboração do mapa conceitual geral do curso

3. Instanciação das entidades da hiperbase

4. Elaboração do esquema HDM

5. Elaboração da tabela tipos de mapas de informação versus tipos de blocos

6. Elaboração da tabela de perspectivas versus tipos de blocos

7. Elaboração dos storyboards

8. Detalhamento das Entidades Hiperbase

a) Elaboração dos mapas conceituais detalhados de cada entidade

b) Linearização dos tópicos

c) Determinação dos mapas de informação de cada tópico

d) Especificação do conteúdo dos mapas de informação

e) Elaboração do conteúdo dos blocos da entidade Bibliografia

9. Projeto das EADs

10. Projeto das EAPs

a) Projeto dos Roteiros

b) Projeto das Avaliações

\subsubsection{Comentários}

O modelo conceitual do MAPHE estende os Mapas Conceituais com relacionamentos do modelo orientado a objetos, com a finalidade de eliminar ambiguiidades. Geralmente, os autores não dominam essas abstraçōes, o que pode trazer dificuldades para descrever o domínio de conhecimento. O EHDM oferece um modelo com primitivas de relacionamentos orientadas ao ensino, que permite representar o domínio de conhecimento e também algumas op̧̧⿸es didáticas (estratégias). 
A metodologia Daphne combina Mapas Conceituais, HDM e Mapeamento de Informação para organizar as informações de um curso, exigindo que o autor domine essas técnicas e as relações entre elas.

O MAPHE propõe um mapeamento do Modelo Orientado a Conceitos para o Modelo de Páginas. Uma página no MAPHE corresponde a um nó hipermídia. O EHDM define o conteúdo de um nó através de um conjunto de atributos, também mapeados de elementos conceituais, que permitem representar as informações essenciais (atributos do tipo núcleo) e complementares (atributos do tipo satélite). Portanto, um nó no EHDM pode corresponder a várias páginas. Isso permite uma maior flexibilidade no projeto de aplicações cuja principal estratégia pedagógica $\varepsilon$ a exploração de material. Os Mapas de Informação utilizados pela metodologia Daphne possuem função semelhante, pois permitem estabelecer mais de um mapa de informação (cada um com vários blocos) para uma entidade instanciada (tópico) a partir do mapa conceitual.

\subsection{Considerações Finais}

O Método para Projeto de Hiperdocumentos para Ensino, ou EHDM (Educational Hyperdocuments Design Method), tem como principal objetivo auxiliar o projeto de hiperdocumentos educacionais. A característica principal do EHDM é a utilização de um modelo para descrever o domínio de conhecimento do hiperdocumento baseado no Modelo de Michener, na técnica de Mapas Conceituais e nos principais métodos genéricos para projeto de aplicações hipermídia encontrados na literatura.

No início deste capítulo foram discutidas as bases em que o EHDM é definido. As fases do método foram apresentadas em seguida. Uma comparação com os demais métodos do Capítulo 3 e os trabalhos relacionados concluíram este capítulo. No próximo capítulo, é apresentada a ferramenta desenvolvida para o SASHE baseada no EHDM. 


\section{Capítulo 7}

\section{EHDT - Educational Hyperdocuments Development Tool}

\subsection{Considerações Iniciais}

Durante a autoria de hiperdocumentos no SASHE (Capitulo 4), o autor encontra várias dificuldades devido à utilização direta dos conceitos do MCA (Seção 4.2). Essas dificuldades motivaram a idéia de incluir uma ferramenta de modelagem no processo de autoria de hiperdocumentos do SASHE.

Este capítulo apresenta o protótipo da Ferramenta para Desenvolvimento de Hiperdocumentos para Ensino, ou EHDT (Educational Hyperdocuments Development Tool), desenvolvido como uma ferramenta de suporte automatizado integrada ao SASHE, e que proporciona um ambiente de modelagem para auxiliar a autoria de hiperdocumentos para ensino neste sistema. O EHDM (Capítulo 6) fornece a base metodológica para o EHDT.

A Seção 7.2 apresenta os requisitos definidos como base para a implementação do protótipo do EHDT. A Seção 7.3 apresenta a arquitetura de módulos do EHDT. As Seções 7.4, 7.5 e 7.6 descrevem os módulos e discutem a forma como procuram atingir, totalmente ou parcialmente, os requisitos definidos. Um exemplo da utilização do EHDT no desenvolvimento de um hiperdocumento para'o SASHE é apresentado na Seção 7.7.

\subsection{Requisitos}

O EHDT tem como principal objetivo auxiliar o desenvolvimento de hiperdocumentos para ensino no SASHE através do suporte automatizado para as etapas propostas pelo EHDM. Os requisitos identificados a partir das principais dificuldades encontradas durante o processo de autoria do SASHE sāo os seguintes:

- Auxiliar a organização da hierarquia de contextos;

- Auxiliar a classificação das informações (função didática); 
- Fomecer abstrações que evitem a tomada de decisões de baixo nível;

- Auxiliar a definição de roteiros.

Os requisitos para ambientes de desenvolvimento de aplicações hipermídia, identificados por Nanard e Nanard (1995), também podem ser considerados dentro do contexto do desenvolvimento do EHDT. Esses requisitos foram brevemente discutidos na Seção 2.3 e são os seguintes:

- Suportar laços de realimentação ("feedback loops") rápidos entre as fases de projeto e prototipação, para facilitar a avaliação e alteração;

- Fornecer recursos para generalizar e instanciar modelos, para facilitar a utilização de abordagens bottom-up e top-down;

- Proporcionar replicação (cloning) ao nível de instância, para a geração de material.

Os requisitos definidos nesta seção foram considerados como diretrizes para a implementação do protótipo do EHDT.

\subsection{Arquitetura do EHDT}

A arquitetura do EHDT é apresentada na Figura 7.1. Os módulos de Edição Gráfica de Diagramas, Geração de Modelos e Geração de Protótipos utilizam o Banco de Dados para armazenar e recuperar as especificações dos modelos de acordo com as operações solicitadas pelo autor através do módulo de Interface com o Usuário.

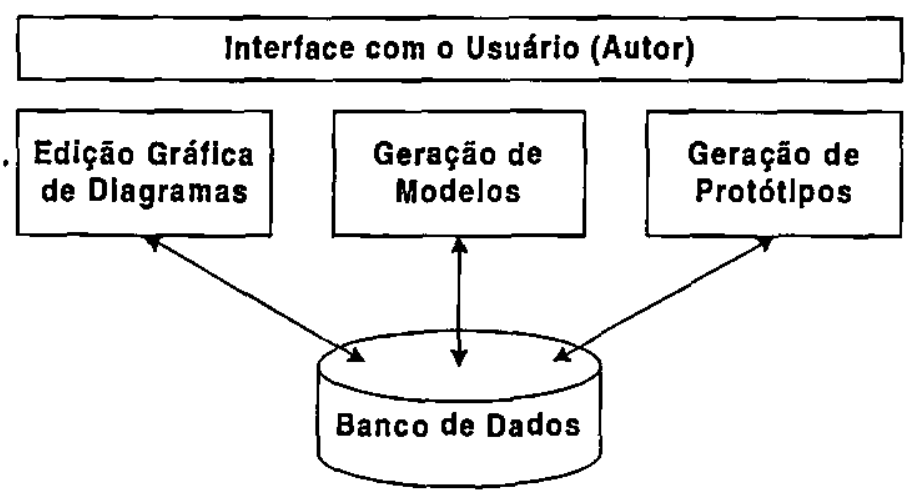

Figura 7.1: Arquitetura do EHDT

O protótipo do EHDT foi desenvolvido utilizando-se a linguagem de programação Borland Delphi. Essa linguagem também foi utilizada no desenvolvimento do SASHE. As próximas seções apresentam as características dos módulos do protótipo. O módulo Interface com o Usuário é apresentado no contexto dos demais módulos. 


\subsection{Edição Gráfica de Diagramas}

O módulo de Edição Gráfica de Diagramas permite a edição dos diagramas conceitual e navegacional ${ }^{5}$, que representam respectivamente, um modelo conceitual hierárquico e um modelo navegacional de contextos do EHDM. Durante a edição, a consistência e validade dos modelos são verificadas, proporcionando ao autor um certo grau de esclarecimento sobre a representação e ajudando-o a eliminar erros.

Os dois diagramas são interconectados através do mapeamento dos elementos conceituais (conceitos, exemplos e resultados) em elementos navegacionais (informações de no), permitindo manter o foco ao alternar de um diagrama para outro. Por exemplo, ao solicitar a edição do diagrama navegacional, o EHDT sempre procura apresentar a parte do diagrama navegacional correspondente à parte do diagrama conceitual que estiver sendo editada no momento. Esse "mecanismo de chaveamento" facilita laços de realimentação rápidos entre a fase de modelagem conceitual hierárquica e a fase de projeto navegacional de contextos. Díaz e Isakowitz (1995) apresentam uma abordagem semelhante no projeto do RMCase, um ambiente para apoiar o desenvolvimento de aplicações hipermídia.

O módulo de Interface com o Usuário é responsável pela apresentação dos diagramas ao autor. Esse modulo procura minimizar o espaço ocupado pelo grafo que representa um diagrama. Para redefinir as posições dos nós (do grafo) quando é necessário mais espaço, o algoritmo determina as novas posições utilizando o conceito de escopo de nós, sem recálculo (Vilela, 1994; Kommers et al., 1998). O editor gráfico do Tootema (Hasegawa \& Nunes, 1995), uma ferramenta para desenvolver sistemas tutores inteligentes para Matemática, também utiliza esse algoritmo, mas com a funcionalidade adicional de minimizar os cruzamentos das arestas do grafo. A Figura 7.2 mostra a interface do EHDT apresentando parte do diagrama conceitual do exemplo de modelagem para a teoria "Movimentos Retilíneos" apresentado na Figura 6.16.

O menu "Editar" possui as op̧̧ões para editar os diagramas: inserir, alterar e excluir. Um clique duplo em um elemento conceitual (conceito ou resultado) permite a expansão deste elemento, ou seja, permite especificar o diagrama conceitual relativo ao elemento expandido. Um elemento expandido aparece no diagrama com o seu nome sublinhado.

\footnotetext{
${ }^{5}$ Nomenciatura utilizada pela interface do EHDT para os modelos do EHDM.
} 


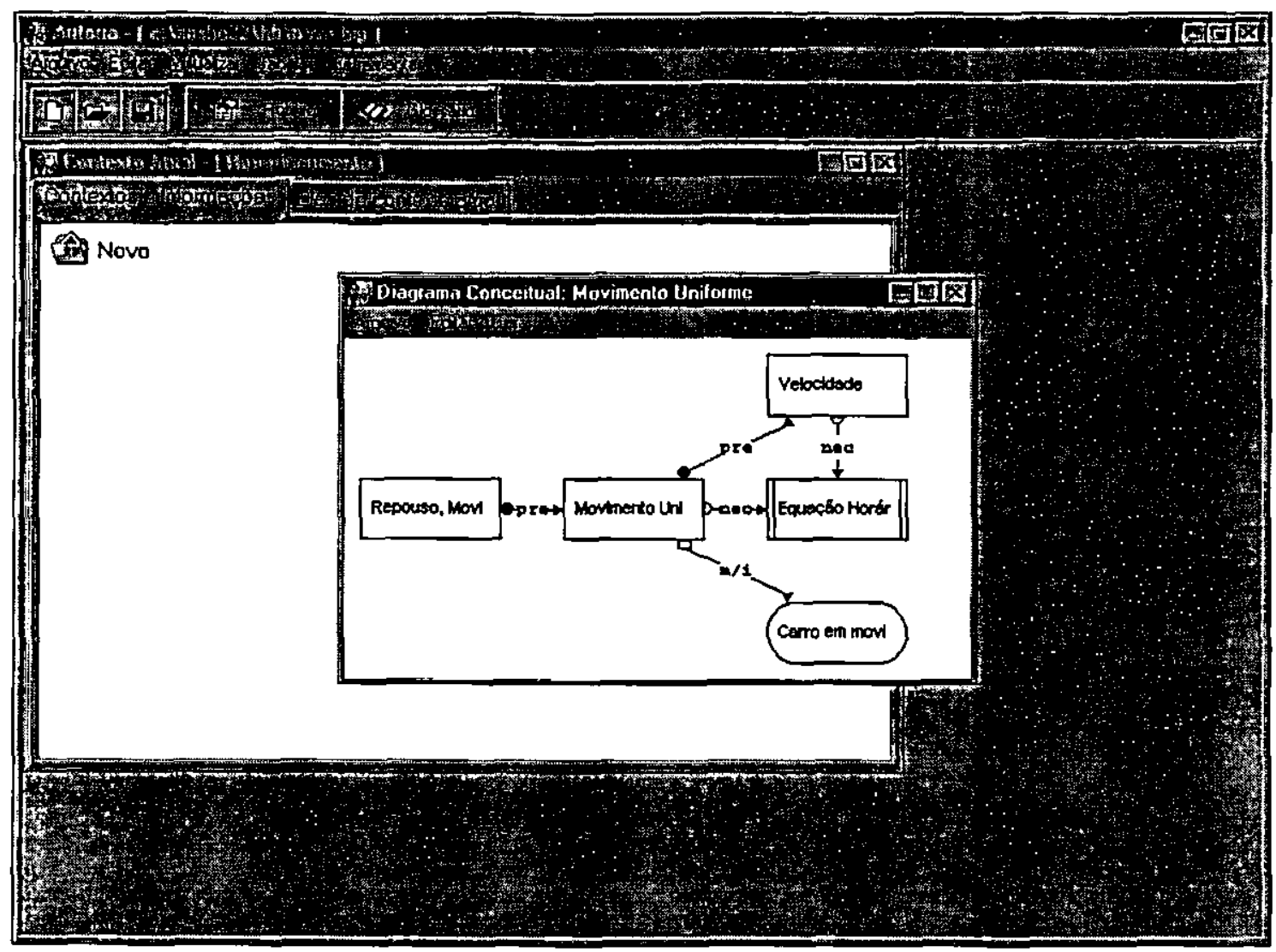

Figura 7.2: Exemplo de Diagrama Conceitual

A Figura 7.3 mostra a interface utilizada para inserir um elemento (conceito, exemplo, resultado ou relacionamento) no diagrama conceitual. Caso a opção escolhida seja a de inserir um relacionamento, a interface solicita a origem, o destino e o tipo do relacionamento.

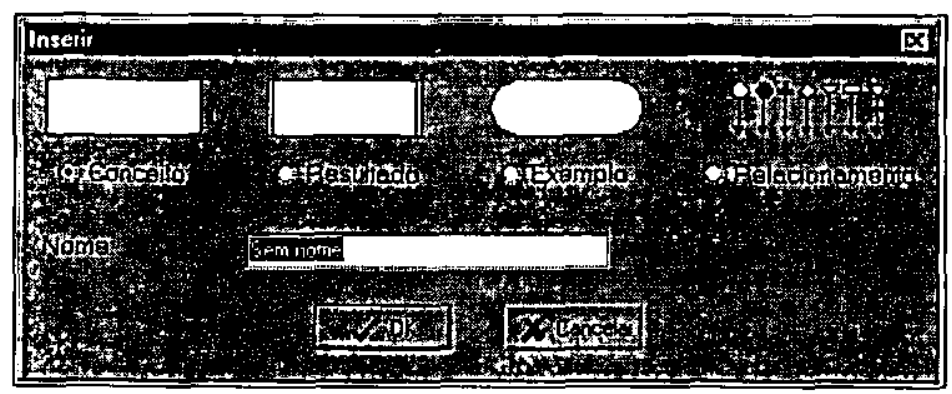

Figura 7.3: Interface para inserir um elemento conceitual

A edição do diagrama navegacional é semelhante à do diagrama conceitual. O "chaveamento" entre os diagramas é solicitado através das opções "Diagrama Conceitual" e "Diagrama Navegacional" do menu "Editar". A Figura 7.4 mostra a interface do EHDT apresentando um exemplo de diagrama navegacional. 


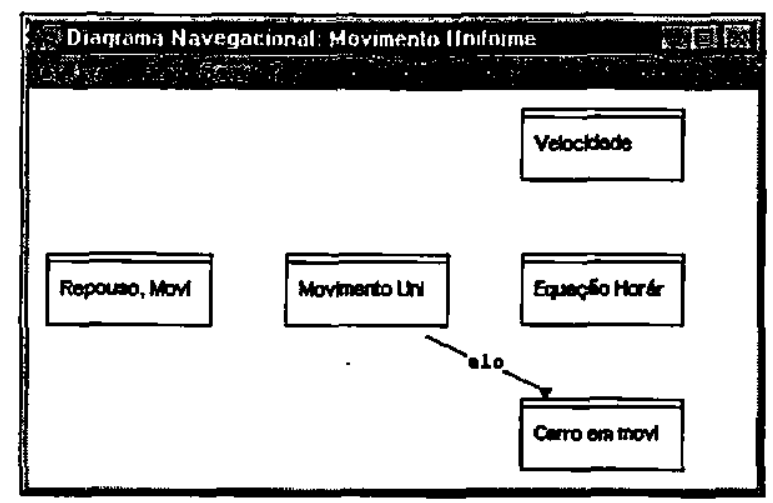

Figura 7.4: Exemplo de Diagrama Navegacional

A Figura 7.5 mostra a interface utilizada para inserir um elemento (contexto, nó ou elo) no diagrama conceitual. Caso a opção for contexto ou nó, pode-se especificar o mapeamento através da caixa de seleção "Derivado de". Caso a opção escolhida seja a de inserir um elo, a interface solicita a origem (nó) e o destino (nó ou contexto) do elo. A âncora relativa ao elo é inserida automaticamente no nó origem, facilitando a operação.

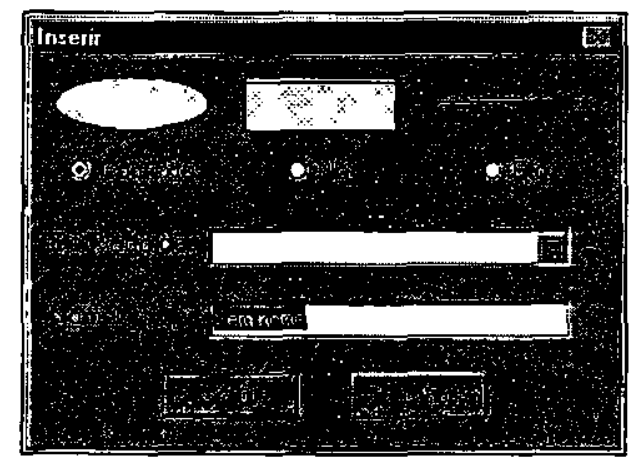

Figura 7.5: Interface para inserir um elemento navegacional

Essa característica de não exigir o tratamento das âncoras nesse nível de projeto facilita a operação de projetar, elos porque elimina a preocupação de inserir âncoras nos arquivos de conteúdo associados às informações do nó. Essas âncoras inseridas automaticamente são tratadas pelo módulo de Geração de Protótipos. No SASHE, é necessário criar uma âncora no arquivo de conteúdo de um nó antes de inserir um elo.

Um ćlique duplo em um contexto permite a èxpansão do contexto, enquanto que a mesma operação em um nó permite a especificação das informações correspondentes ao nó (a expansão do no). A Figura 7.6 mostra a interface para especificar as informações (atributos EHDM) pertencentes a um nó. O exemplo mostra as informações do nó "Movimento Uniforme". As informações essenciais (atributos do tipo núcleo) são indicadas através de uma caixa selecionada à esquerda do seu nome. As demais informações são chamadas de complementares (atributos do tipo satélite). Essa interface também permite adicionar informações, editar as informações 
existentes (classificação e apresentação) e alterar a especificação das âncoras referentes aos elos que partem do nó. O exemplo apresentado na Seção 7.7 detalha essas operações.

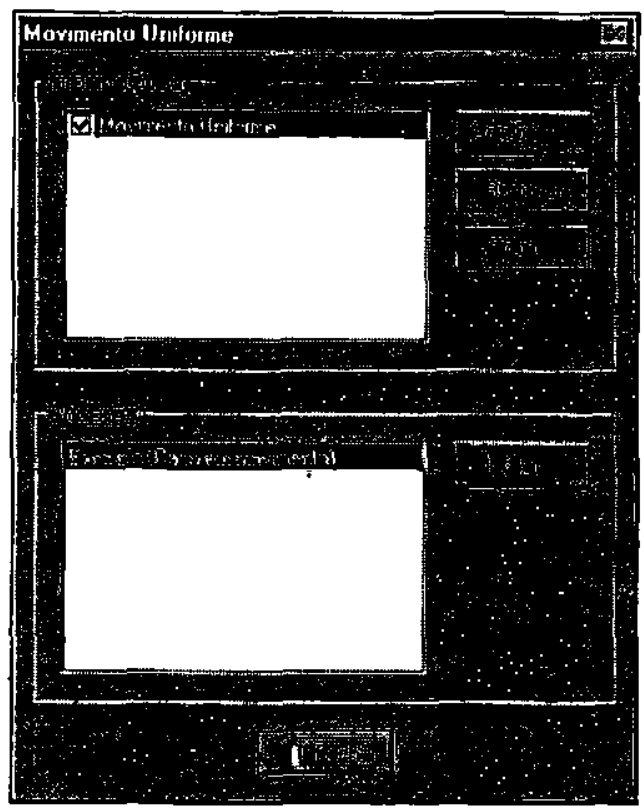

Figura 7.6: Interface para especificar as informaçōes

As informações essenciais de um nó são aquelas que serão apresentadas quando um elo para o nó é acionado. Esse recurso é particularmente interessante para apresentar, ao mesmo tempo, duas informaçб̄es com conteúdo representado por mídias diferentes. Por exemplo, para apresentar uma informação através de uma ilustração e uma narração, deve-se especificar duas informaçōes essenciais: uma do tipo "Imagem" e a outra do tipo "Áudio". O módulo de Geração de Protótipos traduz essa abstração para o MCA, criando um nó de contexto com dois nós terminais e ancorando o destino dos elos para essa informaçăo nesse nó de contexto. Entretanto, esse comportamento não é obtido para as informações complementares. Isso pode ser resolvido permitindo especificar combinações de tipos para uma mesma informação e tratar esse aspecto no módulo de Geração de Protótipos.

\subsection{Geração de Modelos}

O módulo de Geração de Modelos proporciona um mapeamento automatizado do diagrama conceitual para o navegacional, ou seja, do modelo conceitual hierárquico para o modelo navegacional de contextos. Isso facilita laços de alimentação rápidos porque permite avançar rapidamente da fase de modelagem conceitual hierárquica para a fase de projeto navegacional de contextos. 
Vários diagramas navegacionais podem ser gerados a partir de um único diagrama conceitual. Essa característica permite o reuso de modelos, conforme discutido na Seção 6.4. Além disso, a possibilidade de realizar gerações parciais facilita a replicação de estruturas para a geração de material.

A Figura 7.7 mostra a interface para gerar diagramas navegacionais (menu "Gerar", opção "Diagrama Navegacional”). A caixa "Gerar para" mostra o elemento selecionado para o qual será gerado um diagrama navegacional. O contexto destino do diagrama navegacional gerado pode ser selecionado através da caixa de seleção "No contexto". Quando não é selecionado um contexto destino, o algoritmo cria um contexto para o diagrama navegacional no "nível zero".

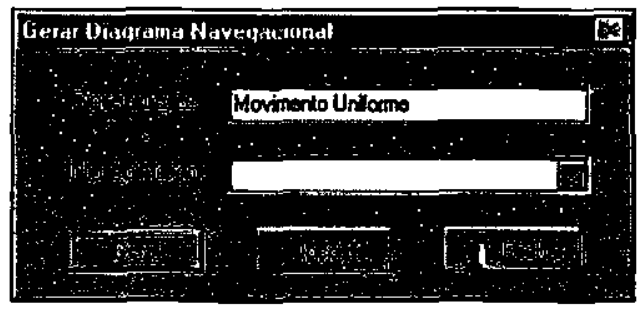

Figura 7.7: Interface para gerar diagrama navegacional

O algoritmo de mapeamento adota o padrão um-para-um, ou seja, cada entidade conceitual (conceito, exemplo, resultado e relacionamento) é mapeada em uma entidade navegacional (contexto, nó e elo). Esse mapeamento possui algumas opçőes que podem ser selecionadas através da interface da Figura 7.8 (menu “Gerar”, opção “Opções”).

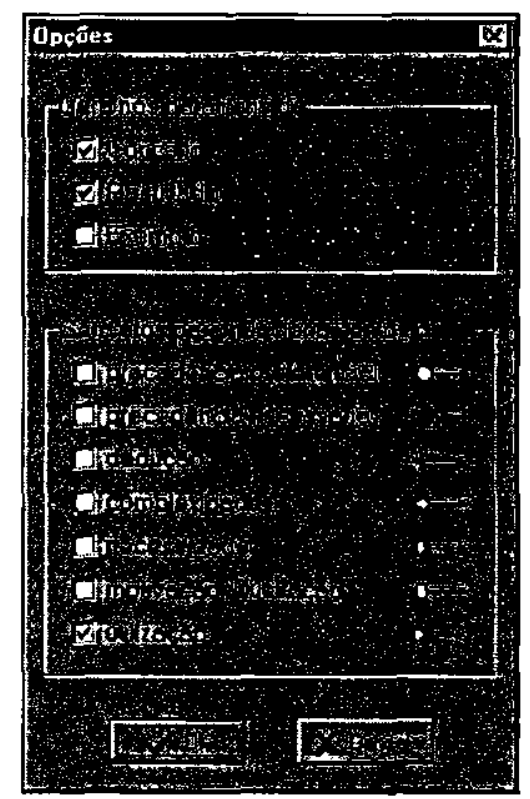

Figura 7.8: Interface para a seleção de opções de mapeamento

No exemplo da Fitgura 7.8, a opção "Exemplo" não está selecionada, stgnificando que os exemplos serāo mapeados para informaçōes nos nós correspondentes aos conceitos ou resultados 
aos quais eles estão relacionados. A seleção dessa opção é recomendada quando os exemplos de um diagrama conceitual são específicos para os conceitos e resultados relacionados a eles. Nesse caso, os exemplos são considerados como informação complementar (atributo do tipo satélite do EHDM) das informações essenciais relativas aos conceitos e resultados. Se essa opção for selecionada, os exemplos serão mapeados para nós no diagrama navegacional.

As opções referentes aos relacionamentos indicam quais relacionamentos serão mapeados para elos. No exemplo da Figura 7.8, apenas o relacionamento "utilização" será mapeado para um elo no diagrama navegacional. A justificativa para as opções dessa natureza reside no fato de que, no EHDM, todos os relacionamentos conceituais não correspondem necessariamente a ligações navegacionais.

O mapeamento automatizado do diagrama conceitual para o diagrama navegacional auxilia a organização da hierarquia de contextos e a classificação das informações. $O$ algoritmo gera um contexto para cada elemento conceitual expandido, mapeando a estrutura hierárquica conceitual para os contextos navegacionais. Essa estrutura de contextos pode não ser a estrutura ideal, mas ela pode ser considerada um ponto de partida para os autores. Os recursos de reestruturação fornecidos pelo módulo de Edição do SASHE (Capítulo 4) podem ser utilizados para adequar essa estrutura às necessidades dos autores. Além disso, nada impede que esses recursos de reestruturação sejam implementados neste protótipo.

Quanto ao auxílio à classificação das informaçðes, o algoritmo classifica automaticamente uma informação baseando-se nas primitivas dos elementos conceituais mapeados. Por exemplo, as informações mapeadas a partir de um conceito ou resultado são classificadas quanto à função didática "definição" e as mapeadas de um exemplo são classificadas como "exemplo". Quando um nó é inserido no diagrama navegacional ou uma informação é adicionada a um nó, a Interface com o Usuário também utiliza esse recurso se o mapeamento for indicado.

Os roteiros podem ser gerados a partir do diagrama conceitual. A sequiência dos elementos do roteiro consiste dos elementos navegacionais correspondentes aos conceituais resultantes de uma ordenação topológica do grafo que representa o diagrama conceitual.

A Figura 7.9 mostra a interface para gerar roteiro (menu "Gerar", opção "Roteiro"). O algoritmo gera um roteiro para o conceito ou resultado selecionado (visualizado na caixa "Gerar para"). No caso de um conceito, o algoritmo gera um roteiro seguindo uma ordenação topológica do diagrama conceitual da expansão do conceito. Para um resultado, o algoritmo verifica também os conceitos e resultados considerados necessários para a sua compreensão (obtidos através dos relacionamentos "necessidade" e "dedução") e inclui roteiros para esses "prérequisitos" no início do roteiro relativo ao resultado selecionado. 


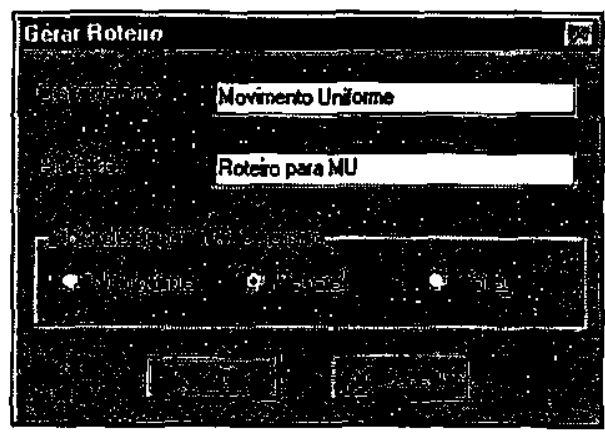

Figura 7.9: Interface para gerar roteiro

A interface da Figura 7.9 também permite selecionar três opções de liberdade de navegação (Seção 4.5). A primeira opção ("Nenhuma") permite que o aprendiz veja somente as informações (essenciais e complementares) pertencentes a cada elemento do roteiro. A opção "Parcial" estabelece o contexto a que pertence o elemento do roteiro como a liberdade de navegação para este elemento. Portanto, essa opção permite que o aprendiz veja as informações de todo o contexto a que pertence o elemento. A última opção ("Total") permite que o aprendiz veja todas as informações do hiperdocumento a partir de qualquer elemento do roteiro.

A geração automática de roteiros com opções de liberdade de navegação proporciona um auxílio para os autores, pois evita a especificação da liberdade de navegação para cada elemento e proporciona um padrão desta para todo o roteiro. Novamente, o resultado pode não ser o ideal ou o esperado. No entanto, o roteiro gerado pode ser editado posteriormente através de uma interface específica para esta tarefa, permitindo ajustes mais finos. A Figura 7.10 mostra essa interface. Um roteiro é apresentado como uma sequêencia de nomes correspondente aos seus componentes. $O$ contexto que define a liberdade de navegação é apresentado entre parênteses.

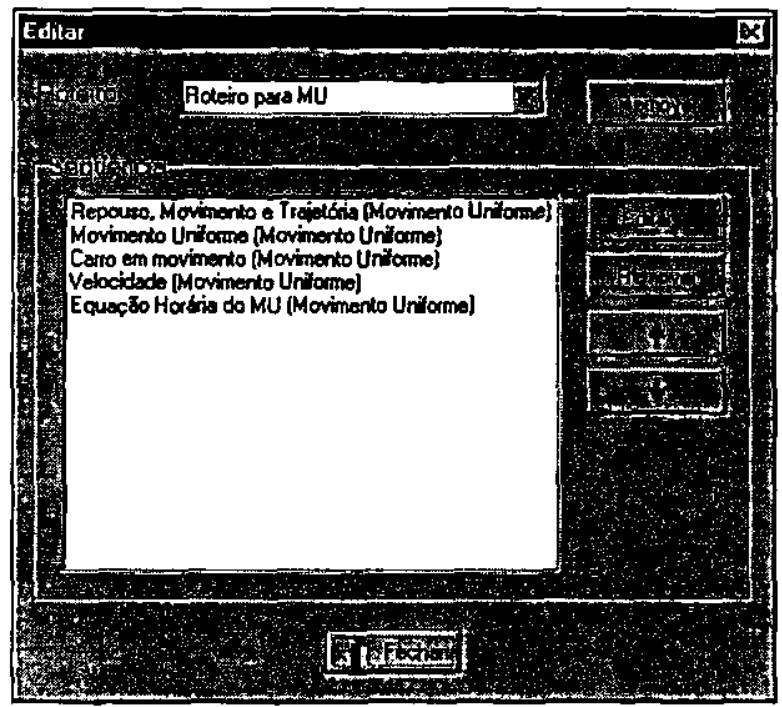

Figura 7.10: Interface para editar roleiros 
Um roteiro também pode ser obtido através da seleção dos seus elementos, em uma abordagem "ad hoc". Os nós são escolhidos através do recurso usual de seleção múltipla e adicionados (menu "Gerar", opção "Roteiro") no final do último roteiro editado. Nessa abordagem, o módulo de Interface com o Usuário efetua uma consistência baseada na especificação conceitual, seguindo os mesmos padrões do algoritmo de geração automática de roteiros.

\subsection{Geração de Protótipos}

O módulo de Geração de Protótipos permite a tradução da especificação do diagrama navegacional (modelo navegacional de contextos) para um hiperdocumento segundo o Modelo de Contextos Aninhados (MCA). O diagrama navegacional pode ser especificado através dos recursos de edição ou pode ser gerado automaticamente a partir do diagrama conceitual. $\mathrm{O}$ módulo contém mecanismos de geração de material com o objetivo de produzir "esqueletos" de conteúdo para que o hiperdocumento protótipo possa ser navegado.

A possibilidade de realizar várias gerações parciais com op̧̧ões idênticas ou diferentes para um mesmo diagrama navegacional facilita a geração de um protótipo maior ou com estruturas opcionais. Esse recurso é útil para que os autores possam experimentar algumas estruturas antes de abstrair a melhor. Entretanto, não existe um mecanismo de abstração automatizado. Segundo Nanard e Nanard (1995), esse mecanismo é difícil de ser conseguido sem a imposição de restriçōes.

O mecanismo de prototipação facilita os laços de realimentação rápidos porque fornece feedback ao autor sem que seja necessário completar todas as etapas de desenvolvimento. De um modo geral, a prototipação de hiperdocumentos facilita os movimentos de ida e volta entre as camadas abstrata e concreta de uma aplicação, permitindo ao autor alternar entre as abordagens bottom-up e top-down (Nanard \& Nanard, 1995). 


\subsection{Exemplo de utilização do EHDT}

Esta seção apresenta o exemplo utilizado para ilustrar e avaliar o EHDT no desenvolvimento de hiperdocumentos para o SASHE. Nesse contexto, é recomendado empregar a seguinte metodologia de desenvolvimento para obter um hiperdocumento:

1. Definir o Escopo do Hiperdocumento;

2. Elaborar um Diagrama Conceitual;

3. Elaborar um Diagrama Navegacional;

4. Gerar e Testar um Protótipo do Hiperdocumento;

5. Avaliar o Protótipo;

6. Repetir as etapas 2, 3,4 e 5 até obter o Hiperdocumento Final.

A primeira etapa visa limitar o domínio de conhecimento que será abordado pelo hiperdocumento. As etapas 2, 3 e 4 correspondem às fases do processo definido pelo EHDM (Figura 6.2): Modelagem Conceitual Hierárquica, Projeto Navegacional de Contextos, Construção e Teste. A etapa 5 decide se o protótipo gerado pode ser considerado ou não o hiperdocumento final. $O$ enfoque para a etapa 6 é o de refinamento do projeto, como sugerido na metodologia apresentada na Seção 6.2. As subseções seguintes descrevem essas etapas de desenvolvimento para um exemplo.

\subsubsection{Definição do Escopo do Hiperdocumento}

Inicialmente, é necessário definir o escopo do hiperdocumento, ou seja, estabelecer claramente os limites do domínio de conhecimento tratado pelo hiperdocumento. Essa atividade fornece um ponto de partida para as demais etapas da metodologia e facilita a seleção dos conceitos, resultados e exemplos relevantes utilizados para representar o domínio de conhecimento desejado.

O hiperdocumento a ser desenvolvido neste estudo de caso pretende auxiliar um aprendiz no estudo dos Movimentos, que é uma das teorias da Física. A parte da Física que estuda essa teoria E a Mecânica. As subseçðes seguintes descrevem as demais etapas no contexto do desenvolvimento desse hiperdocumento. 


\subsubsection{Elaboração de um Diagrama Conceitual}

A etapa de elaboração de um diagrama conceitual consiste em representar o domínio de conhecimento através de um diagrama que corresponde a um modelo conceitual hierárquico do EHDM. O conceito "Movimentos" (Figura 7.11) é o ponto de partida da modelagem, porque abrange toda a teoria delimitada na seção anterior. Esse conceito é expandido em outros conceitos segundo o princípio da diferenciação progressiva (Seção 5.3). O critério utilizado neste exemplo classifica os movimentos em unidimensionais e bidimensionais.

O diagrama resultante da modelagem segundo esse critério é mostrado na Figura 7.12. Os conceitos relativos aos movimentos identificados são os seguintes: os movimentos unidimensionais denominados de "Movimentos Retilíneos" e os movimentos bidimensionais denominados de "Movimentos de Projéteis" e "Movimento Circular". "Conceitos Básicos" abrange os conceitos necessários para compreender os movimentos e, portanto, foi considerado como pertencente à teoria. Os conceitos foram relacionados através do relacionamento de "precedência necessária" para indicar que essa sequiência de apresentação é necessária para o aprendizado.

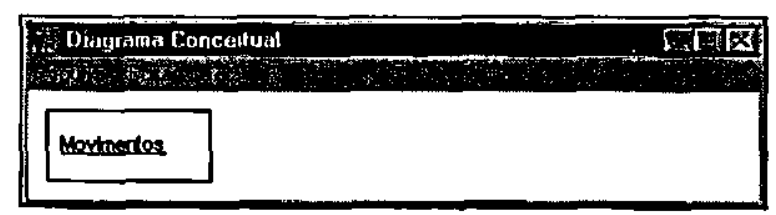

Figura 7.11: Representação do conceito "Movimentos"

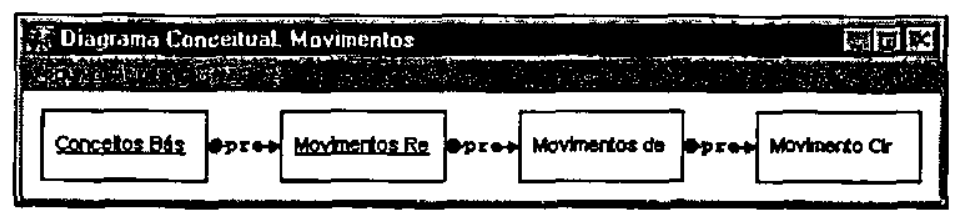

Figura 7.12: Diagrama conceitual para a expansão do conceito "Movimentos"

De forma semelhante, "Conceitos Básicos" foi expandido nos conceitos "Movimento, Trajetória e Referencial", "Tempo e Espaço", "Velocidade" e "Aceleração", conforme o diagrama mostrado na Figura 7.13. O excesso de conceitos pode ser considerado normal nesse estágio inicial de modelagem, pois os conceitos da Figura 7.12 são conceitos mais gerais, situados perto do "topo" da hierarquia, e os conceitos da Figura 7.13 representam as definições iniciais necessárias para a compreensão do restante da teoria. 


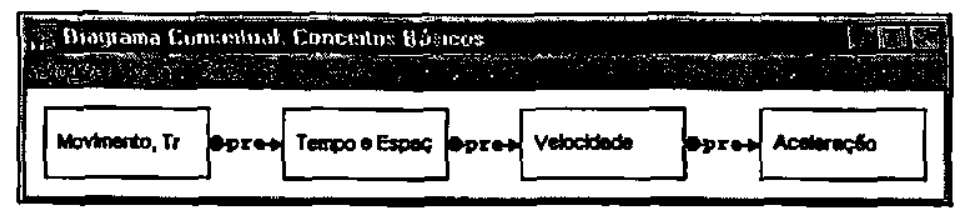

Figura 7.13: Diagrama conceitual para a expansão do conceito "Conceitos básicos"

A Figura 7.14 mostra a expansão do conceito "Movimentos Retilíneos" nos conceitos "MU: Movimento Uniforme" e "MUV: Movimento Uniformemente Variado", nos resultados "Equação horária do MU", "Equação da Velocidade e Equação Horária do MUV" e "Equação de Torricelli", e nos exemplos "Carro em movimento", "Movimento da tartaruga", "Carro freando" e "Salto de pára-quedas". Os conceitos "Movimentos de Projéteis" e "Movimento Circular" são expandidos de forma semelhante.

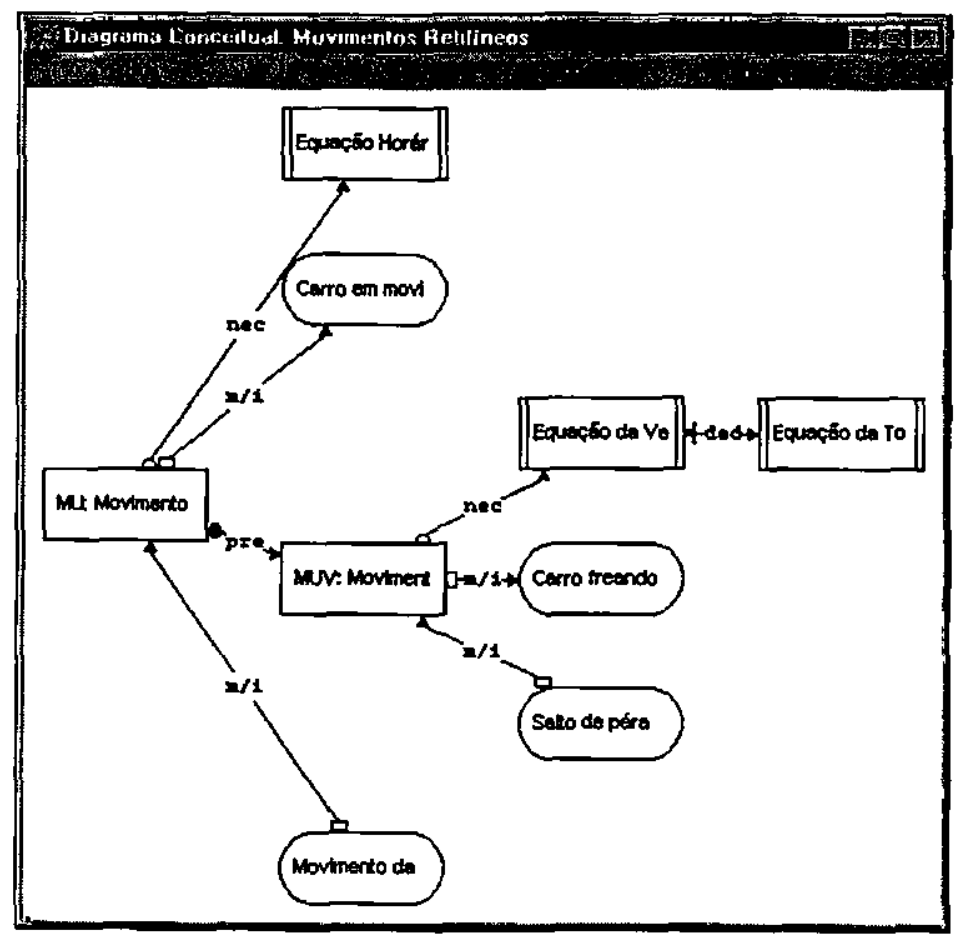

Figura 7.14: Diagrama conceitual para a expansão do conceito "Movimentos Retilíneos"

\subsubsection{Elaboração de um Diagrama Navegacional}

Nesta etapa, os elementos do modelo conceitual hierárquico representado no diagrama conceitual são mapeados para elementos navegacionais (contextos, nós e elos) de um modelo navegacional de contextos. $O$ diagrama navegacional que representa esse modelo pode ser editado ou gerado automaticamente. Neste exemplo, optou-se pela geração automática porque o objetivo é obter rapidamente um protótipo para avaliar o modelo especificado até o momento. A 
Figura 7.15 mostra as opções para essa operação. A caixa "No contexto" é utilizada para indicar o contexto destino do mapeamento. Como não foi especificado um contexto destino, o algoritmo cria um contexto para o diagrama navegacional no "nível zero".

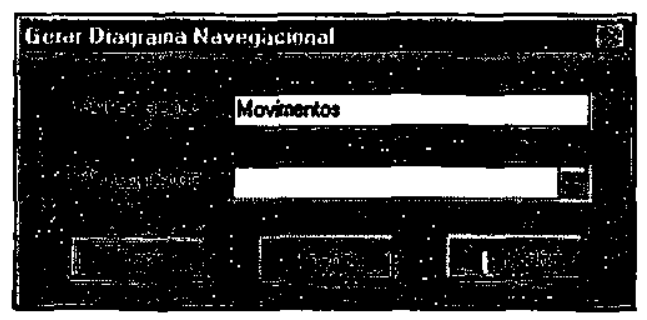

Figura 7.15: Opçōes para gerar um diagrama navegacional para o hiperdocumento

As opções de mapeamento selecionadas para gerar o diagrama navegacional são mostradas na Figura 7.16. De acordo com essas opções, cada elemento do diagrama conceitual (conceito, resultado ou exemplo) é mapeado em um nó no diagrama navegacional. Quanto aos relacionamentos do diagrama conceitual, somente os de "motivação / ilustração" e os de "utilização" são mapeados para elos no diagrama navegacional. As Figuras 7.17, 7.18 e 7.19 apresentam os diagramas navegacionais gerados para os diagramas conceituais das Figuras 7.12, 7.13, 7.14.

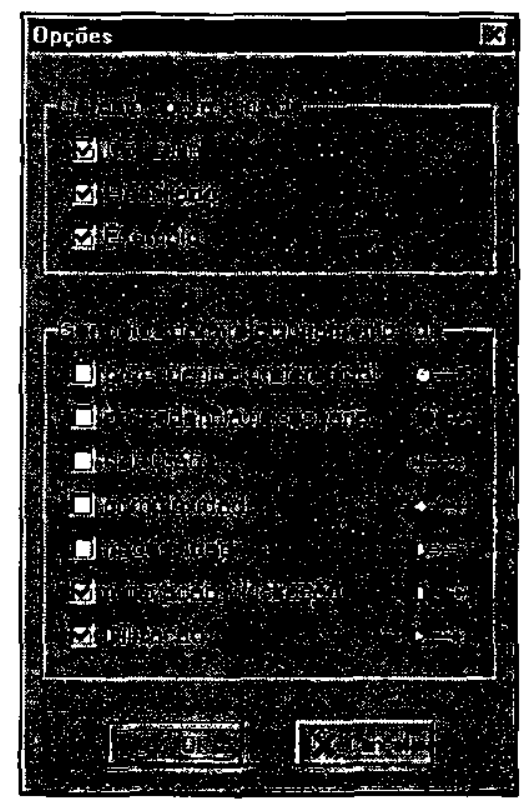

Figura 7.16: Opções selecionadas para gerar o diagrama navegacional

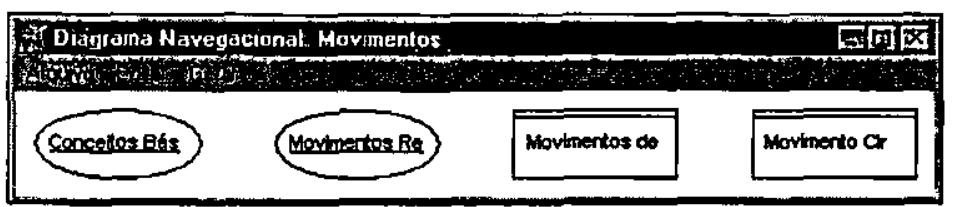

Figura 7.17: Diagrama navegacional gerado a partir do diagrama conceitual da Figura 7.12 


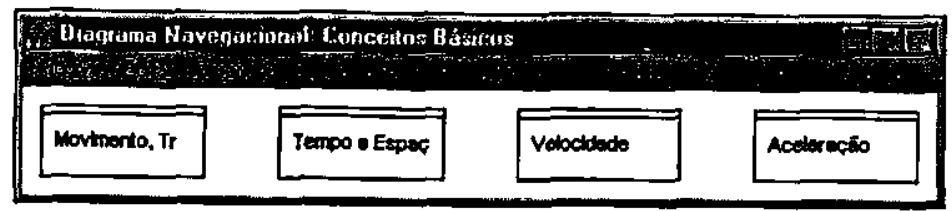

Figura 7.18: Diagrama navegacional gerado a partir do diagrama conceitual da Figura 7.13

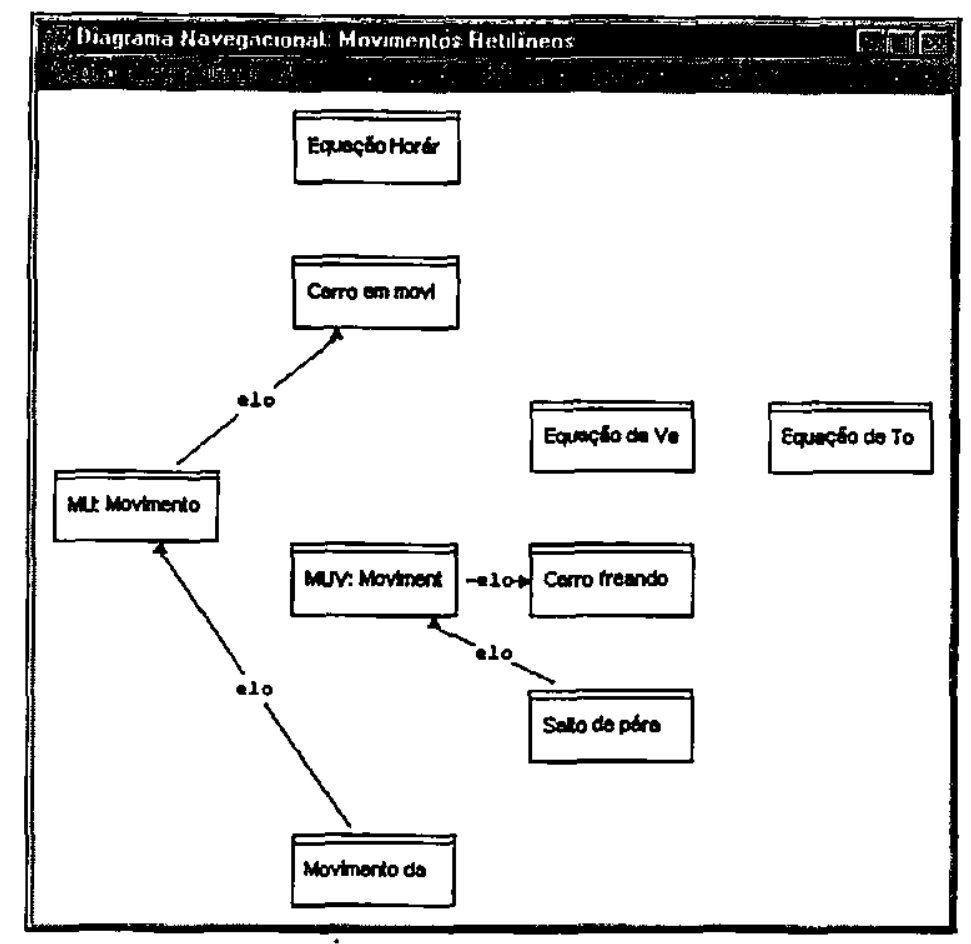

Figura 7.19: Diagrama navegacional gerado a partir do diagrama conceitual da Figura 7.14

A especificação de roteiros completa esta etapa. Os roteiros podem ser especificados através da seleção dos seus elementos ou gerados automaticamente. Novamente, preferiu-se a geração automática de roteiros porque o objetivo é obter um protótipo rapidamente. A Figura 7.20 mostra as opções para gerar um roteiro relativo ao conceito "Movimentos" (um roteiro para navegar através de todo o hiperdocumento). A liberdade de navegação escolhida é a opção "Parcial", ou seja, a partir de um elemento do roteiro o aprendiz pode atingir todas as informações contidas no contexto a que pertence este elemento.

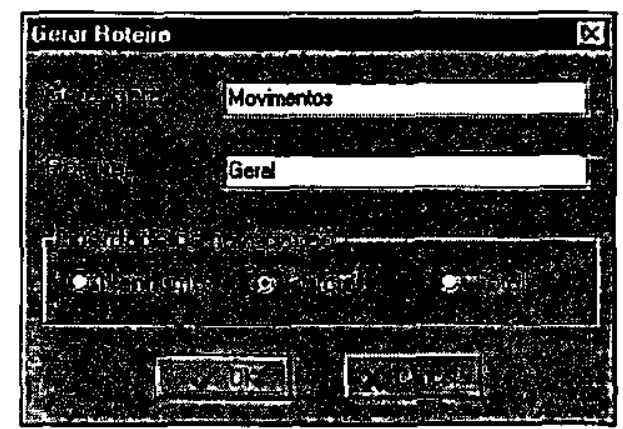

Figura 7.20: Opçōes para gerar um roteiro para o hiperdocumento 
A Figura 7.21 apresenta o roteiro resultante dessa operação como uma seqüência de nomes correspondente aos componentes do roteiro. Pode-se notar que a sequiência gerada obedece a ordem dos relacionamentos especificados no diagrama conceitual. $O$ contexto que define a liberdade de navegação é apresentado entre parênteses.

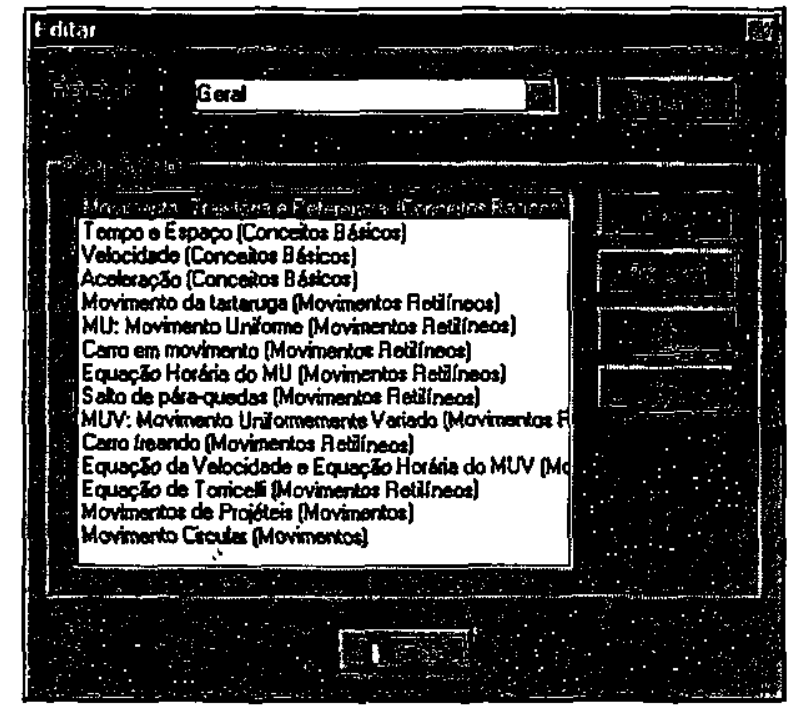

Figura 7.21: Seqüência de elementos de um roteiro

Outra tarefa que pode ser realizada nessa etapa é a edição das propriedades (classificação e apresentação) das informações inseridas pelo algoritmo de mapeamento nos nós. Além disso, outras informações podem ser adicionadas às informações existentes em um nó. A Figura 7.22 mostra exemplos de informações adicionadas utilizando a interface para a edição das informações e âncoras de um nó. No primeiro exemplo, a informação "O Movimento Retilíneo Uniforme", classificada com dificuldade "Fácil", é um texto al ternativo para a informação "MU: Movimento Uniforme", com dificuldade "Regular". Portanto, a primeira informação ("O Movimento Retilíneo Uniforme") é complementar à segunda ("MU: Movimento Uniforme").

No outro exemplo da Figura 7.22, a informação "Gráficos do MU" foi adicionada ao nó "Equação do $\mathrm{MU}$ " como essencial para a compreensão da equação horária do movimento uniforme porque a utilização de gráficos nesse contexto permite visualizar o comportamento do movimento de uma maneira fácil e rápida. Exercícios e exemplos também podem ser adicionados como informações complementares no nó "Equação do MU".

A Figura 7.23 mostra a especificação para a informação "Gráficos do MU" na interface utilizada para adicionar informações ao nó. As caixas "Palavras-Chave", "Função Didática" e "Dificuldade" correspondem à classificação da informação. A apresentação é especificada através da mídia de representação e do caminho do arquivo correspondente ao conteúdo da informação. 

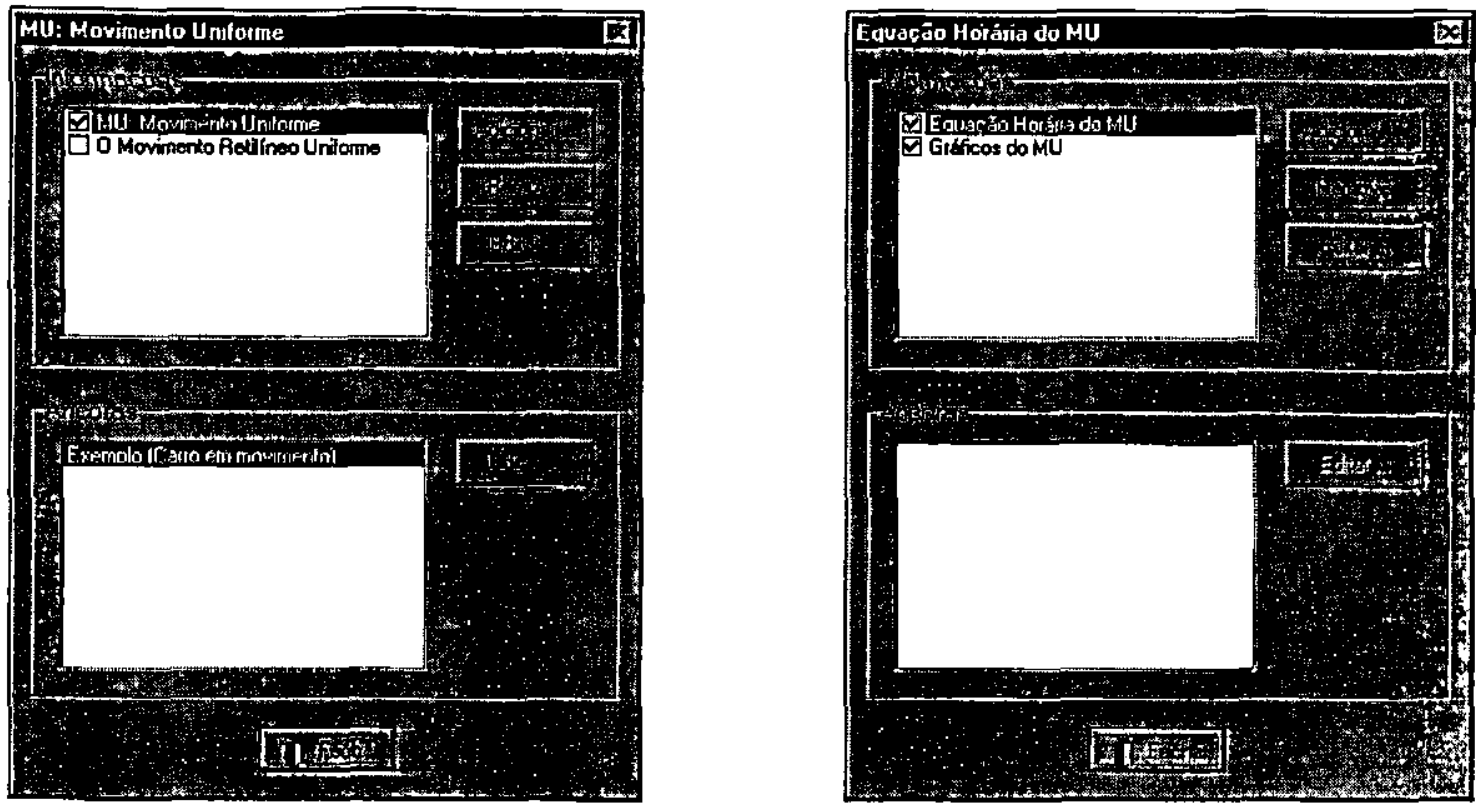

Figura 7.22: Exemplos de informações adicionadas a um nó

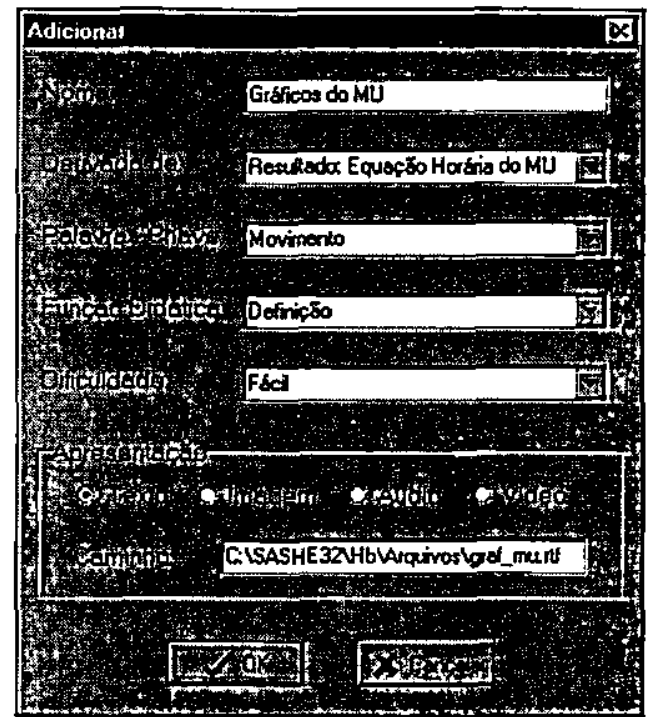

Figura 7.23: Especificação da informação "Gráficos do MU"

\subsubsection{Geração e Teste de um Protótipo}

Durante a etapa de geração de um protótipo, o diagrama navegacional é convertido para um hiperdocumento padrão do SASHE (arquivo com extensão "hip"), para a realização de testes desse protótipo. $O$ algoritmo de prototipação utiliza um mecanismo de geração de material para criar "esqueletos" (páginas com ligaçōes) com o objetivo de permitir a navegação pelo hiperdocumento e, portanto, permitir a realização de testes e avaliação. Cada "esqueleto" é 
associado a uma informação de um nó e é composto por um arquivo do tipo texto com os elos necessários para a navegação.

A Figura 7.24 ilustra a navegação por um hiperdocumento protótipo. Neste exemplo, as janelas denominadas de "MU: Movimento Uniforme" e "Carro em movimento" são os "esqueletos" gerados para estas informações. A janela "Carro em movimento" foi apresentada quando o elo representado pela âncora "Exemplo" na janela "MU: Movimento Uniforme" foi acionado.

Toda alteração realizada nos arquivos correspondentes ao conteúdo do hiperdocumento é preservada. O algoritmo de geração do protótipo verifica as âncoras existentes no arquivo associado à informação e insere apenas as que ainda não pertencem ao arquivo. Isso permite que o hiperdocumento seja desenvolvido aos poucos, evoluindo para o resultado final.

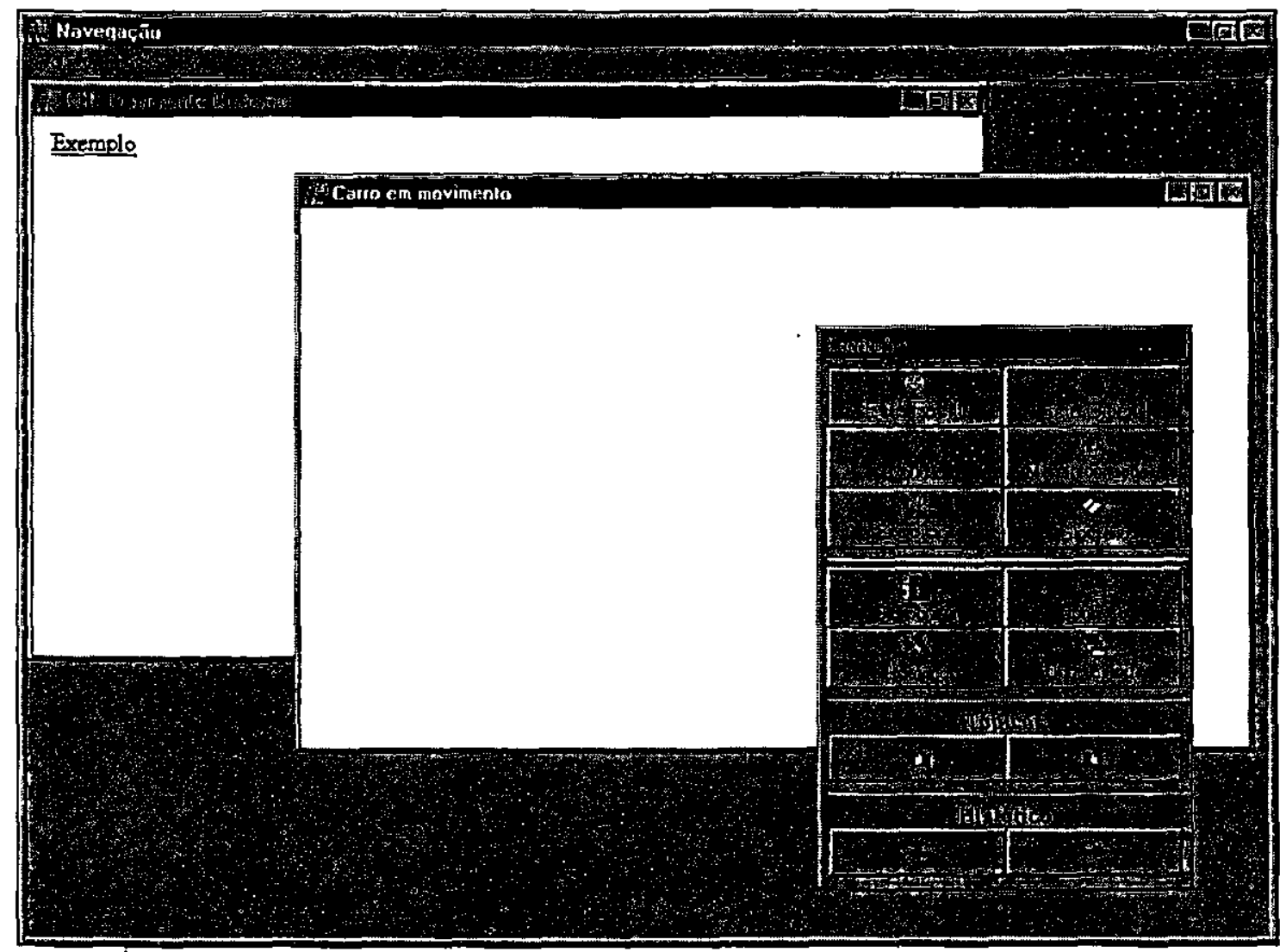

Figura 7.24: Exemplo de navegação pelos "esqueletos" do hiperdocumento protótipo

\subsubsection{Avaliação do Protótipo}

A etapa de avaliação visa analisar o hiperdocumento protótipo sob o ponto de vista educacional. O resultado dessa análise é a decisão de realizar ou não uma iteração no processo de 
desenvolvimento, ou seja, repetir as etapas 2, 3,4 e 5 até obter um resultado positivo na etapa de avaliação.

A Figura 7.25 ilustra a navegação pelas páginas do hiperdocumento final correspondentes às páginas do exemplo da Figura 7.24. O material utilizado no desenvolvimento do hiperdocumento foi obtido do curso de Mecânica Gráfica do Programa Educ@r (USP, 1997) e do livro sobre Física de Barros e Paulino (1998).

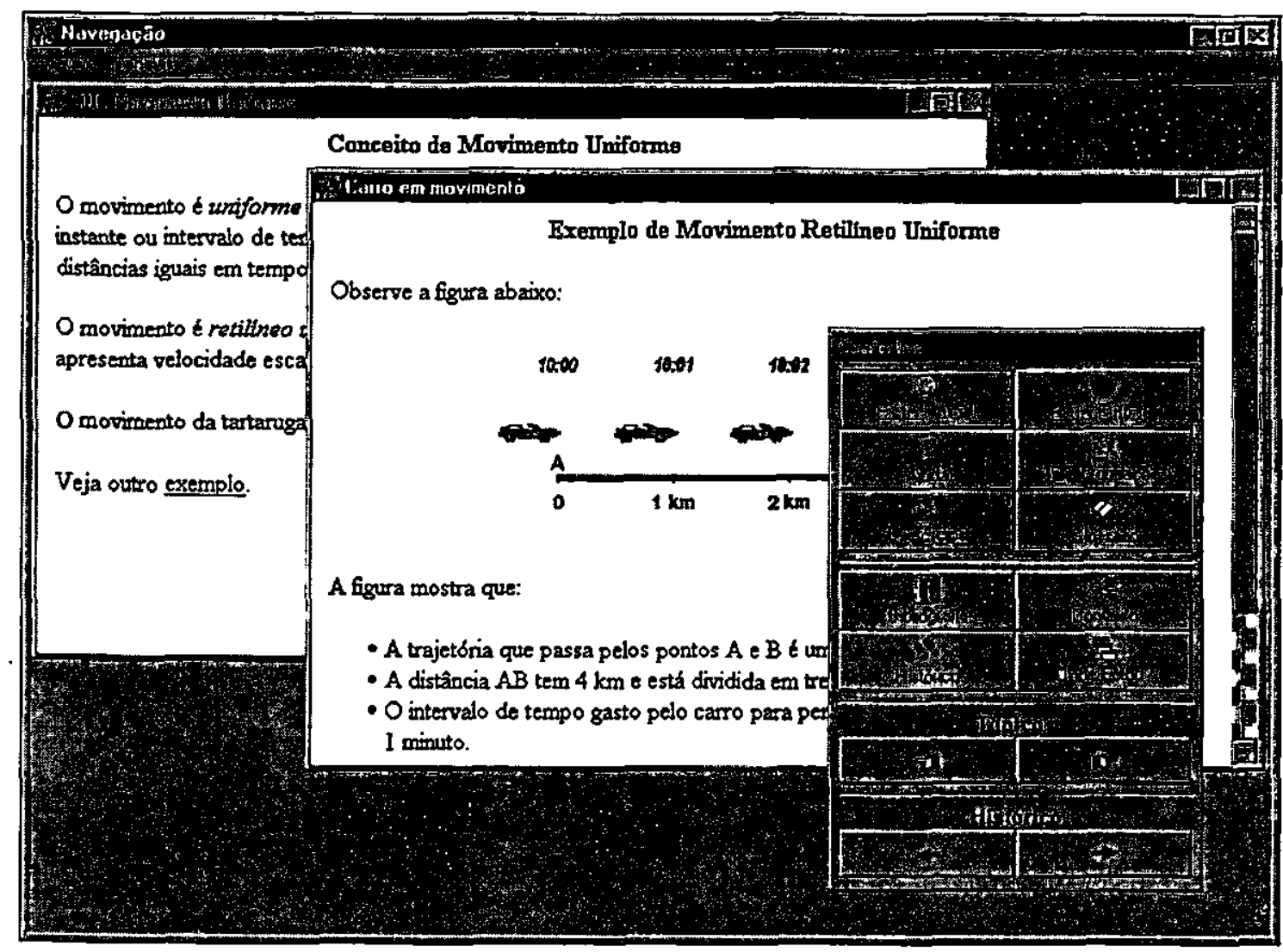

Figura 7.25: Exemplo de navegação pelo hiperdocumento final

\subsection{Considerações Finais}

O protótipo da Ferramenta para Desenvolvimento de Hiperdocumentos para Ensino, ou EHDT (Educational Hyperdocuments Development Tool), tem como principal objetivo auxiliar o desenvolvimento de hiperdocumentos para ensino no SASHE através do suporte automatizado para as etapas propostas pelo EHDM.

No início deste capítulo foram definidos alguns requisitos que constituíram as principais diretrizes de desenvolvimento do protótipo. Em seguida, os módulos que compõem a arquitetura do EHDT foram apresentados, enfatizando como as características de cada módulo procuram eliminar as dificuldades de autoria do SASHE e atingir os demais requisitos. Para concluir o 
capítulo, um exemplo foi apresentado para ilustrar e avaliar o EHDT. No próximo e último capítulo, são apresentadas as principais contribuições deste trabalho e os possíveis trabalhos futuros. 


\section{Capítulo 8}

\section{Conclusões}

\subsection{Considerações Iniciais}

O trabalho apresentado nesta dissertação teve como objetivo propor um método para auxiliar o projeto de hiperdocumentos para ensino e para ser utilizado como base metodológica para o desenvolvimento de uma ferramenta de suporte automatizado para apoiar a autoria de hiperdocumentos para o SASHE.

Esta dissertação apresentou uma visão geral dos aspectos relativos ao processo de desenvolvimento de aplicações hipermídia, os principais métodos genéricos para projeto dessas aplicações da literatura, o SASHE, e a base teórica utilizada para definir um modelo de representação do domínio de conhecimento de um hiperdocumento para ensino: o Modelo de Michener e Mapas Conceituais.

O Método para Projeto de Hiperdocumentos para Ensino, ou EHDM (Educational Hyperdocuments Design Method), proposto neste trabalho foi apresentado em seguida. $\mathrm{O}$ protótipo da ferramenta EHDT (Educational Hyperdocuments Development Tool), proposta como um ambiente de modelagem e desenvolvimento integrado ao SASHE, e um exemplo da sua utilização concluíram a apresentação do trabalho realizado.

\subsection{Contribuiçőes}

As principais contribuições deste trabalho podem ser assim resumidas:

1. O trabalho propõe um método para projeto de hiperdocumentos educacionais, denominado EHDM, que contempla os autores com um modelo que possui uma linguagem orientada para o ensino, evitando o aprendizado de conceitos que podem ser complicados para esses autores (por exemplo, orientação a objetos e entidade-relacionamento). $O$ método mostrou-se suficientemente genérico para tratar grande parte das áreas do conhecimento. 
Além disso, o EHDM permite que processos automatizados sejam implementados baseados nas características específicas de ensino registradas nas especificações dos modelos. A independência do EHDM em relação a sistemas e plataformas hipermídia permite que este seja estendido de diversas maneiras. Por exemplo, pode-se acrescentar uma fase de projeto de interface através da definição de um modelo para o domínio de ensino.

2. Outra contribuição do EHDM consiste na sua utilização como base para a análise e comparação de métodologias de projeto e de estilos de autoria (padrões) de hiperdocumentos para ensino, e também para o desenvolvimento de ferramentas automatizadas de análise e projeto dessas aplicações. A comparação do EHDM com os métodos genéricos de projeto de aplicações hipermídia e com alguns trabalhos relacionados mostra que o método suporta o processo de desenvolvimento de aplicações hipermídia para ensino e apresenta mecanismos para representar algumas peculiaridades dessas aplicações tanto no nível conceitual quanto no navegacional.

3. Resultou do trabalho a implementação de uma ferramenta de suporte automatizado integrada ao SASHE, denominada EHDT, que proporciona um ambiente de desenvolvimento de hiperdocumentos para ensino neste sistema. O EHDT constitui a validação do EHDM em um contexto de aplicação real, pois suporta as fases definidas pelo método dentro de um processo de desenvolvimento baseado em prototipação evolutiva. As características implementadas nos módulos do EHDT, principalmente a geração de protótipos, facilitam as atividades de re-projeto, teste e avaliação de um hiperdocumento para ensino. A independência do EHDM em relação a sistemas e plataformas hipermídia permite que o EHDT seja estendido para traduzir as especificações (gerar protótipos) para outros sistemas e/ou plataformas hipermídia diferentes do SASHE, por exemplo, para a World Wide Web.

\subsection{Trabalhos Futuros}

Alguns dos trabalhos que podem dar continuidade aos resultados apresentados nesta dissertação são:

1. Investigação maior da generalização do modelo utilizado pelo EHDM para descrever o domínio de conhecimento. A semântica rígida dos relacionamentos introduzida pelo 
EHDM dificulta a generalização para domínios que possuem ligações com semânticas mais ricas, por exemplo, os de Filosofia e Sociologia. Por outro lado, a possibilidade de registrar características específicas de um determinado domínio de conhecimento (por exemplo, as informações relativas às classes epistemológicas definidas por Michener) pode fornecer subsídios para automatizar procedimentos que explorem essas características.

2. A extensão do EHDM para permitir a modelagem da interface com o usuário em hiperdocumentos para ensino. Atualmente, o método não fornece um modelo específico para essa tarefa. A Tabela 6.1 ilustra a complexidade deste trabalho; a maioria dos métodos genéricos para projeto de aplicações hipermídia não possui orientações efetivas para a modelagem da interface. Além disso, os aspectos do domínio de ensino podem apresentar novas dificuldades.

3. A definição de um grupo de padrões de projeto para hiperdocumentos educacionais. $O$ enfoque de "padrões de projeto" ("design patterns") tem sido investigado no contexto da World Wide Web para registrar e reutilizar as informaçőes e decisões de projeto (Lyardet et al. 1998). Um estudo desse enfoque no contexto de aplicações hipermídia para ensino deve ser considerado, pois essa abordagem pode fornecer diretrizes de projeto importantes para os autores dessas aplicações.

4. A incorporação de ferramentas automatizadas ao EHDT para auxiliar o teste e avaliação dos protótipos. Apesar do editor gráfico do EHDT proporcionar a verificação da consistência e validade dos modelos representados pelos diagramas, a investigação de recursos adicionais para análise e avaliação do hiperdocumento a partir de outras perspectivas deve ser considerada. Esses recursos podem ser baseados, por exemplo, em "padrões de projeto".

5. A extensão do EHDT para traduzir as especificações para outros sistemas e/ou plataformas hipermídia. Atualmente, o EHDT proporciona a geração de protótipos de hiperdocumentos para o SASHE e, portanto, segundo o MCA. Outra alternativa é implementar o EHDT como um plug-in para um navegador e permitir a tradução das especificações para HTML.

6. A implementação de um dicionário de dados integrado ao EHDT para facilitar a manutenção das especificações (dados referentes aos diagramas). A abordagem adotada pode ser a de tornar o próprio ambiente do EHDT uma aplicação hipermídia, conforme proposto por Díaz e Isakowitz (1995) e Harrison (1995). 
7. A implementação de ferramentas auxiliares adicionais para visualizar a estrutura hierárquica. Atualmente, o editor gráfico do EHDT apresenta o diagrama referente à expansão de um elemento do diagrama de nível superior. Um recurso semelhante ao "browser estrutural" do SASHE (Figura 4.3) pode ser útil para fornecer uma visão geral da estrutura hierárquica. Pode-se considerar a implementação de abordagens mais recentes, como a Hyperbolic Tree (Inxight, 1998), uma tecnologia utilizada para navegar hierarquias.

8. A avaliação do protótipo do EHDT com os usuários (autores). Uma avaliação do protótipo é necessária para que seja possível verificar sua eficácia no projeto de hiperdocumentos para ensino. O EHDM e o EHDT podem ser enriquecidos com a experiência obtida nos projetos desenvolvidos durante essa avaliação.

\subsection{Considerações Finais}

A abordagem sistemática proposta pelo método EHDM mostrou-se útil para apoiar o projeto de aplicaçōes hipermídia para ensino. O protótipo EHDT valida o EHDM como base para o desenvolvimento de ferramentas automatizadas para projeto dessas aplicações. Para os autores de hiperdocumentos para o SASHE, em particular, o EHDT representa uma melhoria na qualidade de projeto de um hiperdocumento, além da possível redução do tempo e dos custos de desenvolvimento neste sistema. 


\section{Referências Bibliográficas}

AUSUBEL, D.P., NOVAK, J.D., HANESIAN, H. Psicologia Educacional. 2.ed. Rio de Janeiro: Interamericana, 1980.

BARROS, C., PAULINO, W.R. Física e Química: livro do professor. São Paulo: Ática, 1998.

BIEBER, M., ISAKOWITZ, T. Introduction to the special Communication ACM issue on Designing Hypermedia Applications. Communications of the ACM, v.38, n.8, p.26-29, 1995.

BIEBER, M., VITALI, F. Toward Support for Hypermedia on the World Wide Web. IEEE Computer, p.62-70, 1997.

BRASIL. Ministério da Educação e do Desporto. Secretaria de Educação Fundamental. Parâmetros curriculares nacionais: história. Brasilia: MEC / SEF, 1998.

CAMPBELL, B., GOODMAN, J.M. HAM: A General Purpose Hypertext Abstract Machine. Communications of the ACM, v.31, n.7, p.856-861, 1988.

CARVALHO, M.R. HMBS/M - Um método orientado a objetos para o projeto e o desenvolvimento de aplicações hipermídia. São Carlos, 1998. 133p. Dissertação (Mestrado) - Instituto de Ciências Matemáticas e de Computação, Universidade de São Paulo.

CASANOVA, M.A. et al. The Nested Context Model for Hyperdocuments. In: Hypertext'91, San Antonio, Texas. Proceedings, p.193-201, 1991.

COLEMAN, D. et al. Object-oriented development: The Fusion Method. Prentice Hall, 1994.

CONKLIN, J. Hypertext: An Introduction and Survey. IEEE Computer, v.10, n.9, p.17-41, 1987.

DÍAZ, A., ISAKOWITZ, T. RMCase: Computer-Aided Support for Hypermedia Design and 
Development. In: International Workshop on Hypermedia Design, Montpellier, France. Proceedings, 1995.

FARIA, W. Mapas conceituais: aplicações ao ensino, currículo e avaliação. São Paulo: E.P.U., 1995.

FORTES, R.P.M. Análise e Avaliação de Hiperdocumentos: uma abordagem baseada na Representação Estrutural. São Carlos, 1996. 179p. Tese (Doutorado) - Instituto de Física de São Carlos, Universidade de São Paulo.

GANE, C., SARSON, T. Análise estruturada de sistemas. Rio de Janeiro: LTC, 1983.

GARZOTTO, F., MAINETTI, L., PAOLINI, P. Hypermedia Design, Analysis, and Evaluation Issues. Comunications of the ACM, v.38, n.8, p.74-86, 1995.

GARZOTTO, F., PAOLINI, P., SCHWABE, D. HDM - A Model-Based Approach to Hypertext Application Design. ACM Transactions on Information Systems, v.11, n.1, p.1-26, 1993.

HABER, R.R. Uma ferramenta de importação de documentos HTML para um ambiente de ensino. São Carlos, 1999. Dissertação (Mestrado) submetida à comissão de pós-graduação Instituto de Ciências Matemáticas e de Computação, Universidade de São Paulo.

HALASZ, F., SCHWARTZ, M. The Dexter Hypertext Reference Model. Communications of the ACM, v.37, n.2, p.30-39, 1994.

HANNAFIN, M.J., PECK, K.L. The Design, Development, and Evaluation of Instructional Software. New York: MacMillan Publishing Company, 1988.

HARDMAN, L., BULTERMAN, D.C.A., ROSSUM, G.V. The Amsterdam Hypermedia Model: Adding Time and Context to the Dexter Model. Communications of the ACM, v.37, n.2, p.50$62,1994$.

HAREL, D. Statecharts: A Visual Formalism for Complex Systems. Science of Computer 
Programming, n.8, p.231-274, 1987.

HARRISON, M.A. The essential elements of hypermedia. In: Earnshaw, RA; Vince, JA., eds. Multimedia Systems and Applications. Academic Press, 1995.

HASEGAWA, R., NUNES, M.G.V. TOOTEMA: uma Ferramenta para a construção de Sistemas Tutores Inteligentes em Matemática. In: Simpósio Brasileiro de Informática na Educação, 6., Florianópolis. Anais, 1995.

HATZIMANIKATIS, A.E., TSALIDIS, C.T., CHRISTODOULAKIS, D. Measuring the Readability and Maintainability of Hyperdocuments. Software Maintanance: Research and Practice, v.7, p.77-90, 1995.

INXIGHT. The Hyperbolic Tree. [online]. Disponível em:

<http://www.inxight.com/products/hw/> [11 Ago. 1998].

ISAKOWITZ, T., STOHR, E.A., BALASUBRAMANIAN, P. RMM: A Methodology for Structured Hypermedia Design. Communications of the ACM, v.38, n.8, p.34-44, 1995.

JONASSEN, D.H., GRABINGER, R.S. Problems and Issues in Designing Hypertext / Hypermedia for Learning. In: Jonassen, D.H., Mandl, H., eds. Designing Hypermedia for Learning, Springer-Verlag, 1990.

JONG, T. Learning and instruction with computer simulations. Education \& Computing, n.6, p.217-229, 1991.

KAWASAKI, E.I., FERNANDES, C.T. Modelo para Projeto de Cursos Hipermídia. In:

Simpósio Brasileiro de Informática na Educação, 7., Belo Horizonte. Anais, p.227-240, 1996.

KOMMERS, P.A.M., FERREIRA, A.F., KWAK, A.W. Document Management for Hypermedia Design. Springer-Verlag, 1998.

LANGE, D.B. An object-oriented design method for hypermedia information systems. In: 
International Conference on System Sciences, 27., Maui, Hawaii. Proceedings, New York, IEEE Press, p.366-375, 1994.

LARGE, A. Hypertext instructional programs and learner control: a research review. Education for Information, v.14, n.2, p.95-106, 1996.

LYARDET, F., ROSSI, G., SCHWABE, D. Discovering and Using Design Patterns in the WWW. In: Simpósio Brasileiro de Sistemas Multimídia e Hipermídia (SBMIDIA'98), 4., Rio de Janeiro. Anais, p.163-174, 1998.

MARQUES, A.M., BERUTTI, F.C., FARIA, R.M. História Moderna através de Textos. São Paulo: Contexto, 1994.

MICHENER, E.R. Understanding understanding Mathematics. Cognitive Science, v.2, n.4, 1978.

MORERA, M.A., BUCHWEITZ, B. Mapas Conceituais: instrumentos didáticos, de avaliação e de análise de currículo. São Paulo: Moraes, 1987.

NANARD, J., NANARD, M. Hypertext Design Environments and the Hypertext Design Process. Communications of the ACM, v.38, n.8, p.49-56, 1995.

NUNES, M.G.V. et al. SASHE: Sistema de Autoria e Suporte Hipermídia para Ensino. São Carlos, ICMSC, 1997. (Notas ICMSC-USP, 33)

NUNES, M.G.V., FORTES, R.P.M. Roteiros em Aplicações no Ensino: A Questão do Controle do Leitor. In: Workshop em Sistemas Multimídia e Hipermídia, 3., São Carlos. Anais, p.1527, 1997.

NUNES, M.G.V., HASEGAWA, R. Developing Intelligent Tutoring Systems for Mathematics. Computers and Artificial Intelligence, v.16, n.6, p.561-581, 1997.

NUNES, M.G.V., VIEIRA, F.M.C., HASEGAWA, R. O ambiente HIP/Windows para a autoria 
de hiperdocumentos multimídia. In: Workshop em Sistemas Hipermídia, 2., Fortaleza. Anais, p.130-138, 1996.

NWANA, H.S. Intelligent Tutoring Systems: an overview. Artificial Intelligence Review, n.4, p.251-277, 1990.

PIMENTEL, M.G. MAPHE: Metodologia de Apoio a Projetos de Hipertextos Educacionais. In: Simpósio Brasileiro de Informática na Educação, 8., São José dos Campos. Anais, p.351-368, 1997.

PIMENTEL, M.G. Modelo Orientado a Conceitos (MOC). In: Simpósio Brasileiro de Informática na Educação (SBIE’98), Fortaleza. Anais, 1998.

PRESSMAN, R.S. Engenharia de Software. São Paulo: Makron Books, 1995.

RATIONAL. UML Resource Center. [online]. Rational, 1995. Disponível em: <http://www.rational.com/uml/index.jtmpl> [02 Fev. 1999].

RIVLIN, E., BOTAFOGO, R., SHNEIDERMAN, B. Navigating in Hyperspace: Designing a Structure-Based Toolbox. Communications of the ACM, v.37, n.2, p.87-108, 1994.

ROSSI, G. Um método Orientado a Objetos para o Projeto de Aplicações Hipermídia. Rio de Janeiro, 1996. 205p. Tese (Doutorado) - Departamento de Informática, Pontifícia Universidade Católica do Rio de Janeiro.

RUMBAUGH, J. et al. Object Oriented Modeling \& Design. Prentice Hall, 1991.

SANTIBAÑEZ, M.R.F., FERNANDES, C.T. SICH: Uma Ferramenta para a Construção de Cursos Hipermídia na WWW. In: Simpósio Brasileiro de Informática na Educação (SBIE'98), Fortaleza. Anais, 1998.

SANTOS, G.H.R. Sistemas Hipermídia para o Ensino: Estendendo as Facilidades para o Tutor e o Estudante. São Carlos, 1997. 63p. Dissertação (Mestrado) - Instituto de Ciências 
Matemáticas de São Carlos, Universidade de São Paulo.

SANTOS, G.H.R. et al. SASHE: Autoria de Aplicações Hipermídia para o Ensino. In:

Simpósio Brasileiro de Informática na Educação, 8., São José dos Campos. Anais, p.425-440, 1997.

SCHWABE, D., ROSSI, G. The Object-Oriented Hypermedia Design Model. Communications of the ACM, v.38, n.8, p.45-46, 1995.

SCHWABE, D., ROSSI, G., BARBOSA, S.D.J. Systematic Hypermedia Application Design with OOHDM. In: Hypertext'96, Washington. Proceedings, p.116-128, 1996.

SOARES, L.F.G. et al. HyperProp: Uma Visão Geral. In: Workshop em Sistemas Hipermídia Distribuídos, 1., São Carlos. Anais, p.1-12, 1995 (a).

SOARES, L.F.G., RODRIGUEZ, N.L.R, CASANOVA, M.A. NCM: A Conceptual Model for Hyperdocuments. In: Workshop em Sistemas Hipermídia Distribuídos, 1., São Carlos. Anais, p.40-46, 1995 (b).

SOARES, L.F.G., RODRIGUEZ, N.L.R., CASANOVA, M.A. Modelo de Contextos Aninhados: Um Modelo Conceitual Hipermídia. Revista Brasileira de Computação, v.7, n.2, p.35-48, 1994.

STREITZ, N.A. Designing Hypermedia: A Collaborative Activity. Communications of the ACM, v.38, n.8, p.70-71, 1995.

TAKEHARA, R.S. ARQTEMA: um Modelo Genérico para Sistemas Tutores Inteligentes em Matemática. São Carlos, 1994. 109p. Dissertação (Mestrado)-Instituto de Ciências Matemáticas de São Carlos, Universidade de São Paulo.

THÜRING, M., HANNEMANN, J., HAAKE, J.M. Hypermedia and Cognition: Designing for Comprehension. Communications of the ACM, v.38, n.8, p.57-66, 1995. 
TURINE, M.A.S. HMBS: Um Modelo Baseado em Statecharts para a Especificação Formal de Hiperdocumentos. São Carlos, 1998. 192p. Tese (Doutorado) - Instituto de Física de São Carlos, Universidade de São Paulo.

TURINE, M.A.S., OLIVEIRA, M.C.F., MASIERO, P.C. HySCharts: Um Ambiente de Autoria e Navegação Baseado no Modelo HMBS. In: Simpósio Brasileiro de Sistemas Multimídia e Hipermídia (SBMIDIA’98), 4., Rio de Janeiro. Anais, p.27-38, 1998.

UNIVERSIDADE DE SÃO PAULO, Centro de Divulgação Científica e Cultural. Programa Educ@r: Mecânica Gráfica. [online]. São Carlos: CDCC-USP, 1997. Disponível em: $<$ http://educar.sc.usp.br/fisica/indice.html> [2 Fev. 1999].

VALENTE, J.A., org. Computadores e conhecimento: repensando a educação. Campinas: Gráfica Central da UNICAMP, 1993.

VILELA, P.R.S. Uma ferramenta para auxílio visual ao teste e depuração de programas. Campinas, 1994. Dissertação (Mestrado) - Faculdade de Engenharia Elétrica, Universidi Estadual de Campinas.

WHALLEY, P. An Alternative Rhetoric for Hypertext. In: McKnight, C., Dillon, A., Richardson, J., eds. Hypertext, a psychological perspective. Ellis Horwood, 1993.

YOURDON, E. Decline \& Fall of the American Programmer. Prentice Hall, 1993.

\section{Bibliografia Consultada}

CANTÙ, M. Dominando o DELPHI 4: A Bíblia. São Paulo: Makron Books, 1998.

FOWLER, M., SCOTT, K. UML Distilled: Applying the Standard Object Modeling Lan Addison-Wesley, 1997. 